\title{
The Biological Significance of Targeting Acetylation-Mediated Gene Regulation for Designing New Mechanistic Tools and Potential Therapeutics
}

\author{
Chenise $\mathrm{O}^{\prime}$ Garro ${ }^{1,+}{ }^{\dagger}$, Loveth Igbineweka ${ }^{1,+}$, Zonaira Ali $^{1}$, Mihaly Mezei ${ }^{2}{ }^{\mathbb{D}}$ and Shiraz Mujtaba ${ }^{1, *}$ \\ 1 Department of Biology, Medgar Evers College, City University of New York, Brooklyn, NY 11225, USA; \\ chenise.ogarro@student.mec.cuny.edu (C.O.); L.Igbineweka@mec.cuny.edu (L.I.); \\ zonaira.ali@student.mec.cuny.edu (Z.A.) \\ 2 Department of Pharmaceutical Sciences, Icahn School of Medicine at Mount Sinai, New York, NY 10029, USA; \\ mihaly.mezei@mssm.edu \\ * Correspondence: smujtaba@mec.cuny.edu \\ + These authors contributed equally to this work.
}

\section{check for} updates

Citation: O'Garro, C.; Igbineweka, L.; Ali, Z.; Mezei, M.; Mujtaba, S. The Biological Significance of Targeting Acetylation-Mediated Gene Regulation for Designing New Mechanistic Tools and Potential Therapeutics. Biomolecules 2021, 11, 455. https://doi.org/10.3390/ biom 11030455

Academic Editor: Vladimir N. Uversky

Received: 22 February 2021

Accepted: 16 March 2021

Published: 18 March 2021

Publisher's Note: MDPI stays neutral with regard to jurisdictional claims in published maps and institutional affiliations.

Copyright: (c) 2021 by the authors. Licensee MDPI, Basel, Switzerland. This article is an open access article distributed under the terms and conditions of the Creative Commons Attribution (CC BY) license (https:// creativecommons.org/licenses/by/ $4.0 /)$.

\begin{abstract}
The molecular interplay between nucleosomal packaging and the chromatin landscape regulates the transcriptional programming and biological outcomes of downstream genes. An array of epigenetic modifications plays a pivotal role in shaping the chromatin architecture, which controls DNA access to the transcriptional machinery. Acetylation of the amino acid lysine is a widespread epigenetic modification that serves as a marker for gene activation, which intertwines the maintenance of cellular homeostasis and the regulation of signaling during stress. The biochemical horizon of acetylation ranges from orchestrating the stability and cellular localization of proteins that engage in the cell cycle to DNA repair and metabolism. Furthermore, lysine acetyltransferases (KATs) modulate the functions of transcription factors that govern cellular response to microbial infections, genotoxic stress, and inflammation. Due to their central role in many biological processes, mutations in KATs cause developmental and intellectual challenges and metabolic disorders. Despite the availability of tools for detecting acetylation, the mechanistic knowledge of acetylation-mediated cellular processes remains limited. This review aims to integrate molecular and structural bases of KAT functions, which would help design highly selective tools for understanding the biology of KATs toward developing new disease treatments.
\end{abstract}

Keywords: epigenetic modifications; acetylation; lysine acetyltransferases; gene regulation; molecular interactions and biological outcomes

\section{Introduction}

Cells have extraordinary potential to calibrate appropriate responses to the everchanging environment for maintaining tissue integrity and physiological balance. One of the longstanding biomedical research goals has been to fully reveal the molecular mechanisms that direct human development, maintain homeostasis, and calculate the intensity of cellular responses to internal and extracellular changes [1,2]. These changes in the cellular milieu stem from hormonal regulation, infections, immune activation, metabolic imbalances, and genotoxic stresses [3]. Intriguingly, despite their identical genomes, it is unclear how cells within the embryonic layers acquire distinct and tissue-specific traits. The multilayered molecular mechanisms that determine a cell's fate remain to be fully understood. Mounting evidence confirms that the epigenetic mechanisms controlling the gene expression system play a vital role in modulating cellular functions in response to environmental changes [4-8]. These epigenetic mechanisms lie at the center of regulating stress responses, metabolic pathways, and diseases (e.g., neurological disorders, chronic inflammation, microbial infections, and cancers) [9-11]. The posttranslational modifications, molecular 
interactions, and noncoding RNAs comprise major epigenetic mechanisms that regulate the outcomes of gene transcription [12-15]. Additionally, posttranslational modificationmediated nucleosomal remodeling controls the transcriptional machinery's recruitment to the gene promoters, intragenic regions, and enhancers [5,16]. A detailed mechanistic analysis of epigenetic pathways that govern gene functions and cellular responses will help to understand normal and pathological situations and aid in developing therapeutic modalities. However, developing a highly selective tool is vital to fully understand the molecular basis of epigenetic mechanisms.

Nucleosomes are composed of DNA and octameric histone proteins. They undergo a wide array of chemical modifications triggered by upstream signals, which enable the modulation of downstream target genes [16]. As compared to the methylation of adenine and cytosine nucleotides-a major DNA modification - proteins undergo posttranslational modifications on residues including serine, threonine, tyrosine, lysine, and arginine [17-19]. These epigenetic modifications include, but are not limited to, phosphorylation, acetylation, methylation, ubiquitination, and sumoylation; which are mediated by kinases, lysine acetyltransferases (KATs), lysine methyltransferases, ubiquitinases, and sumoylases, respectively [20-22]. Serendipitously, most epigenetic modifications are reversible, thereby facilitating modification-dependent and modification-independent molecular interactions [20-22]. Reversal of epigenetic modifications is mediated by phosphatases, lysine deacetylases (KDACs), demethylases, and deubiquitinases [23-26]. The dynamicscatalyzing epigenetic modifications followed by swift removal-broaden the plasticity in cellular responses. During traumatic brain injury, the molecular interplay of KAT2B, KAT3A, and Nicotinamide adenine dinucleotide (NAD)-dependent deacetylase Sirtuin 1 regulates the expression of genes regulated by a hypoxic environment [27]. Interestingly, the interactions between KAT3B and NAD-dependent Sirtuin 1 also regulate metabolic processes [28]. Collectively, these molecular events serve as a target to manipulate cell fate for changing disease outcomes.

Depending upon their roles in regulating transcriptional outcomes, chromatinassociated proteins can be defined as transcriptional cofactors, further characterized as coactivators or corepressors [29-31]. The genetic mutations within transcriptional coactivators lead to developmental disorders, long-term intellectual challenges, and increased susceptibility to life-threatening diseases [32]. Furthermore, dysregulated coactivator functions perturb the stoichiometric balance with transcription factors, which adversely affects downstream gene functions, leading to disease outcomes [29-31]. For instance, deregulated dynamics of KATs or KDACs on the androgen receptor (AR) target gene promoters escalate anti-androgen resistance, which leads to the growth and metastasis of prostate cancer (PCa) cells [33-35]. These data implicate the translational significance of coactivators, which have naturally become the target for a generation of new medicines $[9,36]$. Gene manipulation strategies may not be widely useful, for at least two reasons: first, coactivators are multidomain proteins that mediate several functions, and second, gene editing can generate unintended secondary mutations and off-target effects [37]. Small molecule-mediated perturbations of endogenous coactivator functions can elucidate the mechanistic underpinnings of crucial mechanisms that will help develop high-affinity therapeutic modalities. Although the role of phosphorylation was discovered much earlier in bridging cellular signaling networks, lysine acetylation was noted for the first time in 1964 [38]. This review aims to integrate the biochemical, molecular, and structural bases of KAT functions, which would increase our understanding of KAT-directed biology and its involvement in disease pathogenesis.

\section{The Biochemistry and Epigenetics of Lysine Acetylation on Chromatin}

Acetylation of cellular proteins involves the KAT-mediated covalent linkage of the acetyl moiety from acetyl-CoA to the $\varepsilon-\mathrm{N}$ on the side chain of a lysine residue to form $\varepsilon$-N-acetyllysine [39]. An acetylated lysine moiety then becomes a pivotal hub for recruiting bromodomain-containing proteins or KDACs that trigger a wide range of biochemical activ- 
ities and molecular interactions (Figure 1A,B) [40,41]. The association between acetylation of histone proteins and transcriptionally active regions has been experimentally established using deoxyribonuclease-1 sensitivity and chromatin immunoprecipitation (ChIP) assays [42]. Genome-wide ChIP-on-ChIP data have revealed that most KATs function as coactivators-cooperating with transcription factors, general transcription machinery, and RNA polymerase II to express target genes [43]. Furthermore, site-specific acetylation on a histone protein neutralizes the positive charge of the lysine residues, inducing chromatin remodeling to facilitate DNA access by transcriptional machinery $[39,44-46]$. In addition to chromatin, KAT-mediated acetylation modulates the functions of transcription factors by enhancing their stability and transcriptional activities (Figure 1A,B) [47]. The KAT2A/-2B and KAT5-mediated acetylation and molecular interactions with KAT3A/-3B increase the stability of the c-Myc protein [48]. Taken together, although we understand the role of acetylation in the regulation of protein-coding genes, the role of acetylation remains lesser known in the expression of noncoding genes.

Across the genome, there appear to be at least 20 KATs located on different chromosomes. They are composed of several domains, including bromodomain, chromodomain, one or more zinc fingers, plant homeodomain, MOZ, Ybf2 (Sas3), Sas2, and Tip60 (MYST; Figure 2) [20,39]. However, only 13 KATs have been shown to possess acetyltransferase activity under both in vitro and in vivo conditions [49-51]. Interestingly, KAT2A and -2B share a significant degree of sequence similarity but are located on different chromosomes (Table 1 and Supplemental Figure S1). KAT3A and -3B, which also share a greater degree of homology, are master transcriptional coactivators involved in the acetylation of at least two-thirds of the proteome. As shown in Table 1, there are four groups of KATs, (KAT2A / 2B, KAT3A/-3B, MYST, and SRC) [52]. Most KATs mediate acetylation of enhancers in the vicinity of promoters, as well as of intragenic regions of transcriptionally active genes [47]. However, KATs do not act alone; rather, they exist as part of a molecular complex that mediates interactions with the chromatin loop through mediators (Figure 1A,B) [47]. An unbiased proteomics analysis using mass spectrometry revealed that at least 2000 proteins could undergo acetylation, thereby underlining the essential nature of acetylation [49]. Unfortunately, the lack of a prototype epigenetic signature and an overlap in the enzymatic activities of KATs raises several important questions that necessitate the development of novel tools to understand the genome-wide dynamics of acetylation. These questions are centered on elucidating the mechanistic details that will provide insights into the selectivity for protein-protein interactions, which will subsequently determine the biological outcomes.

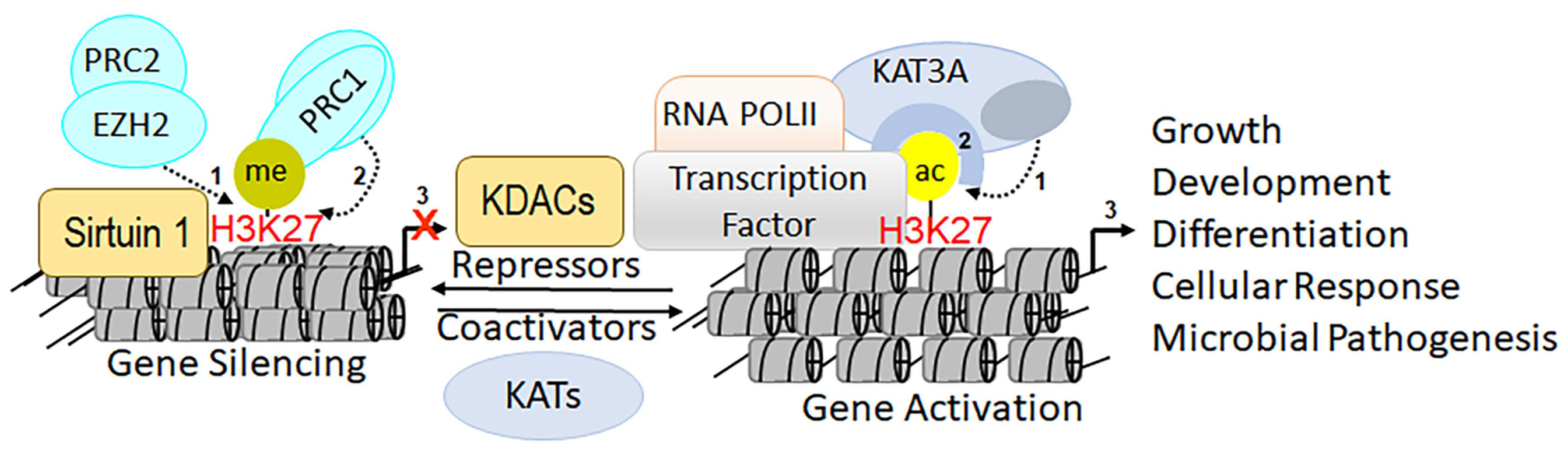

(A)

Figure 1. Cont. 


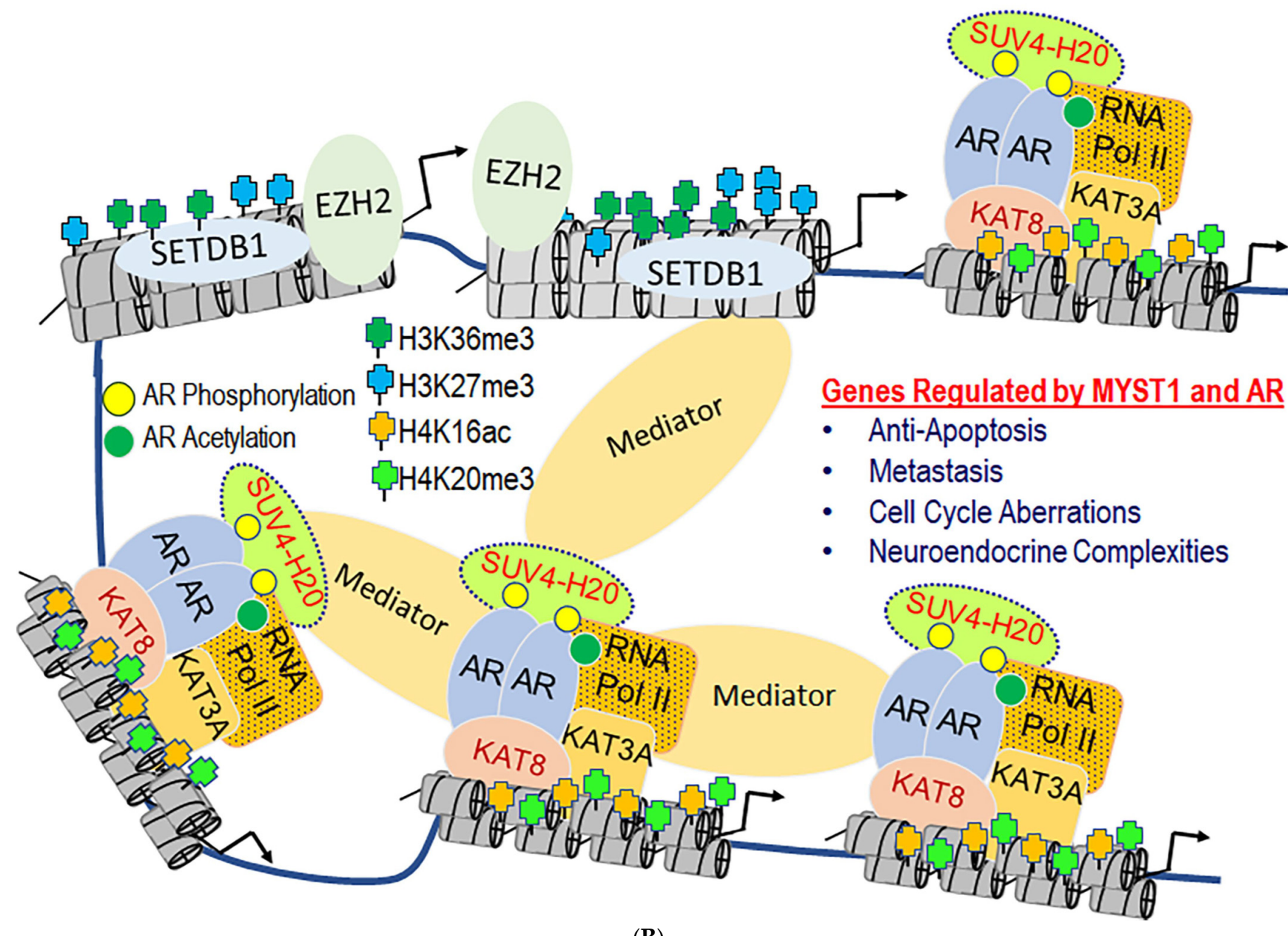

(B)

Figure 1. (A) Transcriptional coactivator (KAT)- and corepressor (KDAC)-mediated mutually exclusive epigenetic modifications on the chromatin landscape. H3K27 site can be methylated (me) by lysine methyltransferase (EZH2) and acetylated (ac) by KAT3A/-3B. While methylation of H3K27 leads to gene silencing, acetylation of H3K27 causes gene activation. EZH2 is a part of the polycomb repressor complex (PRC)-2, which enzymatically methylates H3K27 (1), and subsequently recruits methyl-lysine-binding chromodomain-containing proteins (which are a part of PRC-1). Similarly, acetylation of lysine residues by KATs (1) is followed by the recruitment of bromodomain on the acetylated lysine sites (2). Additionally, acetylated lysine residues can also recruit KDACs (like NAD-dependent Sirtuin 1) which deacetylate and cooperate with PRC complexes. On the one hand, these epigenetic modifications play a key role in growth, development, and differentiation; on the other hand, they can cause developmental disorders and cancers. (B) Global regulation of the human epigenome by lysine acetylation and methylation on chromatin has the potential to govern cellular responses by activation or silencing of individual and long-distance genes. Androgen Receptor (AR) is a ligand-binding transcription factor that undergoes phosphorylation (yellow balls) and acetylation (green balls) upon binding to the hormone testosterone. In normal situations, this would lead to the development of the prostate and secondary male characteristics. However, dysregulated dynamics of AR and coactivator functions have the potential to cause prostate cancer. In prostate cancer cells, coactivators KAT3A and KAT8 can acetylate AR and the chromatin of the target genes to induce cell proliferation and metastasis. Furthermore, the trimethylation of H3K27 and H4K20 sites by EZH2 and SUV4-20H2 creates a microenvironment that cooperates with KAT3-A and KAT8 to resist antiandrogen therapy. One of the roles of mediators in transcription is to serve as the chromatin organizers. 


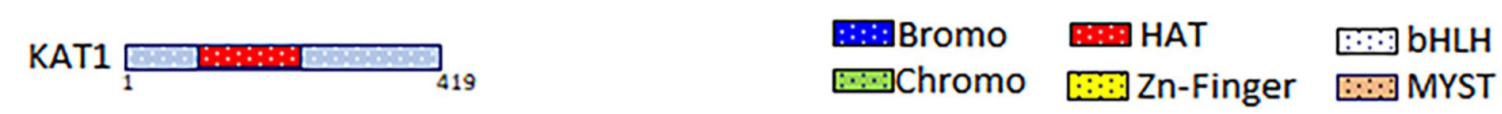

KAT2A

KAT2B

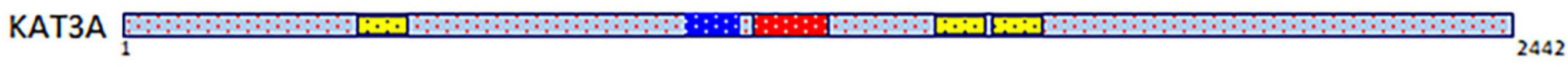

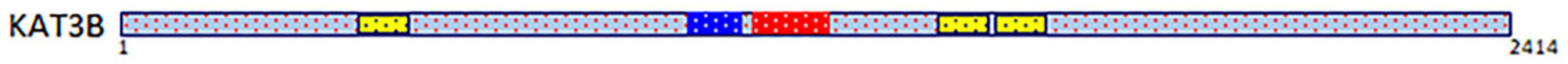

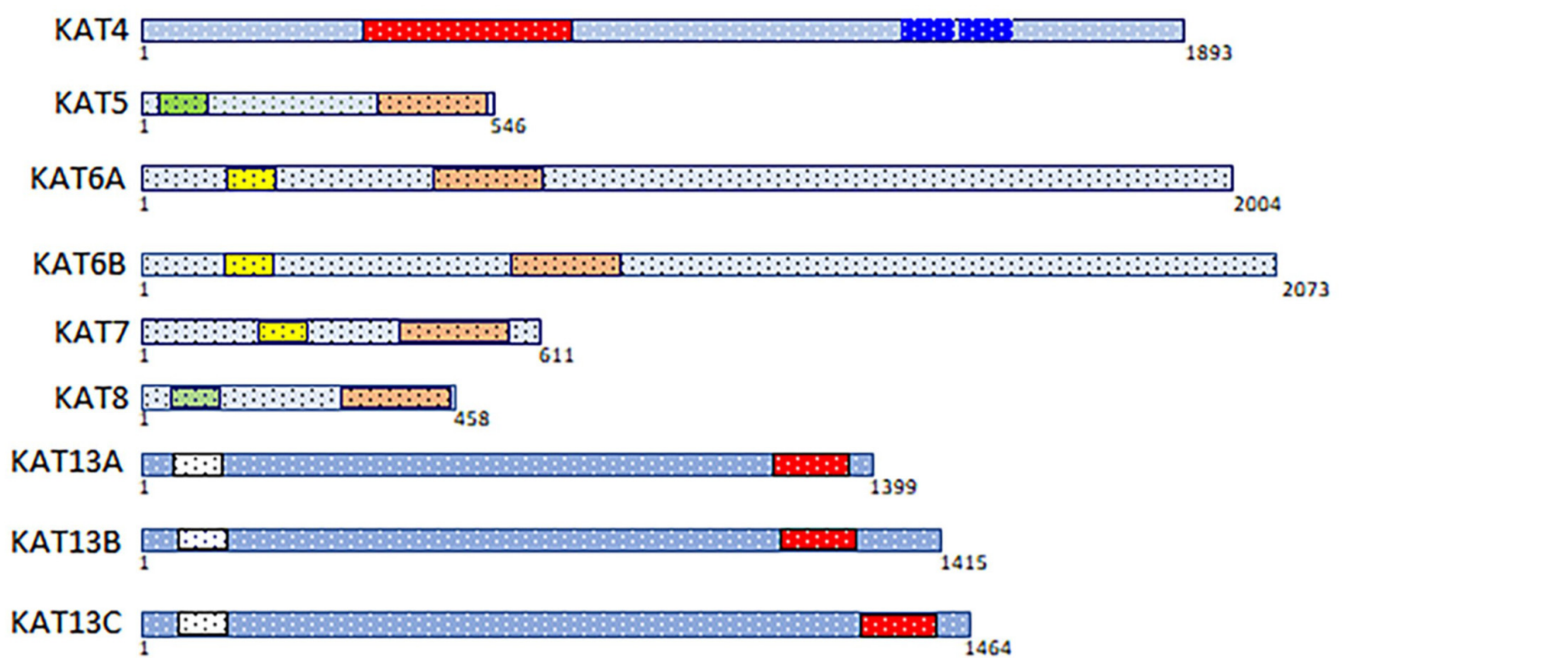

Figure 2. The domain composition and organization of KATs present in humans. KATs are multidomain proteins that perform more than one function. For instance, KAT2A/-2B, KAT3A/-3B, and KAT4 have a bromodomain, an acetyl-lysine binding module, whereas KAT8 has a MYST domain and a chromodomain.

Table 1. Chromosomal and cellular location of human KATs.

\begin{tabular}{ccccc}
\hline Name & $\begin{array}{c}\text { Generic } \\
\text { Name }\end{array}$ & $\begin{array}{c}\text { Chromosomal } \\
\text { Location }\end{array}$ & $\begin{array}{c}\text { Number of Amino } \\
\text { Acids }\end{array}$ & Cellular Location \\
\hline KAT1 & HAT1 & 2 & 419 & Nucleus \\
\hline KAT2A & GCN5 & 17 & 837 & Nucleus \\
\hline KAT2B & PCAF & 3 & 832 & Nucleus \\
\hline KAT3A & CBP & 16 & 2404 & Nucleus \\
\hline KAT3B & p300 & 22 & 2414 & Nucleus \\
\hline KAT4 & TAF1 & X & 1893 & Nucleus \\
\hline KAT5 & TIP60 & 11 & 546 & Nucleus \\
\hline KAT6A & MYST3 & 8 & 2004 & Nucleus and Cytosol \\
\hline KAT6B & MYST4 & 10 & 2073 & Nucleus \\
\hline KAT7 & MYST2 & 17 & 611 & Nucleus \\
\hline KAT8 & MYST1 & 16 & 458 & Nucleus
\end{tabular}


Table 1. Cont.

\begin{tabular}{ccccc}
\hline Name & $\begin{array}{c}\text { Generic } \\
\text { Name }\end{array}$ & $\begin{array}{c}\text { Chromosomal } \\
\text { Location }\end{array}$ & $\begin{array}{c}\text { Number of Amino } \\
\text { Acids }\end{array}$ & Cellular Location \\
\hline KAT9 & ELP3 & 8 & 547 & Nucleus \\
\hline KAT12 & TFIIIC90 & 9 & 822 & Nucleus \\
\hline KAT13A & NCOA1 & 2 & 1399 & Nucleus, Plasma Membrane, and Cytosol \\
\hline KAT13B & NCOA3 & 20 & 1415 & Nucleus and Cytosol \\
\hline KAT13C & NCOA2 & 8 & 1464 & Nucleus \\
\hline KAT13D & CLOCK & 4 & 846 & Nucleus \\
\hline
\end{tabular}

\subsection{Cellular Localization of KATs}

KATs are conventionally categorized into two distinct groups based on their subcellular localization [53]. Type A KATs (KAT-A) are found in the nucleus and are involved in regulating gene activities via the acetylation of chromatin [54-57]. Further, KAT-As have a bromodomain (a small modular domain of approximately 110 amino acids) that facilitates the binding of chromatin-associated proteins to the acetylated lysine sites on histone and nonhistone proteins [54-57]. KAT2A, $-2 \mathrm{~B},-3 \mathrm{~A},-3 \mathrm{~B}$, and -4 are well-known examples of KAT-As that cooperate with activators to enhance transcription.

Type B KATs (KAT-B) are localized in the cytoplasm and are responsible for acetylating the newly synthesized histones before their assembly into nucleosomes [52]. KDACs remove the acetyl groups added to histones by KAT-Bs upon entry into the nucleus and incorporation into chromatin. Interestingly, KAT-Bs lack a bromodomain module [53]. KAT1 is one of the few known examples of a KAT-B involved in histone deposition and chromatin assembly [58]. Despite this discrete classification, KAT proteins function cooperatively as part of multiple complexes. Collectively, mechanisms directing the dichotomy in cellular localization of KATs have not been fully investigated. Table 2 lists the tissues in which KATs are expressed and their involvement in various cancers. While KAT1, $-3 \mathrm{~A},-3 \mathrm{~B},-4$, $-5,-6 \mathrm{~B},-13 \mathrm{~A},-13 \mathrm{~B}$, and $-13 \mathrm{D}$ are most widely expressed, KAT8 is frequently nondetectable in normal tissues but is overexpressed in lung, breast, and endometrial cancers. These data underscore that investigating the tissue-specific roles of KATs could elucidate new regulatory functions for these enzymes.

Table 2. Tissue distribution and cancer specificity of KATs.

\begin{tabular}{|c|c|c|c|}
\hline Name & Tissue & Cancer Type & References \\
\hline KAT1 & $\begin{array}{l}\text { Appendix, bone marrow, lymph node, tonsil, nasopharynx, esophagus, } \\
\text { stomach, duodenum, small intestine, colon, rectum, urinary bladder, } \\
\text { testis, epididymis, vagina, cervix, uterine, endometrium, placenta, skin }\end{array}$ & $\begin{array}{l}\text { Liver, ovarian, cervical, } \\
\text { skin, testis }\end{array}$ & [59-62] \\
\hline KAT2A & Skin, spleen, cerebral cortex, parathyroid & $\begin{array}{l}\text { Renal, colorectal, } \\
\text { melanoma, testis, } \\
\text { thyroid }\end{array}$ & {$[48,62-67]$} \\
\hline KAT2B & Cerebellum, thyroid, salivary, stomach, urinary bladder, placenta & $\begin{array}{l}\text { Glioma, thyroid, } \\
\text { melanoma }\end{array}$ & {$[48,62,68,69]$} \\
\hline KAT3A & $\begin{array}{l}\text { Cerebellum, thyroid, nasopharynx, gallbladder, oral mucosa, } \\
\text { esophagus, small intestines, colon, rectum, urinary bladder, testis, } \\
\text { fallopian tubes, vagina, cervix, uterine, endometrium, placenta, skin }\end{array}$ & $\begin{array}{l}\text { Renal, thyroid, lung, } \\
\text { head, neck, testis, } \\
\text { breast }\end{array}$ & {$[62,70-75]$} \\
\hline КАТЗВ & $\begin{array}{l}\text { Cerebral cortex, parathyroid, adrenal, bone marrow, esophagus, colon, } \\
\text { rectum, placenta, skin }\end{array}$ & $\begin{array}{l}\text { Renal, thyroid, } \\
\text { carcinoid, stomach, } \\
\text { renal, head, neck }\end{array}$ & {$[62,70-77]$} \\
\hline
\end{tabular}


Table 2. Cont.

\begin{tabular}{|c|c|c|c|}
\hline Name & Tissue & Cancer Type & References \\
\hline KAT4 & $\begin{array}{c}\text { Cerebellum, thyroid, salivary, stomach, urinary bladder, placenta, } \\
\text { hippocampus, caudate, adrenal, appendix, tonsil, skeletal muscle, lung, } \\
\text { nasopharynx, bronchus, gallbladder, esophagus, duodenum, small } \\
\text { intestines, colon, rectum, kidney, testis, epididymis, fallopian tube, } \\
\text { vagina, cervix, uterine, endometrium, ovary, placenta, soft tissues, skin, } \\
\text { hippocampus, heart muscle, skeletal muscle, lung, bronchus, seminal } \\
\text { vesicle, breast }\end{array}$ & $\begin{array}{l}\text { Lung, glioma, thyroid, } \\
\text { lymphoma, pancreatic, } \\
\text { carcinoids }\end{array}$ & {$[62,78-80]$} \\
\hline KAT5 & $\begin{array}{l}\text { Cerebral cortex, parathyroid, adrenal, caudate, cerebellum, thyroid, } \\
\text { nasopharynx, colon, rectum, placenta, stomach, duodenum, ovary, } \\
\text { cervix, uterine, oral mucosa, gallbladder }\end{array}$ & $\begin{array}{l}\text { Renal, melanoma, } \\
\text { testis, lymphoma }\end{array}$ & {$[62,81-96]$} \\
\hline KAT6A & Cerebral cortex, caudate, cerebellum & $\begin{array}{l}\text { Glioma, thyroid, } \\
\text { carcinoid }\end{array}$ & {$[62,89-96]$} \\
\hline KAT6B & $\begin{array}{l}\text { Cerebellum, thyroid, salivary, stomach, urinary bladder, placenta, } \\
\text { hippocampus, caudate, adrenal, appendix, tonsil, skeletal muscle, lung, } \\
\text { nasopharynx, bronchus, gallbladder, esophagus, duodenum, small } \\
\text { intestines, colon, rectum, kidney, testis, epididymis, fallopian tube, } \\
\text { vagina, cervix, uterine, endometrium, ovary, placenta, soft tissues, skin }\end{array}$ & $\begin{array}{l}\text { Renal, glioma, thyroid, } \\
\text { lung, head, skin, neck }\end{array}$ & {$[62,96,97]$} \\
\hline KAT7 & Testis & $\begin{array}{l}\text { Glioma, thyroid, } \\
\text { melanoma }\end{array}$ & {$[62,98-101]$} \\
\hline KAT8 & - & $\begin{array}{l}\text { Lung, breast, } \\
\text { endometrial }\end{array}$ & {$[62,102-106]$} \\
\hline KAT9 & $\begin{array}{l}\text { Appendix, duodenum, small intestine, colon, rectum, kidney, urinary } \\
\text { bladder, prostate, endometrium, placenta }\end{array}$ & $\begin{array}{l}\text { Renal, colorectal, } \\
\text { thyroid, prostate, liver }\end{array}$ & [62,107-109] \\
\hline KAT13A & $\begin{array}{l}\text { Cerebral cortex, hippocampus, cerebellum, thyroid, parathyroid, } \\
\text { adrenal, lymph node, nasopharynx, bronchus, gallbladder, pancreas, } \\
\text { oral mucosa, esophagus, stomach, duodenum, small intestines, colon, } \\
\text { rectum, kidney, urinary bladder, testis, fallopian tube, breast, vagina, } \\
\text { placenta }\end{array}$ & $\begin{array}{l}\text { Thyroid, carcinoid, } \\
\text { head, neck }\end{array}$ & {$[62,110-121]$} \\
\hline KAT13B & $\begin{array}{l}\text { Cerebral cortex, hippocampus, cerebellum, thyroid, parathyroid, } \\
\text { adrenal, lymph node, nasopharynx, bronchus, gallbladder, pancreas, } \\
\text { oral mucosa, esophagus, stomach, duodenum, small intestines, colon, } \\
\text { rectum, kidney, urinary bladder, testis, fallopian tube, breast, vagina, } \\
\text { placenta, soft tissue, skin }\end{array}$ & $\begin{array}{l}\text { Thyroid, carcinoid, } \\
\text { head, neck }\end{array}$ & [122-127] \\
\hline KAT13D & $\begin{array}{l}\text { Cerebral cortex, hippocampus, cerebellum, thyroid, parathyroid, } \\
\text { adrenal, lymph node, nasopharynx, bronchus, gallbladder, pancreas, } \\
\text { oral mucosa, esophagus, stomach, duodenum, small intestines, colon, } \\
\text { rectum, kidney, urinary bladder, testis, fallopian tube, breast, vagina, } \\
\text { placenta, soft tissue, skin }\end{array}$ & $\begin{array}{l}\text { Thyroid, breast, } \\
\text { cervical, head, neck }\end{array}$ & {$[62,128]$} \\
\hline
\end{tabular}

\subsection{Genome-Wide Expression of KATs}

Engineered mouse models deficient in KAT2A, $-3 \mathrm{~A},-3 \mathrm{~B},-5,-6 \mathrm{~A},-6 \mathrm{~B}$, or -8 exhibit a lethal phenotype that demonstrates a vital role for the KATs during embryonic development $[129,130]$. To understand the tissue-wide expression of KATs, websites including human protein atlas [62], uniport [131], antibodypedia [132], metabolic atlas [133] and nextprot $[134,135]$ were reviewed. These websites showcased expression levels for RNA and protein for each KAT. The tissue-specific levels of KATs, RNA, and protein expression were scored as low $(30 \%)$, medium $(60 \%)$, and high $(100 \%)$. The RNA transcripts of KAT1, $-2 B,-5$, and -8 were found in endocrine tissues, proximal digestive tract, muscle, bone marrow, and lymphoid tissue at high levels. A moderate level of RNA for KAT1, $-13 A$, and $-13 C$ was observed in the brain, kidney, and urinary bladder, whereas a lower level of KAT2 and $-13 A$ RNA was observed in the lung and gastrointestinal tract (Figure $3 \mathrm{~A}$ ). 


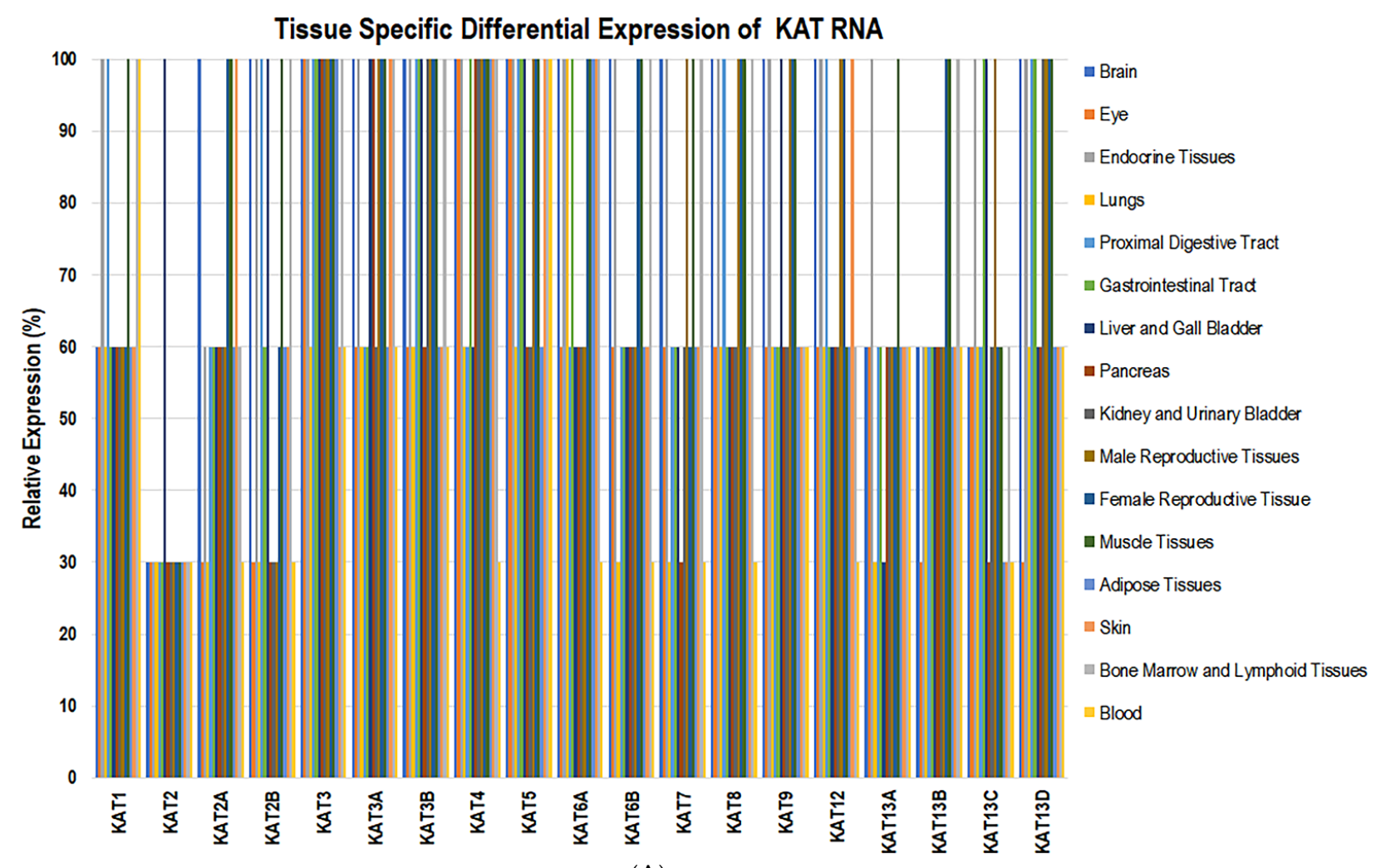

Tissue Specific Differential Level of KAT Protein Expression

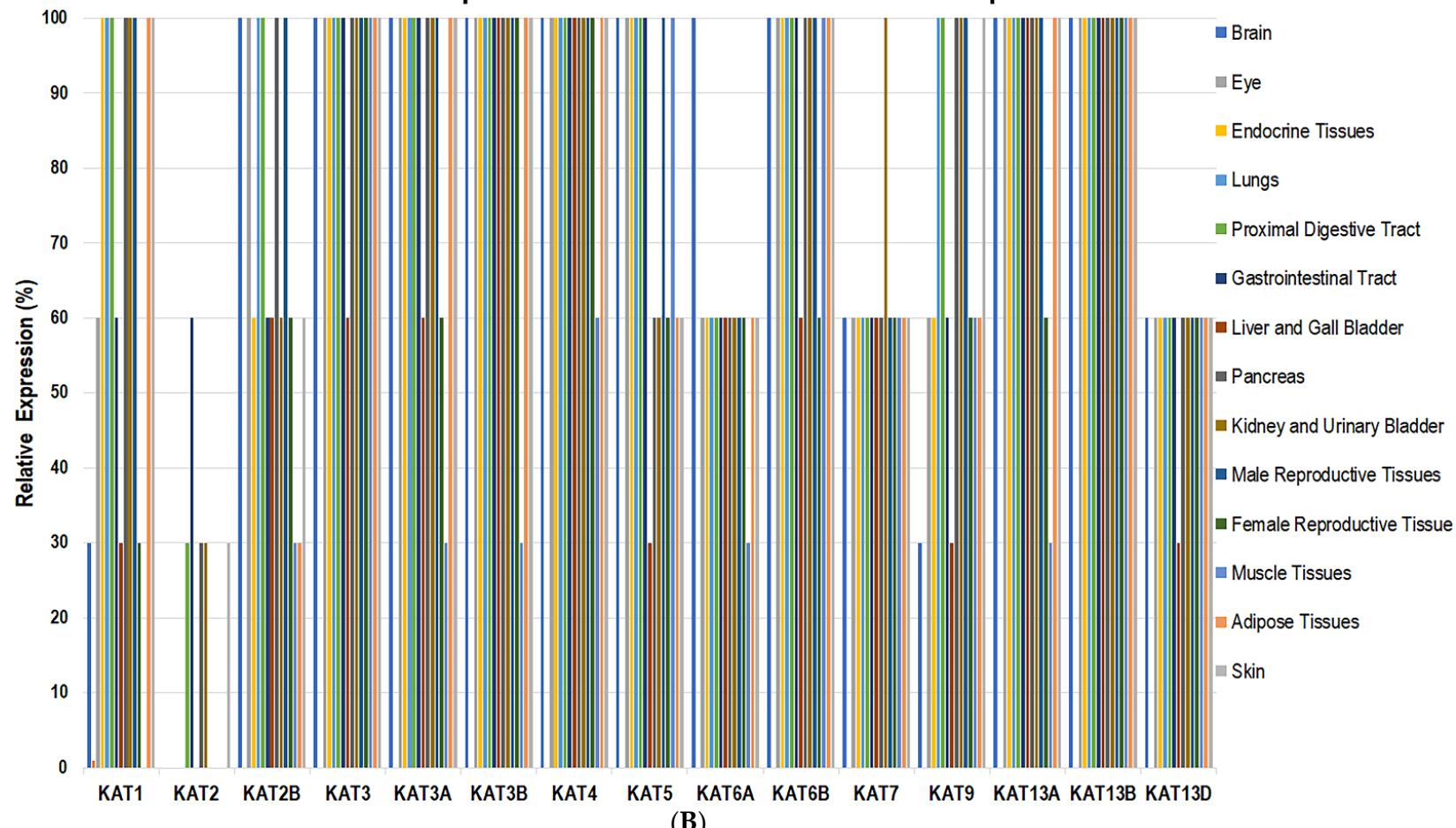

Figure 3. (A) Tissue-specific and genome-wide differential expression of KAT RNAs. Low expression corresponds to 30\%, moderate expression corresponds to $60 \%$, and high expression corresponds to $100 \%$. (B) Tissue-specific and genome-wide differential expression of KAT proteins. Low expression corresponds to $30 \%$, moderate expression corresponds to $60 \%$, and high expression corresponds to $100 \%$. 
Proteins for KAT1, $-3,-4,-6 \mathrm{~B},-13 \mathrm{~A}$, and $-13 \mathrm{~B}$ were observed in the lung, proximal digestive tract, kidney, and urinary bladder. The KAT6A, -7 , and $-13 \mathrm{D}$ were expressed in endocrine glands, lung, proximal digestive tract, gastrointestinal tract, kidney, and urinary bladder. KAT1 and KAT9 proteins were expressed in the brain and pancreas (Figure 3B). These findings suggest that the expression levels of KATs themselves are regulated by differential gene expression, cellular and tissue specificity. The RNA levels of KAT8 are significantly elevated in non-small-cell lung carcinoma and have been linked with the promotion of cell proliferation [102]. KAT5 plays a vital role in generating resistance to chemotherapy in cases of non-small-cell lung carcinoma [81]. The fusion of the KAT3B gene and the transcriptional coactivator monocytic leukemia zinc finger protein can cause acute myeloid leukemia [91,92]. These data suggest that alterations in KAT expression negatively affect cellular growth programs.

KAT13A regulates gene expression during puberty-which appears to positively correlate with the overexpression of cellular proto-oncogene tyrosine-protein kinase and cancer progression [127]. KAT13B is found in oocytes and mammary glands [127]. Previous studies have suggested that KAT13B plays a role in both growth hormone regulation and reproductive functions. Additionally, KAT13B has been known to interact with KAT3B and KAT2B. Deletions of KAT13A and -13B have been linked to vascular and skeletal pathologies within these tissues [136].

The KAT13D regulates circadian rhythms by heterodimerizing with the brain and muscle Arnt-like protein-1, a transcription factor that regulates circadian rhythms and relaxes the chromatin via the acetylation of histone 3 [137]. KAT13D deletion has been linked to a decreased lifespan, whereas a KAT13D gene polymorphism has been associated with behavioral changes [138]. These behavioral patterns include sleep deprivation, shift work schedule, altered mealtime, and excessive artificial light exposure at night. Interestingly, dysfunction of the molecular clock is linked to uncontrolled cell proliferation in human cancers. Therefore, more knowledge on KAT-directed pathways and strategies to modulate acetylation levels on the chromatin of disease-specific genes will help treat manifestations of developmental syndromes, neurological disorders, and cancers.

\subsection{Genome-Wide Acetylation Marks on Chromatin}

The octameric nucleosome are comprised of 147 base pairs of DNA wrapped twice around two copies of histone $\mathrm{H} 2 \mathrm{~A}, \mathrm{H} 2 \mathrm{~B}, \mathrm{H} 3$, and $\mathrm{H} 4$ [139]. Lysine acetylation on human histone $\mathrm{H} 2 \mathrm{~A}$ occurs at positions $\mathrm{K} 5$ (H2AK5ac) and $\mathrm{K} 9$ (H2AK9ac); on $\mathrm{H} 2 \mathrm{~B}$, at positions $\mathrm{K} 5$ (H2BK5ac), K12 (H2BK12ac), K15 (H2BK15ac), K16 (H2BK16ac), K20 (H2BK20ac), and K120 (H2BK120ac). On histone H3, acetylation occurs at positions K4 (H3K4ac), K9 (H3K9ac), K14 (H3K14ac), K18 (H3K18ac), K23 (H3K23ac), K27 (H3K27ac), K36 (H3K36ac), and K56 (H3K56ac). On histone H4, acetylation occurs at positions K5 (H4K5ac), K8 (H4K8ac), K12 (H4K12ac), K16 (H4K16ac), K20 (H4K20ac), and K91 (H4K91ac) (Figure 4) [6,20,39,47].

The presence of $\mathrm{H} 3 \mathrm{~K} 9 \mathrm{ac}, \mathrm{H} 3 \mathrm{~K} 56 \mathrm{ac}$, and $\mathrm{H} 2 \mathrm{AK} 9 \mathrm{ac}$ on promoters serves as marks for transcriptionally active genes $[6,20,39,47]$. Similarly, transcriptionally active enhancers are enriched with the H3K27ac mark. The presence of KATs in the vicinity of an active gene is not restricted to a simple enzymatic function, but it is instrumental in promoting complex molecular assembly. Inhibitors of KDACs activate transcription, indicating that the coregulatory activities of KATs and KDACs on the chromatin modulate promoter activities. A recent report suggested that $\mathrm{H} 4 \mathrm{~K} 20 \mathrm{ac}$ was associated with low expression levels on promoters that do not overlap with transcriptionally active genes $[6,20,39,47]$. However, the coactivators KAT3A and KAT2B are recruited to H4K20ac via their acetyl-lysine-binding bromodomains. Furthermore, the H4K20 site underwent trimethylation by Pr-SET, which binds strongly to the chromodomain, in a Drosophila model [6,20,39,47]. H4K20me3 mediated by SUV4-20H2 in humans is involved in epithelial-mesenchymal states in pancreatic cancer [140]. Taken together, while it is possible to pull down large protein complexes, determining the role of individual domains and the timing of acetylation and deacetylation requires integration of combinatorial approaches, including small molecules, clustered reg- 
ularly interspaced short palindromic repeats (CRISPR) gene-editing systems, and real-time ChIP assays.

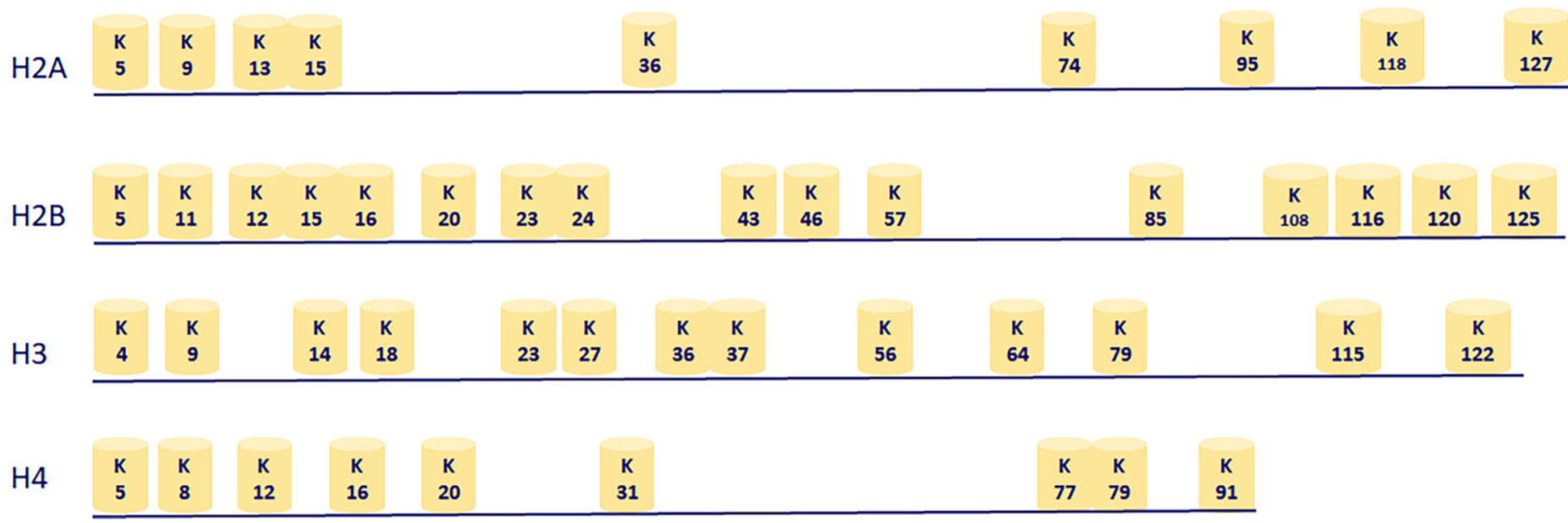

Figure 4. Site- and position-specific acetylation of lysine on nucleosomal histone proteins by KATs serve as a signature for the outcome of transcriptional activity by recruiting either bromodomain or KDACs.

\subsection{Sequence Analysis of Acetyltransferase Domain of KATs}

The overall sequence similarity amongst KATs was low. While the longest KAT sequence had 347 residues, the multiple sequence alignment extended to 650 residues. This extension was mainly because the KAT13 and KAT3A/-3B families aligned rather well, but they did not align with the MYST (KAT5, -6A, -6B, -7, and -8) and Gcn5-related N acetyltransferases (GNAT) (KAT2A and -2B) families. Supplementary Figure S1 shows the full multiple sequence alignment, and Figure 5 shows partial alignment with the highest degree of sequence similarity.

The European Molecular Biology Laboratory (EMBL) analysis also generated a guide tree (i.e., hierarchical clustering based on the pairwise alignment scores) as well as a phylogenetic tree (i.e., hierarchical clustering based on the multiple sequence alignment scores), as shown in Figure 6A,B, respectively [141-143]. This figure also shows the family to which the sequences belong (GNAT, MYST, steroid receptor coactivator (SRC), or CREB-binding protein (CBP)/p300). The families SRC, MYST, and CBP/p300 were clearly separated into different branches of both trees. However, the GNAT family had members in two branches; KAT1 (the only GNAT family member not associated with bromodomains) was in the CBP/p300 family. Comparing the two trees, the phylogenetic tree produced more subclusters than the guide tree, thus providing additional information about these protein domains (Figure 6A,B). 


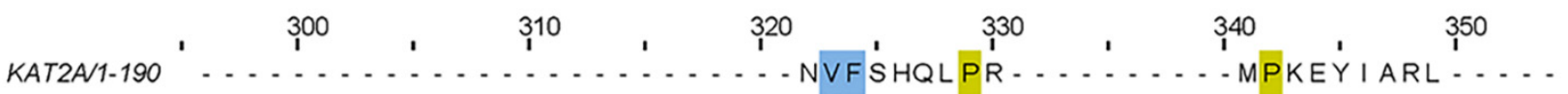

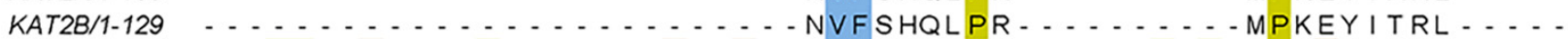
KAT13A11-235 QQTPPASGYQ - SPDMKAWQQGA I GNNNVFSQAVQNQ . . . . PTPAQP - GVYNNMSITVS KAT13B/1-342 QHPQAASIYQ-SSEMKGWPSGNLARNSSFSQQQFAHQ - . - GNPAVYSMVHM - . . . KAT13C/1-342 QQSQANPAYQAPSDI NGWAQGNMGGNSMFSQQSPPHF - - - GQQANT SMY SNNMNINVS KAT4/1-347 KHIKKKAKMRE - . - Q QERQA - SGGGEMFFMRTPQDL - TGKDGDL - . . . . ILAE KAT5/1-140 KAT8/1-274 KAT7/1-195 KAT6AV1-277 KAT6B/1-275 KAT9/1-99 KAT1/1-82 KAT3A11-309 KAT3B/1-311 KYMKYEKSYRFHLGQCQWRQ - - PPGKE I YRKS - . NI SVYEVDGKDHKIY CQNL CLLAK ........ - LRRHMAKCVWKH - - PPGDE I YRKG - . SI SVFEVDGKKNK I Y CQNL CLLAK KYMKSRT I LQQHMKKCGWFH - PPANEIYRKN - - NISVFEVDGNVST I YCQNLCLLAK KYMKSKNILLRHSKKCGWF H - PPANEI YRRK - - DL SVFEVDGNMSK I YCQNL CLLAK

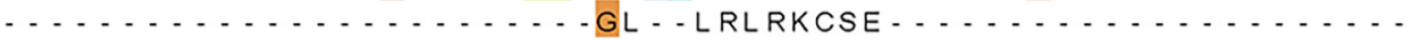

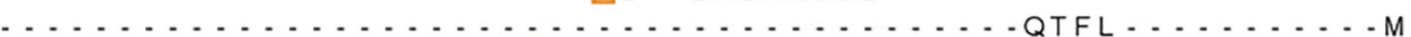
KFLRR . . . . . . . . . QNH . . PEAGEVFVRVVASSDKTVEVKPGMK . . . . . . . . S DFLRR . . . . . . . . QNH - PESGEVTVRVVHASDKTVEVKPGMK . . . . . . A

KAT2A $1-190$ KAT2B/1-129 KAT13A/1-235 KAT13B/1-342 KAT13C/1-342 KAT4/1-347 KAT5/1-140 KAT8/1-274 KAT7/1-195 KAT6A/1-277 KAT6B/1-275 KAT9/1-99 KAT1/1-82 KAT3A/1-309 KAT3B/1-311

KAT2A $1-190$ KAT2B/1-129 KAT13A/1-235 KAT13B/1-342 KAT13C/1-342 KAT4/1-347 KAT5/1-140 KAT8/1-274 KAT7/1-195 KAT6A/1-277 KAT6B/1-275 KAT9/1-99 KAT1/1-82 KAT3A $1-309$ КАT3B/1-311

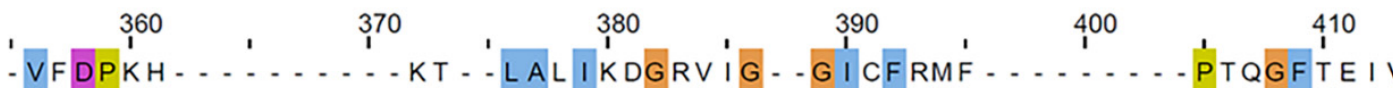
- VFDPKH......... . . - LAL I KDGRVIG - - G I CFRMF . . . . . PSQGFTEIV MAGGNTNVQNMNPMM . - . . Q QMQMS SLQMPGMNTVC . . . . . PEQ INDPALRHTGL - NG S SG HMGQ ......... . MNMNPMPMSGMP - MG ..... . PDQKYC . . . . . . MATNTGGMS SMNQMT . -GQISMTSVTSVPTSGLSSMG . . . . . . . PEQVNDPALRGGN . YSEEN ............ GPLMMQVGMATK .... IKNYYKRK - PGKDPGAPDCKYGETV

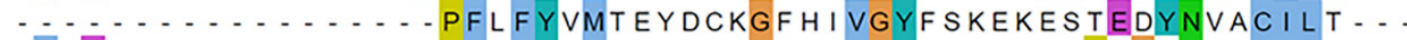
LFLDHK - . . . TLYFDVEPFVFYILTEVDRQGAHIVGYFSKEKESPDGNNVACILT . . LFLDHK - . . . TLYYDVEPFLFYVMTEADNTGCHLIGYFSKEKNSFLNYNVSCILT . . LFLDHK - . . . TLYYDVEPFLFYVLTQNDVKGCHLVGYFSKEKHCQQKYNVSCIMI ... LFLDHK - . . . TLYYDVEPFLFYVLTKNDEKGCHLVGYF SKEKL CQQKYNVSCIMI . .

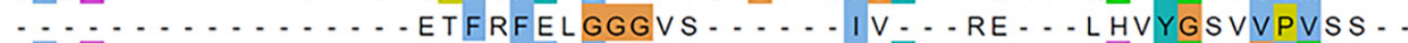
WF IETA ............ SF IDVDDER . . . . WHYFL - . . . FEKYNKDGAT . . . RFVDSGEMSESFPYRTKALFAFEEIDGVD . . . . V VIFFGMH . . VQEYGSDCPPPN . RFVDSGEMAESFPYRTKALFAFEEIDGVD . . . . L LFFGMH . . VQEYGSDCPPPN .

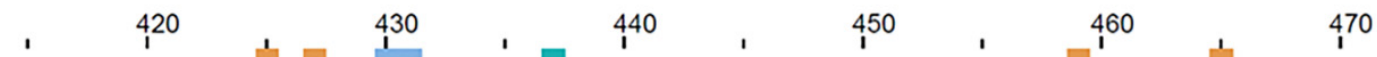
FCAVTSNEQVKGYGTHLMNHLKEYHIKHNILÝFLTYADEYAI - - GYFKKQGFSKDIKV FCAVTSNEQVKGYGTHLMNHLKEYHIKHDILNFLTYADEYA I - - GYFKKQGFSKEIKI

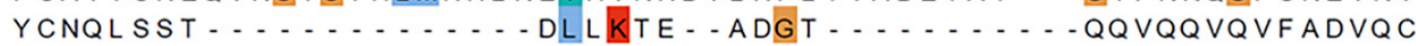
YCHTSPFLGSLHPGQLLQAFENNLFRAP _ I YLHKMP . . ETDFLIIRTRQGYYIRELV -... L PPYQRRGYGKLL IEFSYELSKVE - - GKTG -

- . - LPPYQRRGYGKFL I AFSYELSKLE - - STVG

-. - MPQYMRQGYGKML I DFSYLLSKVE - - EKVG

-..- LPQYQRKGYGRFL I DFSYLLSKRE - -GQAG

- - - MPQHQRQGFGRFL I DFSYLLSRRE - - GQAG

- - RDPTKFQHQGFGML LMEEAERIAREE - - HGSGKIAVISGVGTRNYYRKIGYRLQGPY

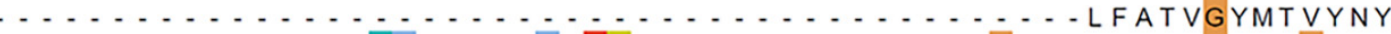
- - TRRVYIS - . . . . Y YLDS - I HFFRPR - - CLRTAVYHEILIGYLEYVKKLGYVTGHIW - - QRRVYIS - . . . . Y YLDS - VHFFRPK - CLRTAVYHE IL IGYLEYVKKLGYTTGHIW

Figure 5. Partial multiple sequence alignment of the acetyltransferase sequences from 15 KATs that show the most sequence similarity/identity. The sequence numbers refer to the full alignment. 
A

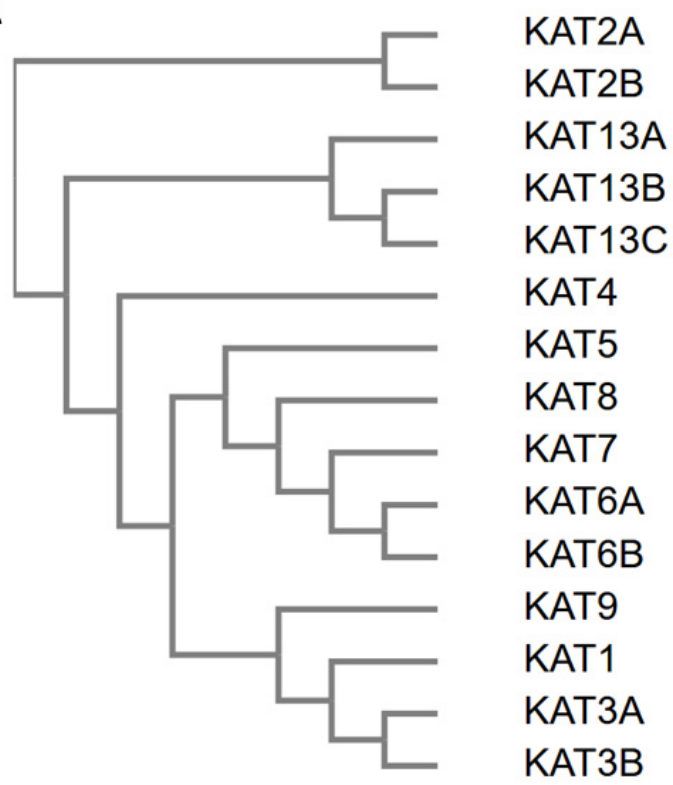

B

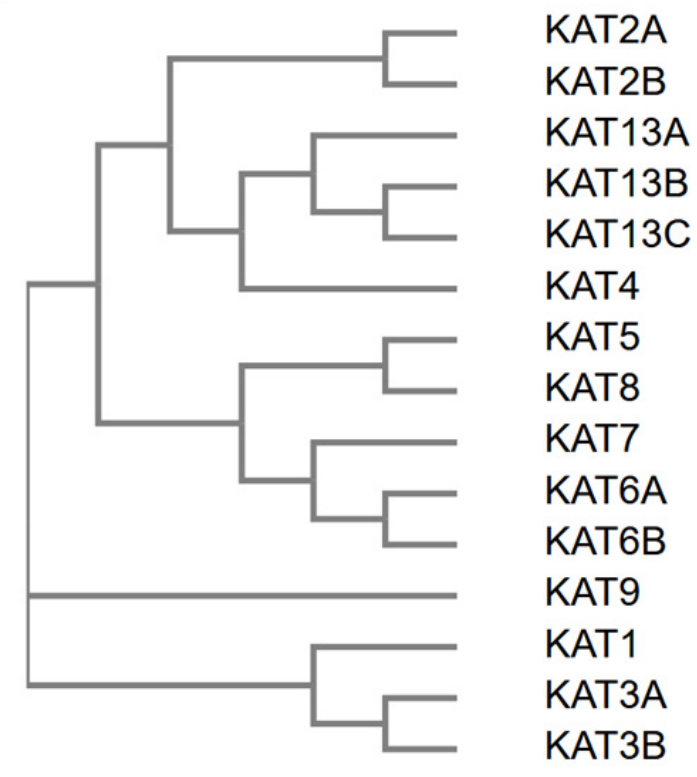

Figure 6. Hierarchic clustering of the KAT sequences. Panel (A) represents the guide tree, and panel (B) represents the phylogenetic tree.

\subsection{Structural Analysis of Acetyltransferase Domain of KATs}

To compare the structures of the different KAT families, representative structures were aligned. The crystal structures were obtained from the Protein Data Bank (PDB) [144-146], which involved a multiple sequence alignment to the smallest acetyltransferase domain (KAT2A) [147]. This alignment of the corresponding atoms was needed for the overlay. Figure 7A-C show the structures of KAT2A (PDB id: 1cm0), KAT8 (PDB id: 2giv), and KAT3A (PDB id: 5u7g), respectively. The binding site is shown in Figure 7D with the three structures superimposed. In all panels, the binding site is facing the viewer. The KAT-binding site is bordered by a beta-sheet composed of three strands and by two alpha helices (HX1 and HX2). In KAT2A, one of the beta strands was formed by residues 51-86, the longer alpha helix (HX1) is formed by residues $92-109$, and the shorter alpha helix (HX2) is formed by residues 121-130. These helices are labeled in Figure 7D as HX1 and HX2, respectively. Interestingly, the structural alignment was nearly perfect for the betasheet-especially for HX1—but significantly worse for HX2. This observation was also consistently noted when several family members were used for the structural alignment (data not shown). In fact, the sequence alignment did not match any of the aligned residues to the shorter helix of KAT2A. However, when other KAT3A structures were added to the alignment (data not shown), the helices that matched the shorter helix of KAT2A aligned very well within the family. These findings suggest that the shorter helix is responsible for the specificity of each KAT. 


\section{A: KAT2B}

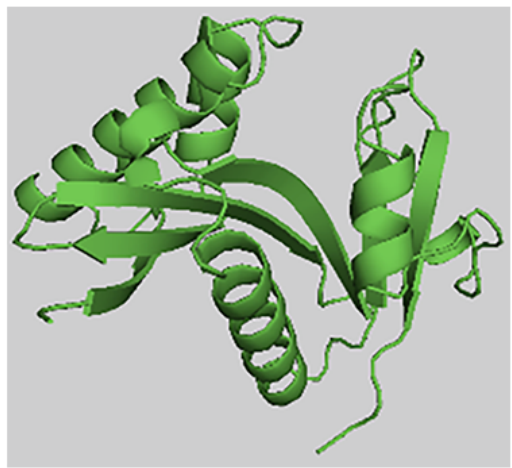

B: KAT8

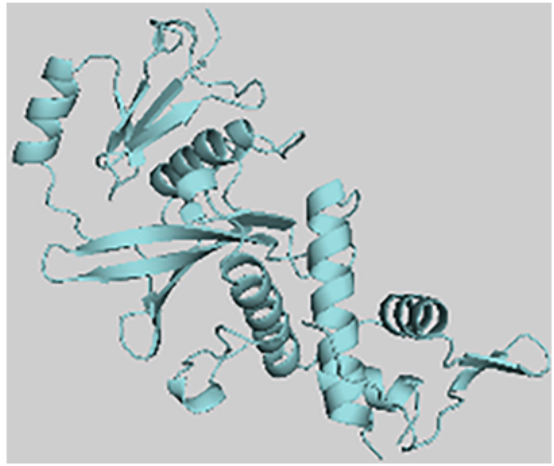

C: KAT3A

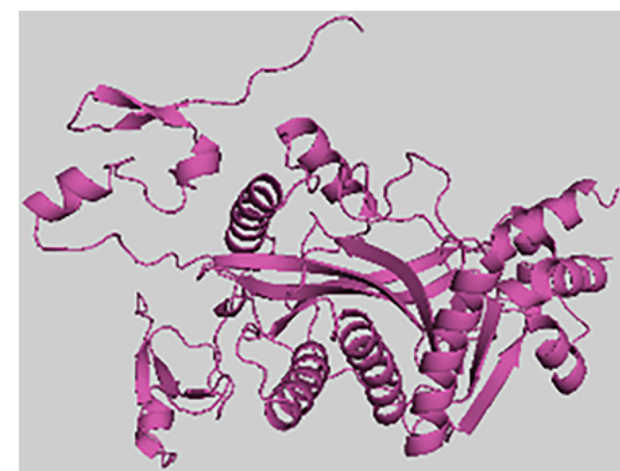

D: Overlay of Structures of KAT2B, KAT8 and KAT3A

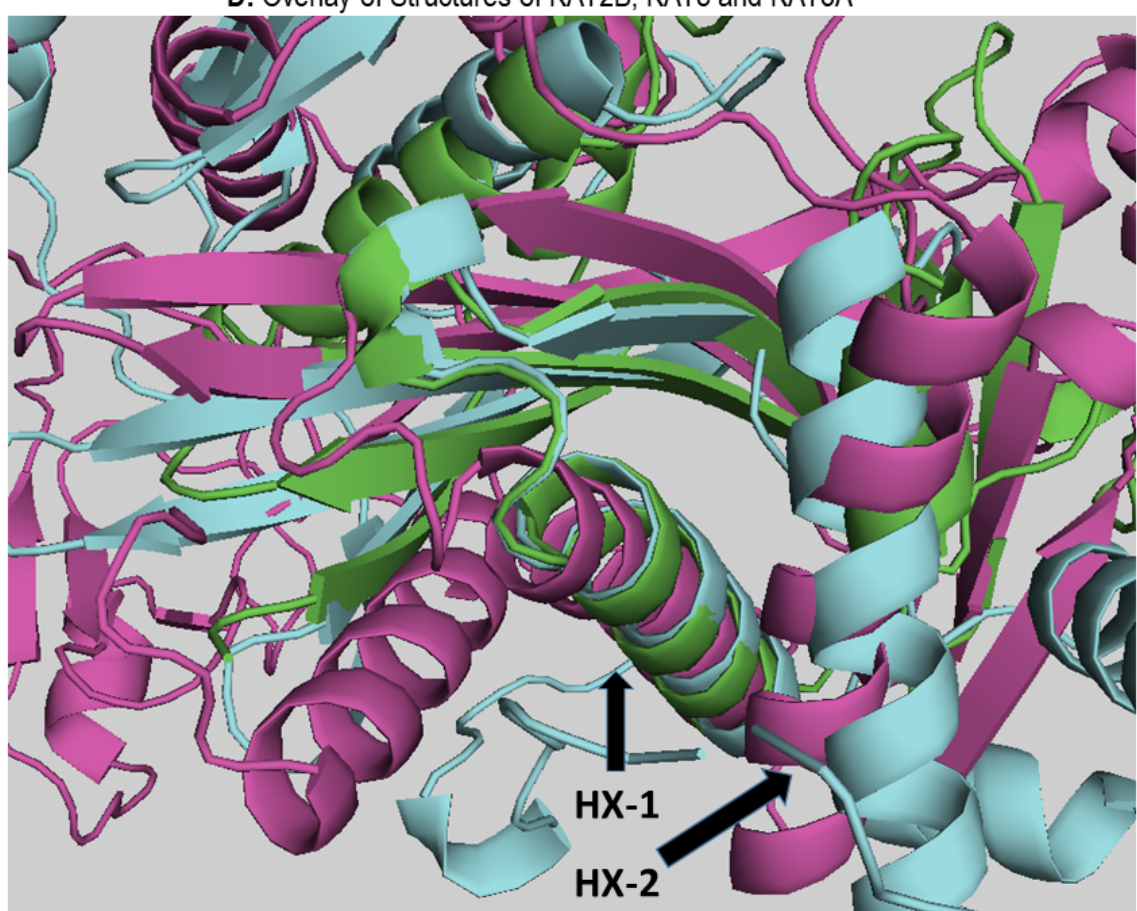

Figure 7. Cartoon representation of the KATs representative of the class. Panel (A) represents KAT2A. Panel (B) represents KAT8, and panel (C) represents KAT3A. Panel (D) represents the superimposition of KAT2A, KAT8, and KAT3A family representatives, showing the binding site region.

\subsection{Mutually Exclusive Crosstalk between Epigenetic Marks}

Mutually exclusive epigenetic modifications on the histone proteins of the enhancer and promoter regions facilitate activation or repression [5]. For instance, H3K9 or H3K27 sites could undergo either trimethylation (me3) or acetylation. While H3K9me3 and H3K27me3 are hallmarks of gene repression, $\mathrm{H} 3 \mathrm{~K} 9 \mathrm{ac}$ and $\mathrm{H} 3 \mathrm{~K} 27 \mathrm{ac}$ indicate gene activation (Figure 8) [148]. These mutually exclusive events play a crucial role during development and embryogenesis in multicellular organisms [149,150]. Additionally, H3K9 and H3K27 can undergo biotinylation and sumoylation [151]. However, the functional readouts of these modifications are not yet fully understood. Similarly, the biotinylation of H4K12 blocks the activation potential of H4K12ac [152]. Although mutually exclusive modifications on histone tails induce antagonistic effects, such is not the case with H3K36: Both H3K36ac and H3K36me3 activate downstream transcriptional events [14,153]. In transcription factors like p53, acetylation is mutually exclusive to methylation and ubiquitination on lysine 382 [154-156]. We still do not know whether there are separate pools of differentially modified p53 and histone proteins in cells which different-or the same. The ability of 
lysine residues to undergo mutually exclusive modifications makes the acetylation process more complex than kinase-mediated phosphorylation.

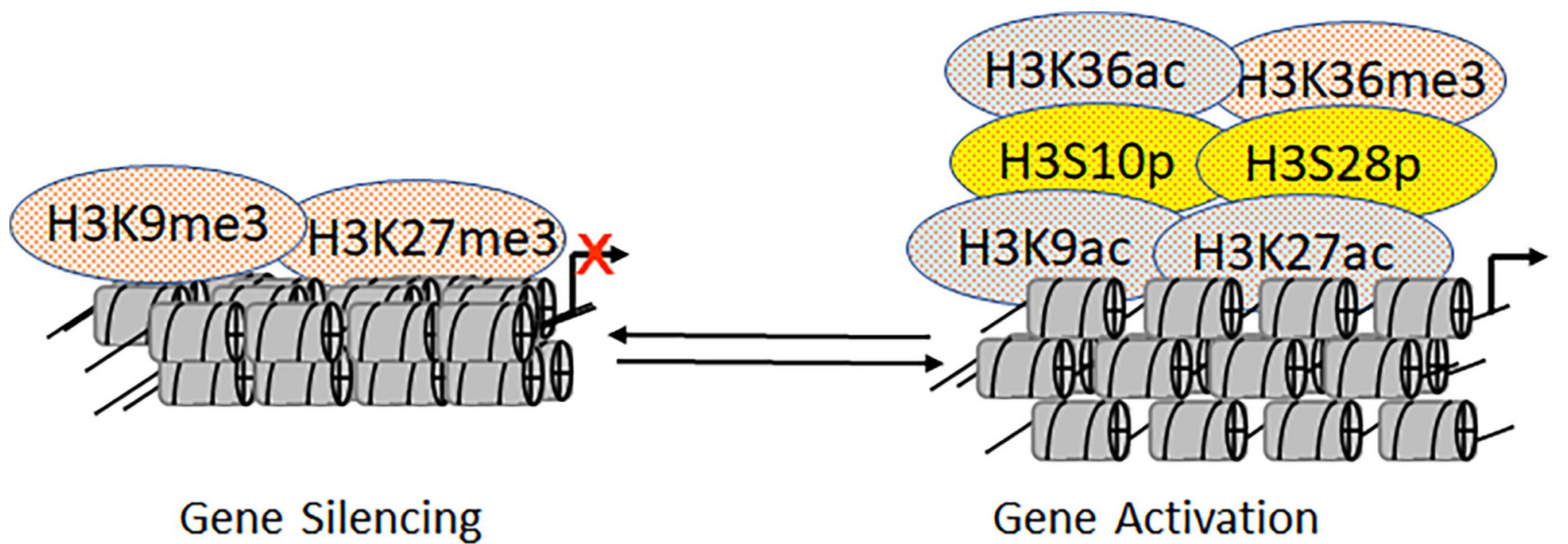

Figure 8. Mutually exclusive acetylation and methylation on lysine residues H3K9 and H3K27. Cross-talks between H3K9 and phosphorylation at $\mathrm{H} 3 \mathrm{~S} 10$ and between $\mathrm{H} 3 \mathrm{~K} 27$ and phosphorylation at H3S28. Together, these epigenetic modifications unfold mechanisms, which are responsible for cellular response to extracellular signals.

Phosphorylation is integral to the site-specific and combinatorial epigenetic modifications on the nucleosomal histone proteins [157]. The phosphorylation of histone $\mathrm{H} 2 \mathrm{~A}(\mathrm{X})$ flags the nucleosomes near the site of DNA damage [157]. Moreover, phosphorylation at serine 10 on histone $\mathrm{H} 3$ (H3S10p) and serine 32 on histone H2B are associated with epidermal growth factor-responsive gene transcription. H3S10p and phosphorylation of serine 28 on the histone H3 (H3S28p) play a pivotal in controlling the expression of proto-oncogenes [157]. In Tetrahymena, the biological role of H3S10p is associated with mitosis, and the level of H3S28p is induced by ultraviolet B treatment. Previous studies have defined the positive effects of histone $\mathrm{H} 3$ phosphorylation on the growth factormediated expression of the $c$-fos and c-jun proto-oncogenes [158]. Subsequently, the threedimensional, ternary complex structure of the Tetrahymena KAT2A domain-bound to both acetyl-CoA and $\mathrm{H} 3$ peptide-revealed major interactions between its catalytic site and the H3 peptide [40,41,159-161]. Later, biochemical analysis of this structure revealed that the phosphorylated histone $\mathrm{H} 3$ had a higher binding affinity for KAT2A than the unphosphorylated peptide. Further, it was established that the H3S10p facilitated the H3K9ac [40,41,159-162]. However, it is not clear whether H3S10p and H3K9ac coexist on the same histone tail. Furthermore, using a dual-specific antibody that unambiguously recognizes both $\mathrm{H} 3 \mathrm{S10p}$ and $\mathrm{H} 3 \mathrm{~K} 9 \mathrm{ac}, \mathrm{H} 3 \mathrm{S10}$ p was confirmed to be essential for the acetylation of H3K9. Interestingly, the SUV39h1-mediated methylation of H3K9 inhibited H3S10p. Finally, in a yeast model system, the NuA4-mediated acetylation occurring at lysine 5, 8, 12 , and 16 on histone $\mathrm{H} 4$ was inhibited by phosphorylation on serine 1 by Casein kinase 2 which is believed to exist in a complex with KDACs to enhance deacetylation [163].

In addition to the crosstalk between phosphorylation and lysine acetylation, there is cooperativity between acetylation and arginine methylation. During the transcriptional activation of nuclear receptor $\mathrm{p} 160$, the coactivator-arginine methyltransferase 1 interacts with KAT3A, which leads to the methylation of arginine 17 and the acetylation of lysine residues 18 and 23 on histone H3 [162]. We understand the significance of crosstalk between neighboring modifications better than distant modifications from antibody studies. Together, data from mass spectrometry and antibody-based investigations may not fully reveal the existence of different pools of nucleosomes undergoing differential modifications. The use of highly selective small molecules and specific antibodies with real-time live imaging technologies could prove to be useful to address these questions. 


\section{Acetylation of Nonhistone Proteins}

\subsection{Metabolism, Developmental Disorders, and Cancers}

High-resolution mass spectrometry and bioinformatics analyses have revealed that acetylated proteins are detectable in the nucleus and cytoplasm, as well as in the endoplasmic reticulum and mitochondria $[49,50,164]$. The presence of acetylated proteins in mitochondria raised questions about the molecular link between acetylation and metabolism, which has been recently established $[49,50,164]$. For example, one of the first indications of such a relationship emerged from the role of acetyl-CoA as a cofactor in lysine acetylationand as a metabolite bridging glycolysis with the tricarboxylic acid cycle. Biochemical data confirmed that the depletion of acetyl-CoA reduces the levels of cellular acetylation [165]. The enzyme acetyl-CoA synthetase short-chain 2 (ACSS2), which converts acetate into acetyl-CoA, interacts with KAT3B, resulting in enhanced chromatin acetylation [166]. This interaction is indispensable for the differentiation of neuronal cells, as the knockdown of ACSS2 causes reduced acetylation and loss of memory in mice [164]. Furthermore, in the presence of high glucose levels, the transcription factor $\mathrm{C} / \mathrm{EBP} \alpha$ is acetylated by KAT3A, which induces its transcription function [167]. Conversely, the deacetylation of $\mathrm{C} / \mathrm{EBP} \alpha$ stimulates the expression of genes involved in mitochondrial biogenesis, stimulating ATP production to maintain energy levels under low-glucose conditions. In addition to ACSS2, pyruvate and citrate are converted by the pyruvate dehydrogenase complex and ATP-citrate lyase into acetyl-CoA (Figure 9).

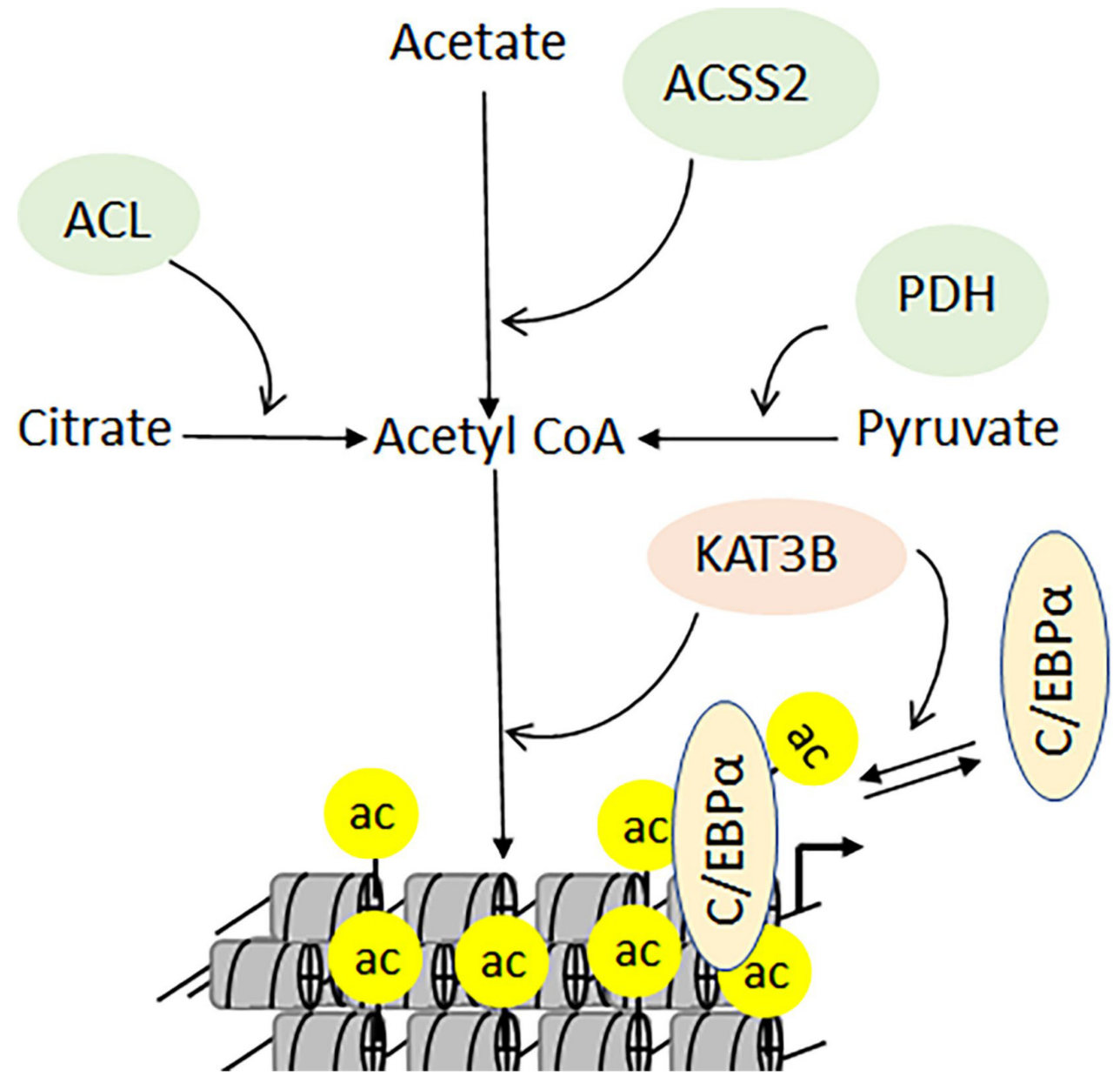

Figure 9. The acetyl-CoA is a key metabolite that could be generated by three different enzymes. Pyruvate dehydrogenase complex (PDH) generates acetyl-CoA in mitochondria, whereas ATP-citrate lyase (ACLY) and acyl-CoA synthetase shortchain family member 2 (ACSS2) generate a nonmitochondrial pool of acetyl-CoA. 
Congenital mutations in KATs can cause developmental disorders, intellectual challenges, cardiac problems, and craniofacial, genital, and behavioral abnormalities [47]. Notably, these mutations do not impact the acetyltransferase function of KATs. Still, they do influence protein-protein interactions and the formation of molecular complexes that work in tandem with the general transcriptional machinery [47]. These mutations are present in KAT3A, -3B, -6A, and -6B. However, mutations in KAT3A lead to Rubinstein-Taybi syndrome, impacting the level of acetylation [47]. The dysfunctional KAT complexes tilt the stoichiometric balance towards KDACs. Therefore, calibrating the use of KDAC-dependent inhibitors could elicit a potential therapeutic advantage in certain clinical situations.

The acetylation-mediated function of KATs (supporting either tumor suppression or uncontrolled growth) is dependent upon the upstream signals, cell types, and types of mutations involved [168]. Somatic mutations in KATs that deregulate the level of acetylation also result in oncogenesis [169]. Genetic translocation leading to the expression of fusion proteins is a major mechanism by which cells gain uncontrolled self-renewal and growth properties [170,171]. The myeloid/lymphoid or mixed-lineage leukemia protein (MLL) regulates gene expression during early development and hematopoiesis by trimethylation at lysine 4 on histone H3 (Figure 10A) [172]. In murine models, deregulated MLL causes anxiety and cognitive defects [173]. Additionally, MLL demonstrates a higher tendency toward chromosomal translocation that generates different types of MLL fusion proteins (MLL-FP; Figure 10B). The fusion of MLL with KAT3A causes acute lymphoblastic leukemia and acute myeloid leukemia, respectively (Figure 10C) [170,174,175]. In normal situations, MLL and KAT3A cooperate during the differentiation of hematopoietic stem cells that are deregulated upon the formation of MLL-KAT3A fusion protein [170,174,175]. The MLL-KAT3A can cause acute myeloid leukemia (Figure 10D) [170,174,175]. Missense, inactivating, and truncation mutations within $K A T 3 A /-3 B$ may cause breast, gastric, ovarian, and small-cell lung cancers as well as diffuse, large cell, and follicular lymphoma [72]. Deletion, amplification, and translocation of the KAT6B gene can lead to leiomyoma and bladder, colorectal, and small-cell lung cancers [176]. Together, these data suggest that the functions of KATs have been characterized better in disease situations than in normal cells.

\subsection{Target Acetylation Pathway in Nuclear Factor-Kappa B-directed Chronic Diseases}

The nuclear factor kappa-light-chain-enhancer of activated B cells (NF-kB) family of master transcription factors plays a central role in expressing genes that regulate innate and adaptive immune responses [177-179]. The induction of NF- $\mathrm{kB}$ is triggered by inflammatory signals, bacterial and viral infections, free radicals, heavy metals, and ultraviolet light [177-179]. The dysregulation of NF- $\mathrm{kB}$ transcriptional activities leads to cancers, acute and chronic inflammation, autoimmune disorders, and septic shock [180]. Classical activation of NF- $\mathrm{kB}$ involves the release of the cytoplasmic p65/p50 heterodimer from IкB, which facilitates its nuclear localization and interaction with coactivators on the promoters of immune-response genes, leading to a cellular response (Figure 11) [181]. While the phosphorylation of IKB leads to its ubiquitination, the phosphorylation of p65 leads to its nuclear localization [182]. The interaction of $\mathrm{p} 65 / \mathrm{p} 50$ with coactivators plays a crucial role in modulating downstream genes that mediate appropriate cellular responses depending on the type and level of cellular stress [183]. The molecular interplay between KAT3A/-3B and Rel A epitomizes a critical aspect of NF- $\mathrm{KB}$ biology: KAT3A/-3B has been shown to acetylate Rel A on lysine 310 (RelAK310ac) [182]. Together with its phosphorylation on serine 276, RelAK310ac plays a major role in recruiting the positive transcriptional elongation factor P-TEFB. Conversely, the methylation of lysine 310 by SETD6 proteins facilitates the interaction of Rel A with the histone methyltransferase GLP/G9a, leading to the downregulation of transcription (Figure 11) [184,185]. Recently, several reports have established a pivotal link between acetylation and the activation of NF- $\mathrm{kB}$-directed pathways, which are central to the development of cancers and chronic inflammatory bowel disease. One key protein that has emerged to modulate the transcriptional activities of NF- $\mathrm{KB}$ is BRD4, which is a member of the bromodomain and extra-terminal domain 
families [186]. The tandem double bromodomain with BRD4 has the capacity to bind acetylated chromatin as well as NF- $\mathrm{kB}$ [187]. BRD4 has been shown to regulate the levels of enhancer RNA [188]. Given these multiple roles, BRD4 has emerged as a potential drug target. Reports have also suggested that BRD4 inhibitors may suppress the activation of TNF $\alpha$, IL-6, IL-17A, and IL-8 [189,190].

A.

MLL

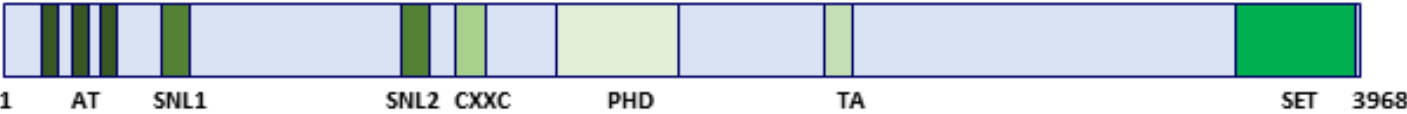

B.

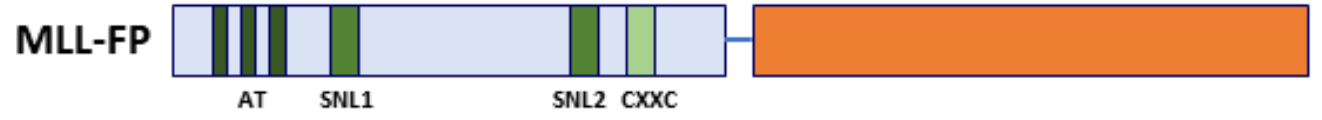

C.

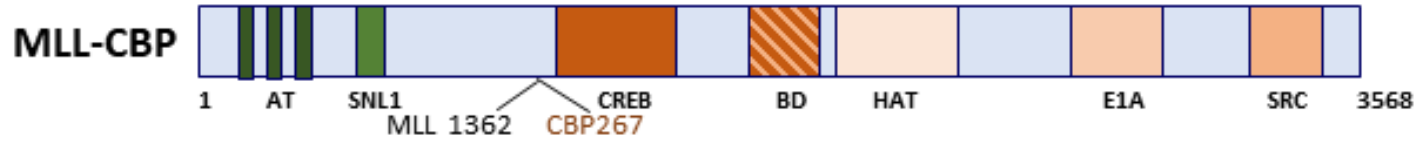

D.
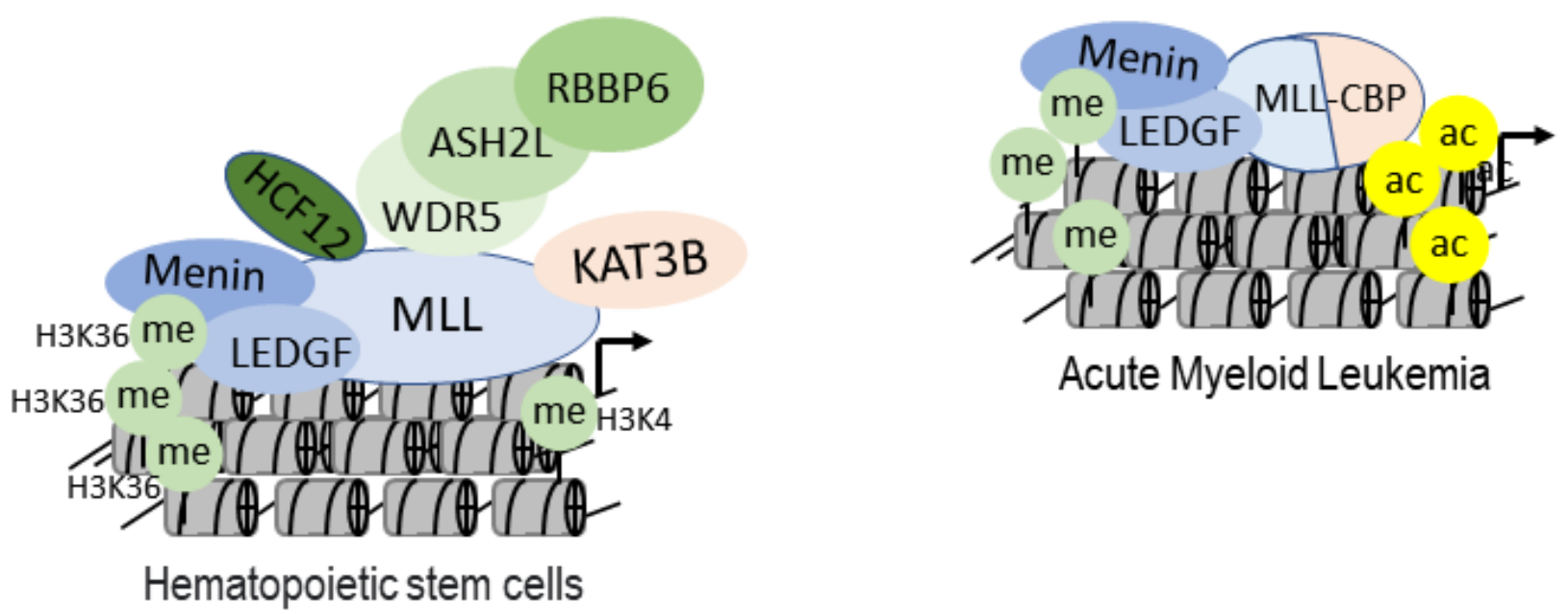

Figure 10. N-terminal of $M L L$ fuses with the bromodomain and histone acetyltransferase domain (HAT) domain of CBP/KAT3A to form MLL-KAT3A fusion protein that has the potential to cause acute myeloid leukemia (AML). Panel (A) represents the full-length multidomain MLL protein. Panel (B) represents a typical MLL fusion protein (MLL-FP) formed mainly by the N-terminal domain of MLL. Panels (C,D) represent the constitution of MLL-KAT3A fusion protein and highlight the altered chromatin landscape that changes the cell fate of hematopoietic stem cells towards AML. 


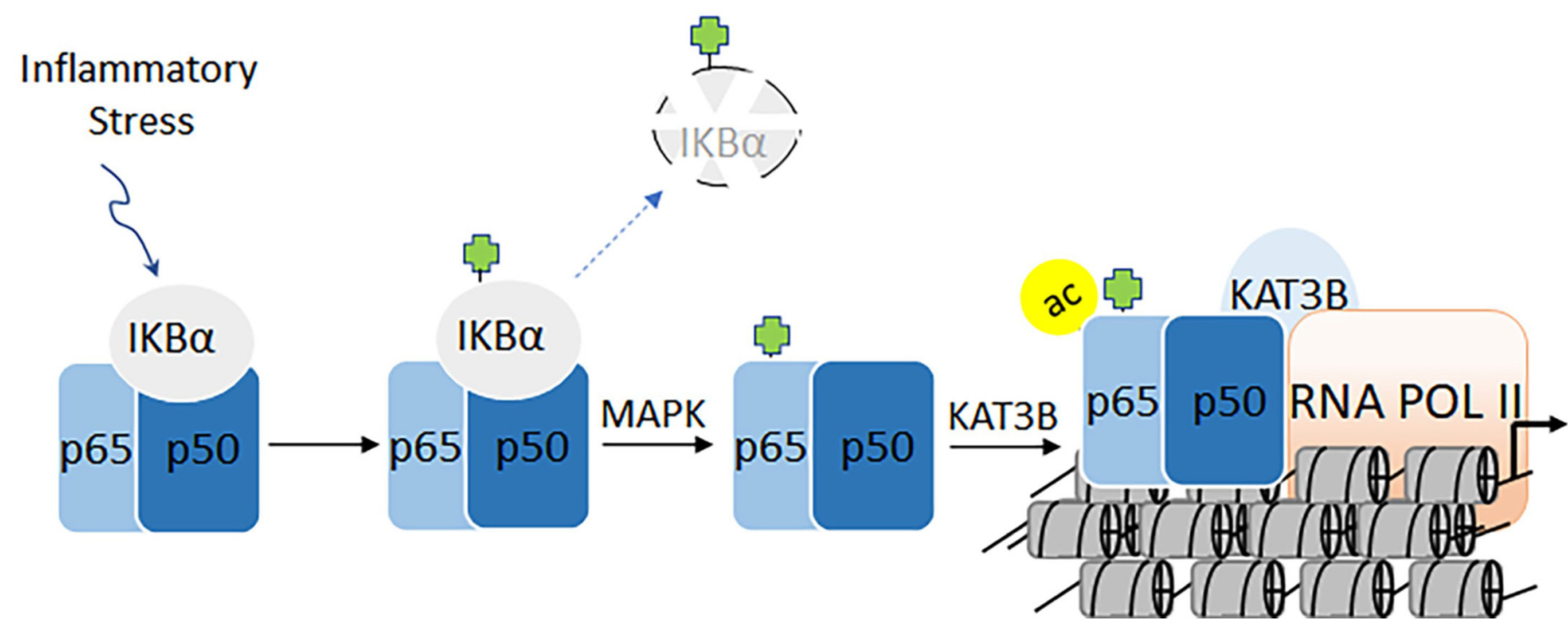

Figure 11. Proinflammatory signals trigger phosphorylation followed by ubiquitination-mediated degradation of I $k \mathrm{~B} \alpha$. This dissociation of the ternary complex releases p65/p50 from I $\mathrm{B} \mathrm{B} \alpha$ heterodimer. Subsequently, the phosphorylation of p65 on serine 276 (yellow balls) by the mitogen-activated protein kinase leads to acetylation of lysine 310 on p65 (green balls), which potentiates the transcriptional activity of NF- $\mathrm{kB}$.

\subsection{Multifaceted Roles of p53 C-Terminal Domain during Genotoxic Stress}

The role of tumor suppressor protein p53 has ranged from a viral antigen to a central player in regulating cellular responses to a wide range of genotoxic stresses over the past four decades [191-193]. Recent investigations have systematically established that the functions of p53 extend beyond the regulation of apoptosis and cell cycle arrest to include biological processes such as metabolism, oxidative balance, aging, autophagy, and ferroptosis [154,156]. Epigenetic modifications and protein-protein interactions are the major determinants that confer multitier gene regulatory capabilities to p53 [194]. The tumor suppressor protein p53 was also discovered to be one of the first nonhistone proteins that could undergo KAT-mediated acetylation on its C-terminal domain (CTD) $[195,196]$. The other major epigenetic modifications of p53 include phosphorylation, ubiquitination, and methylation [154,156]. Additionally, sumoylation, neddylation, O-GlcNAcylation, adenosine diphosphate ribosylation, hydroxylation, and $\beta$-hydroxybutyrylation have been shown to modulate the transcriptional activities of p53 [154,156]. During genotoxic stress, activation of p53 involves its phosphorylation on serine 15, which rescues p53 from the Mouse double minute 2 homolog (MDM2) - a major E3 ubiquitin ligase and negative regulator of p53 (Figure 12A). Subsequently, the lysine 382 on the p53 CTD undergoes acetylation by KAT3A/-3B (p53Kac382). Notably, MDM2 can ubiquitinate p53 at six lysine residues within the CTD (K370, K372, K373, K381, K382, and K386; Figure 12B). High levels of MDM2 activity promote $\mathrm{p53}$ 's polyubiquitination and nuclear degradation, whereas low levels induce monoubiquitination and nuclear export. However, in the cytoplasm, p53 can perform transcription-independent roles [154]. 
A.

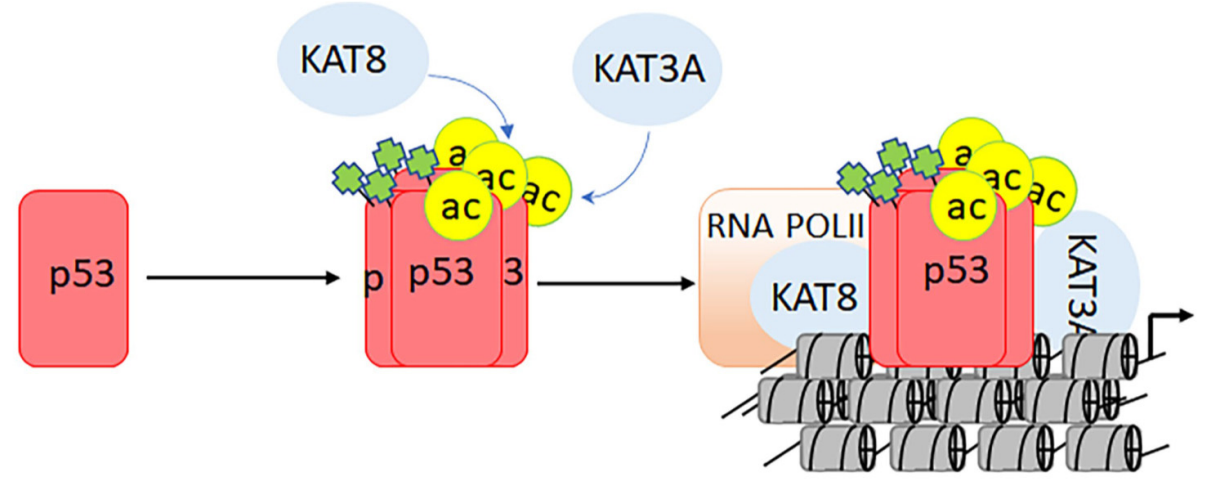

B.

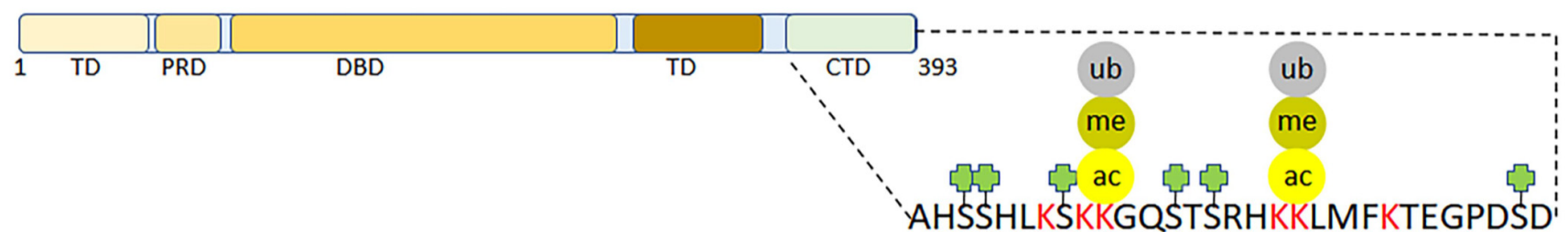

Figure 12. KAT3A and 3B regulates the tumor suppressor functions of p53 by molecular interaction and acetylation on the C-terminal doman (CTD). Panel (A) represents the activation of p53 under genotoxic stress which results in the phosphorylation at serine 15 (green box) and acetylation of p53, at lysine 120 by KAT8 and lysine 382 by KAT3A/3B (yellow circles). These modifications are critical for the stability and transcriptional activation of p53. Panel (B) represents the C-terminal tails of p53 that-like histone tails—serve as modification and recruitment sites for coactivators.

Three unstructured regions within the p53 protein are located within the N-terminal domain between the DNA-binding and oligomerization domains and CTD $[55,194,197]$. Furthermore, the unstructured CTD serves as a major recruitment platform for coactivatorsand has been shown to exhibit various secondary conformations during these molecular interactions. Additionally, the CTD has been shown to bind DNA independent of any sequence specificity. The major sites of acetylation on the CTD are K320, K372, K373, K381, and K382 (Figure 12B) $[55,194,197]$. The K382, which can be acetylated by KAT3A/-3B, has gained increased attention, possibly because of the availability of robust antibodies that recognize this site. The p53K382ac serves as a docking site for the bromodomain-mediated recruitment of KAT3A/-3B and the induction of the downstream target CDKN1A leads to growth arrest [55,194,197]. In addition to its interaction with bromodomains, the acetylation of p53 has been shown to impact DNA binding and cellular localization [198]. Furthermore, acetylation at K120 by KAT8 plays a crucial role in p53-mediated apoptosis $[155,199]$. The synergy between acetylation at K164 by KAT3A/-3B and K120 acetylation contributes to p53directed cell cycle arrest $[153,199]$. More recently, the p53-3KR mouse model that expresses acetylation-deficient p53 (K117/161/162R)—which mirrors K120/164R mutations in human p53 - was used to demonstrate that while the apoptotic and growth arrest functions of p53 were lost, p53-dependent metabolic regulation was still intact [191]. Unlike wild-type p53, the CTD-deleted p53 lacks the ability to bind DNA and activate downstream target genes (Figure 12B). Collectively, biochemical, cellular, and animal models have provided major answers regarding the biological role of p53. However, the underlying mechanisms that direct crosstalk between acetylation and various modifications of p53 for activating downstream target genes selectively require further investigation. One possibility would be to take advantage of the CRISPR gene editing system to mutate the active site of the KATs and use small molecules against the conserved modular domains of p53 coactivators.

\subsection{The Role of MYST Family in Gene Regulation and Cellular Response}

The MYST family of KATs (which includes KAT5, -6A, -6B, -7, and -8) plays a central role in maintaining cellular homeostasis and stem cell patterning during embryogenesis $[102,129,176]$. These KATs are also involved in regulating DNA damage responses, cell 
cycle control, and apoptotic pathways [47]. The genome-wide screening of KATs revealed that KAT6A is most susceptible to having varying copy numbers, enabling cells to exhibit a tumorigenic phenotype [200]. A KAT6A-TIF2 fusion protein suppresses the expression of CDKN2A, which leads to the downregulation of cellular senescence [93]. The human KAT6A gene was first identified in patients with acute myeloid leukemia [176]. The KAT6A and $-6 \mathrm{~B}$ genes are composed of plant homeodomain, serine-rich, and methionine-rich domains. In the studied patients, KAT6A formed in-frame fusion proteins with KAT3A or -3B. Further, the KAT6A-TIF2 fusion was shown to provide hemopoietic stem cells with the sustained potential for self-renewal during leukemic transformation [93]. Experimental models have revealed that while KAT6A is important for the differentiation of hematopoietic stem cells, KAT6B is essential for the differentiation of neuronal cells into neurons, astrocytes, and oligodendrocytes [201]. KAT5 was one of the first members of the MYST family to be identified for its ability to interact with the HIV transactivator protein (Tat) [202]. Interestingly, interactions between KAT5 and HIV Tat prevent apoptosis, thereby indirectly supporting HIV persistence in immune cells [202]. Among the MYST family, KAT5 is most closely related to KAT8 which, when mutated, affects only male flies. Breast, ovarian, colorectal, renal, gastric, and hepatocellular cancers exhibit lower levels of KAT8 protein and H4K16ac than their normal tissue counterparts [104,203-205]. These findings are associated with poor prognosis and increased risk of metastasis in these tissues. Besides, male-specific lethal proteins 1, 2, and 3 (MSL1, MSL2, and MSL3) form a complex with KAT8 to mediate H4K16ac [47]. The biological significance of this complex was first investigated in a Drosophila model of dosage compensation. Mutations in MSL3 affect the level of H4K16ac [47]. However, compared to KAT8, the specific roles for MSL1, MSL2, and MSL3 are still not well understood. In addition to the acetylation of H4K16, H4K20 can undergo mono-, di-, or trimethylation-or acetylation. However, the crosstalk between these neighboring modifications is not clear. KAT8 has the ability to be a part of two different complexes: the MSL-1 and the MSL1v1 complexes [11]. Furthermore, the role of the methyl-lysine-binding chromodomain has yet to be elucidated in translational models (Figure 13A).

In $\mathrm{PCa}$, the functional synergy between the $\mathrm{AR}$ and NF- $\mathrm{BB}$ has the potential to increase the chemoresistance to antiandrogens that could promote aggressive tumor growth $[33,206,207]$. Although the underlying mechanisms are less clear, the regulatory abilities of coactivators can bridge the transcription functions of both AR and NF- $k B$. Indeed, KAT8 has been shown to costimulate AR and NF-kB functions in PCa cells [33]. A report also demonstrated that the activation of NF- $\mathrm{KB}$ promoted the deacetylation of KAT8 by NAD-Sirtuin 1 . Furthermore, the mutually exclusive interactions between KAT8 and NAD-Sirtuin 1 or AR regulate the acetylation of lysine 16 in histone $\mathrm{H} 4$ [33]. Notably, in AR-negative PC3 cells (as well as in AR-depleted LNCaP cells), the downregulation of KAT8 activates the cleavage of poly ADP ribose polymerase (PARP) and caspase 3, leading to apoptosis. In contrast, in AR-expressing PC3 cells (PC3-AR), the depletion of KAT8 induces CDKN1A/p21 expression, which results in G2M arrest. Concomitantly, the levels of phosphorylated retinoblastoma, E2F1, CDK4, and CDK6 proteins are all reduced. Additionally, the expression of tumor protein D52 is unequivocally affected in PC3, PC3-AR, and LNCaP cells, suggesting that the functional interactions of KAT8 with AR and NF- $\mathrm{B}$ are critical for PCa progression (Figure 13A,B) [33]. 
A.

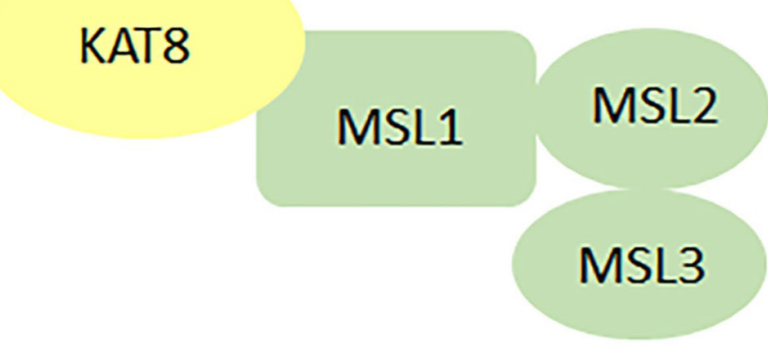

B.

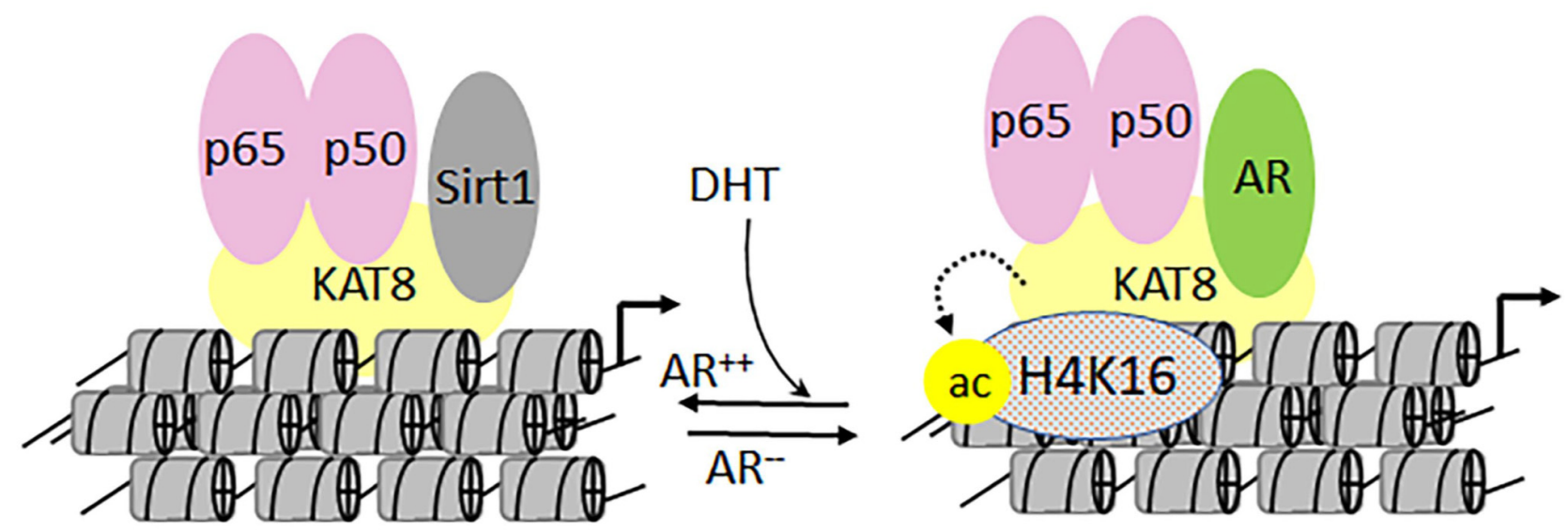

Figure 13. Differential molecular interactions mediated by KAT8 lead to modulation of downstream target genes. Panel (A) represents the interaction of KAT8 with MSL1, MSL2, and MSL3. Panel (B) represents the dichotomy in MYST interactions with NF-KB and AR in prostate cancer cells.

\subsection{KAT2A and -2B in Transcriptional Regulation of HIV Activation}

In human cells, KAT2B forms a complex with Ada2, Ada3, Spt3, PAF400, PAF65 $\beta$, TAF15/20, PAF65 $\alpha$, TAF30, and TAF31 [47]. Although the acetylation activities of KAT2A and $-2 \mathrm{~B}$ were characterized early on, the epigenetic signature of these complexes remains to be determined (Figure 14A) $[47,208]$. HIV Tat is a 102-amino acid polypeptide that plays a central role in the transcriptional activation of HIV, which occurs on the long terminal repeat of the proviral DNA. Tat initiates transcription by interacting with the transactivation response element (TAR). KAT2A acetylates four lysine residues at the C-terminal of HIV integrase, including K258, K264, K266, and K273 [209]. Knocking down KAT2A reduces HIV integration, leading to a decline in infectivity [209]. Additionally, K264, K266, and K273 are acetylated by KAT3B. KAT2B regulates transcriptional activation by acetylation of lysine 28 on HIV Tat (TatKac28) and binds to Tat acetylated lysine 50 (TatKac50) through its bromodomain. While TatKac28 helps the recruitment of Tat to the CDK9/PTEF-B complex, the TatKac50 helps to dissociate Tat from TAR, which leads to enhanced HIV Replication [54]. The bromodomain of KAT2B competes for the TatKac50 site, which helps Tat/TAR dissociation. Together, these epigenetic changes promote chromatin remodeling that further accelerates the replication and expression of HIV proteins that devastate the human immune system (Figure 14B) $[54,210]$. Finally, blocking the acetyltransferase module of KAT3A/-3B as well as the KAT2B bromodomain with small molecules reduces Tat-mediated activation of HIV replication [211]. 


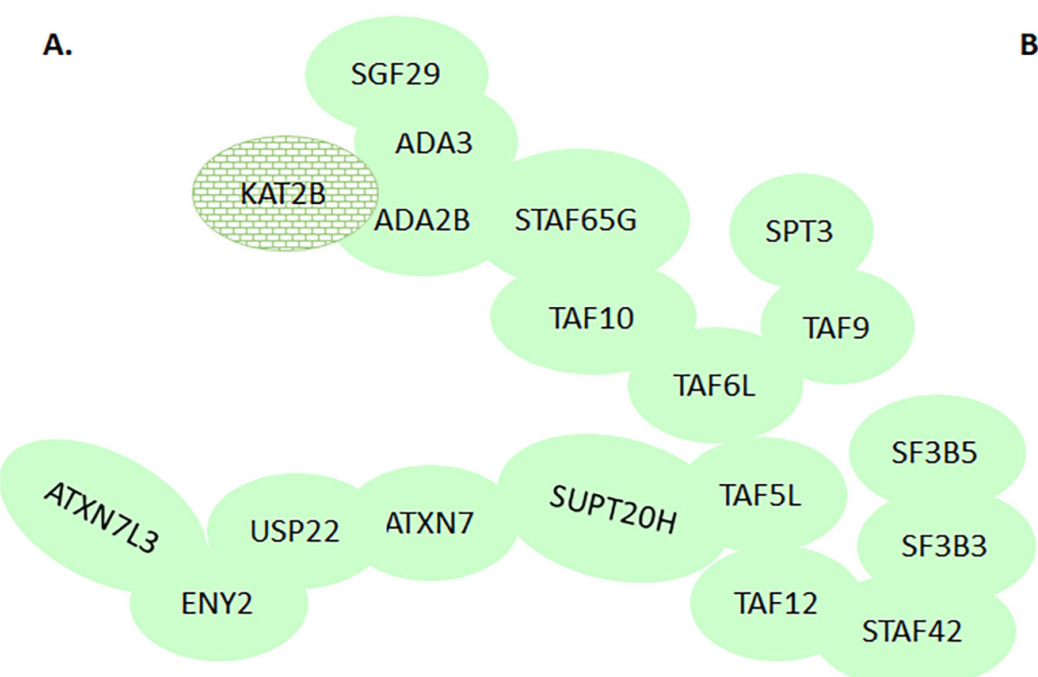

B.

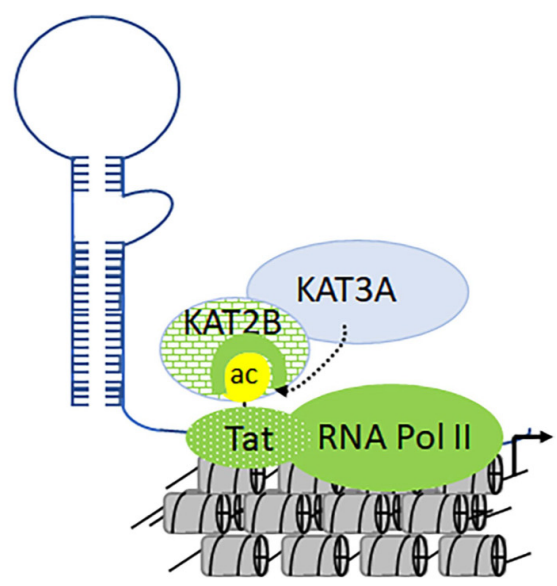

Figure 14. Differential molecular interactions mediated by KAT2A/-2B lead to modulation of downstream target genes. Panel (A) represents the interaction of KAT2A/-2B with $700 \mathrm{kDa}$ general transcriptional factors. Panel (B) represents the dichotomy in KAT2B interactions with HIV Tat acetylated at lysine 50. Acetylation of Tat by KAT3B facilitates bromodomainmediated recruitment of KAT2B.

\subsection{The Dynamics of KATs and KDACs in Models of Traumatic Brain Injury}

The brain is one of the most metabolically active organs and is critically dependent upon normal physiological levels of oxygen. Traumatic brain injury (TBI) from sudden accidents or cardiac arrest can cause immediate oxidative stress, acute inflammation, apoptosis, the indiscriminate release of neurotransmitters, and unchecked ionic influxes [212,213]. These cellular imbalances result in severe cerebral hypoxia, an acute medical condition that reduces the oxygen circulation to the brain. It is often fatal. Administration of valproate to patients with TBI (inhibiting KDACs that would lead to increased acetylation) underlines the crucial interplay between KATs and KDACs [214]. Mice models suggest that histone acetylation is causally related to memory enhancement [215]. An earlier report suggested that histone acetylation may reverse ischemic brain injury in neonatal rats [27]. Another report by Gao et al. demonstrated that TBI reduced the levels of histone $\mathrm{H} 3$ acetylation in the hippocampal region [216]. Taken together, these epigenetic changes affect the hypoxiaregulated genes. Hypoxia-inducible factors (HIFs) are the major transcription factors that respond to declines in cellular and physiological oxygen levels by regulating gene expression during hypoxia [27]. HIFs are hydroxylated on proline residues under normal oxygen conditions and are later degraded by an oxygen-dependent proteasomal pathway mediated by the von Hippel-Lindau protein (Figure 15A) [217]. However, under hypoxic conditions, KAT2B acetylates HIF-1 $\alpha$ on lysine 674 , which activates hypoxia-responsive genes in the presence of KAT3B (Figure 15A,B) [217]. Transcriptional regulation by KAT3A and -3B enhances acetylation-mediated hypoxic gene expression [216]. HIF-1 is a heterodimer that consists of alpha and beta subunits [218]. The upregulation of HIF-1 $\alpha$ has been shown to improve tolerance to hypoxia and reduce neuronal cell loss. The NAD-dependent NAD-dependent Sirtuin 1 deacetylates HIF-1 $\alpha$, which loses its ability to interact with KAT3B to activate hypoxia-regulated genes. Additionally, NAD-dependent Sirtuin 1 plays a significant role in the maintenance of mitochondrial function in the brains of zebrafish during hypoxia. The NAD-dependent Sirtuin 1 increases oxidative metabolism due to the inhibitory effects of acetylation by reversing deacetylation (Figure 15A,B) [218]. Clearly, we are only beginning to probe the complex relationships between KATs and KDACs in normal brain/neurological disorders. Although gene knockout models will provide a broad look at the functional significance of KATs and KDACs, the use of CRISPR and small molecules will give a better understanding of brain function during normal and disease-affected situations. 
In summary, KATs orchestrate acetylation-dependent and acetylation-independent mechanisms that are multilayered and intertwined with the functions of transcription factors activated by upstream cues. Additionally, the biological role of integrates gene regulation, metabolic processes, and stress-directed cellular responses. Given their essential role in human biology, a combinatorial approach is the key to designing tools for unraveling the complete functions of KATs. One approach could be to develop highly selective small molecules to target KATs utilizing computational and chemical biology approaches.
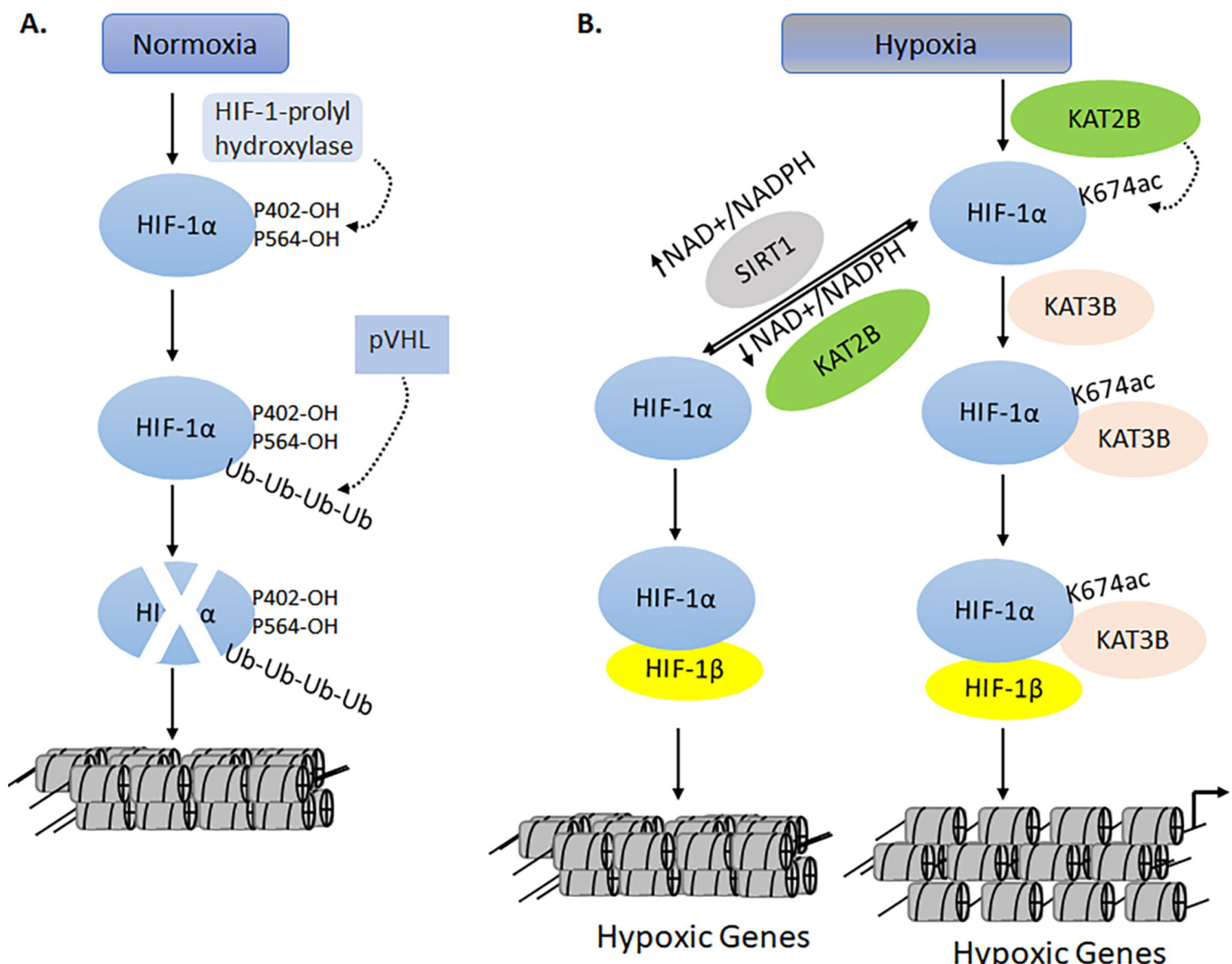

Figure 15. Molecular interplay of acetylation, deacetylation, and ubiquitination by KATs, KDAC, and ubiquitinases on the oxygen-sensitive transcription factor hypoxia-inducible factor (HIF)- $1 \alpha$. Panel (A) represents the ubiquitinationmediated degradation of HIF- $1 \alpha$ when oxygen is normal. Panel (B) represents the acetylation-mediated stabilization and transcriptional activation of HIF- $1 \alpha$.

\section{Chemical Biology of Acetylation-Mediated Mechanisms Directed by KAT3A/-3B}

Advancements in sequencing technology and data from the human genome project have reached a zenith in rapidly detecting mutations and diagnosing human genetic diseases. However, understanding the role of the epigenetic basis of disease pathogenesis is challenging, due to the involvement of an array of posttranslational modifications and molecular interactions. Most chromatin-associated proteins, including KATs, consist of multiple domains that interact with the transcriptional machinery in more than one fashion. Determining the influence of the KAT-associated protein complexes on their enzymatic 
activity and substrate specificity is challenging. Additionally, the enzyme kinetics of a recombinant KAT may not be consistent with their in vivo activity. This may limit data interpretation from in vitro assays with in vivo disease models. Together, gene manipulation may not fully reveal a modular domain's role in mediating epigenetic modifications versus molecular interactions. A small molecule can block the specific function of a target protein without affecting its endogenous expression, unlike microRNA, small interfering RNAs and gene knockout-based approaches [219,220]. Furthermore, small molecules have an added advantage, in that they can easily enter the cells without transfection or electroporation because of their low molecular weights [221]. Small molecules targeting bromodomains have been shown to negatively affect the level of acetylation $[56,194,222,223]$. Such investigations increase our knowledge regarding the mechanisms involved in the assembly of activator-versus-repressor complexes on the gene promoter.

KAT3A/-3B-mediated H3K27ac serves as a marker for gene activation [224]. However, H3K27me3 by EZH2 leads to gene silencing [225]. Thus, KAT3A modulators can control gene activation versus silencing on disease-specific promoters. A study using human melanocytes showed that downregulation of KAT3A activity inhibited growth and induced cellular senescence [226]. Additionally, depending upon the cellular context, KAT3A activity is required for the G1/S transition of the cell cycle [73]. KAT3A/-3B undergoes chromosomal translocation, causing myeloid leukemia [227]. KAT3A also serves as a pharmacological target for minimizing p53-induced pathology in normal tissues. Below, we discuss the potential of inhibiting the acetylation-directed functions of KAT3A/-3B by small molecules A485, C646, and nitrile-curcuminoid (NiCur) in various model systems.

\section{1. $A 485$}

The small molecule A485 was identified by virtual screening as a potent catalytic inhibitor of KAT3A/-3B [228,229] (Figure 16A). A485 demonstrates selectivity for not inhibiting the acetyltransferase activities of KAT2A, $-2 \mathrm{~B},-6 \mathrm{~A}$, and $-6 \mathrm{~B}$. However, at a higher concentration, A485 shows selectivity for bromodomain and extra-terminal bromodomain proteins and 150 nonepigenetic targets. It also displays binding to dopamine and serotonin transporters, along with a modest inhibition of Polo-like kinase 3. A485 treatment was shown to result in a dose-dependent decrease in H3K27ac. A485 selectively inhibits tumor proliferation, including several blood-related cancers and AR-positive PCa. Further, A485 inhibited tumor growth in castration-resistant PCa xenograft models; it also led to a decrease in the mRNA levels of MYC and the AR-dependent gene SLC45A3, and a reduction in MYC protein levels [228-231].

\section{2. $\mathrm{C} 646$}

The compound C646 was identified by in silico screening (Figure 16B) [230]. C646 has been tested in several cell lines and has also been shown to modulate the antibacterial properties of macrophages and inflammation [230-232]. KAT3A and -3B were highly expressed in five gastric cancer (GC) cell lines (SGC-7901, MKN45, MGC-803, BGC-823, and KATO III) compared with a normal human gastric epithelial cell line (GES-1) [230-232]. C646, a selective inhibitor of KAT3A and -3B, inhibited cell viability and cell cycle progression and promoted apoptosis in all five GC cell lines. Except for the MGC-803 cell line, KAT3A mRNA levels in the other four GC cell lines were significantly higher than those in GES-1 cells. The protein expression levels of KAT3A and -3B in the five GC cell lines were significantly higher than those in the GES-1 cells. Finally, C646 treatment significantly reduced the levels of histone $\mathrm{H} 3$ acetylation in both GC cells and normal gastric epithelial cells $[230,231]$. 


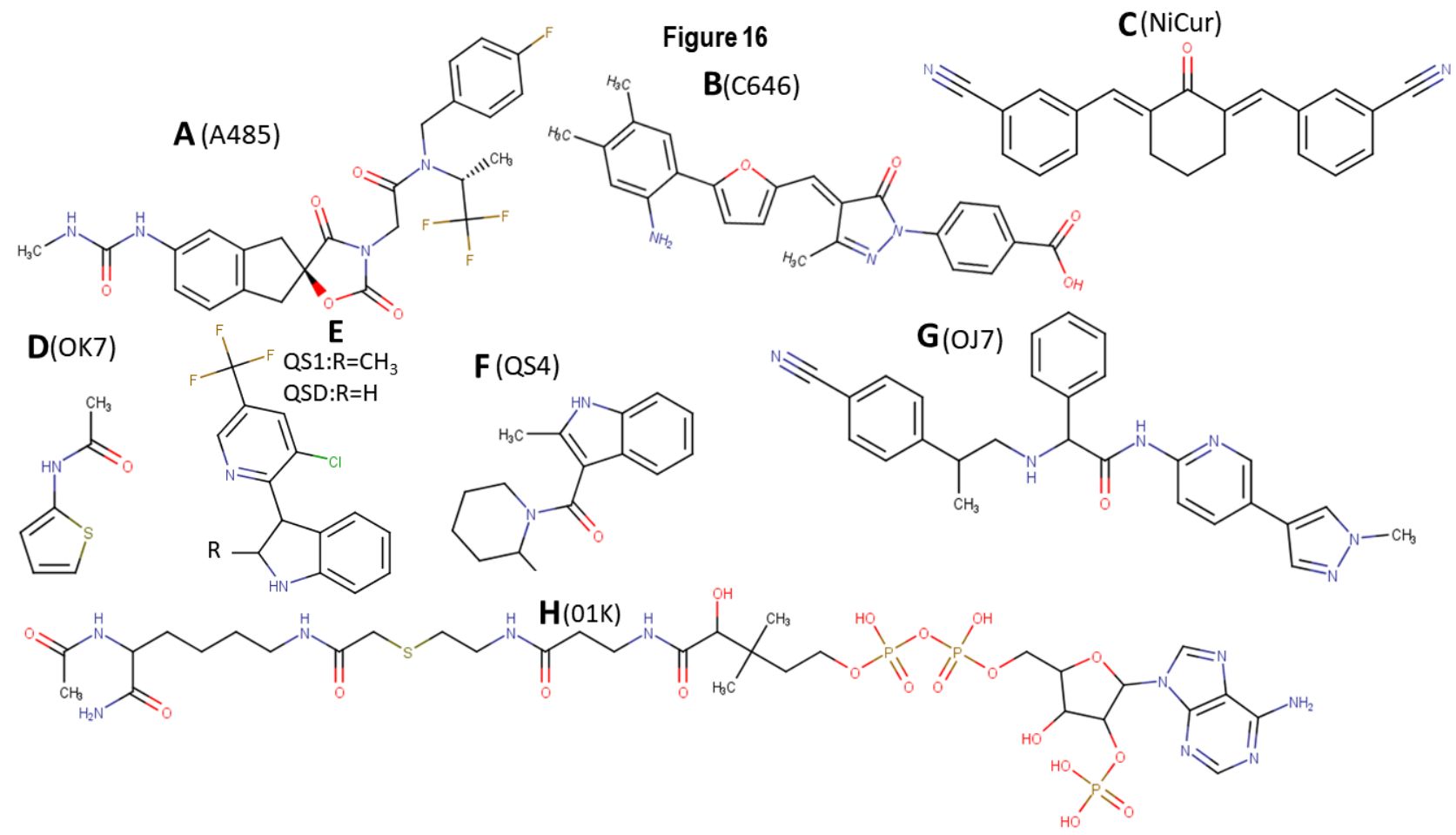

Figure 16. Chemical structure of the ligands: (A) A485, (B) C646, (C) NiCur, (D) 0K7, (E) QS1 and QSD, (F) QS4, (G) OJ7, and $(\mathbf{H})$ OK1.

\subsection{NiCur}

The activation of p53-mediated apoptosis controls the growth of tumors and can trigger a massive loss of normal cells as side effects [55,194,223]. Structurally modified C5-curcumin analogs (both acyclic and cyclic) and a NiCur were previously demonstrated to exhibit anti-inflammatory, antiangiogenic, and anticancer activities. Cell-based screening assay revealed that NiCur was most potent in inhibiting KAT3A acetylation activity [223]. Molecular docking and in vitro acetylation assay revealed that NiCur binds to the active sites of KAT3A and not KAT2B. Additionally, under conditions of DNA damage, NiCur inhibited the levels of p53K382ac and the occupation of p53 on the CDKN1A promoter. Furthermore, NiCur inhibited apoptosis in normal gastric epithelial cells. Collectively, these data demonstrate that the inhibition of KAT3A epigenetic functions by NiCur can inhibit p53 toxicity in normal cells $[55,194,223]$.

In summary, depending upon the biological context, the inhibition of KAT3A/-3Bmediated acetylation functions can block the growth of cancer cells and antagonize p53 activation. These data underline the broader implications of small molecule inhibitors, which could be developed further into a highly selective KAT inhibitor. Virtual screening of ligands has become a more effective tool to screen many compound libraries rapidly. It has the potential to address the underlying target-based mechanisms and structure-guided design of new analogs. In the future, chemically conjugating the inhibitors of KAT3A/-3B enzymatic activity with KAT3A/-3B bromodomain could entirely block the acetylationbased functions of KAT3A/-3B. These studies lay the foundation for developing highaffinity KAT3A modulators that could serve as a valuable mechanistic tool for transforming cellular fate by reprogramming the epigenetic landscape.

\subsection{Structural Analysis of Ligands Binding to KAT3A/-3B Acetyltransferase Domain}

Several crystal structures of KAT3B bound to ligand are available in the PDB. The structures discussed here include PDB IDs 3biy, 4bhw, 5kj2, 6pf1, 6pgu, 6v8k, 6v8n, and 6v90, which bind ligands 01K [233], 6TF/A485 [228], OJ7 [234], OK7 [71,234], QS4 [71], 
QS1 [71], and QSD [71], respectively, as well as the docked pose of the ligand NiCur, developed in our laboratories. Note that the ligand labeled 6TF in the $5 \mathrm{kj} 2$ structure is A485 from the discussion above. The structures of ligands OK7 (Figure 16D), QS1 and QSD (Figure 16E), QS4 (Figure 16F), OJ7 (Figure 16G), and 01K (Figure 16H) are shown, respectively. The docked structure of our ligand NiCur docked to KAT3A is shown in Figure 17. The ligand-p300 structure from the PDB and the models of our compounds were analyzed for ligand-protein contacts. Contacts were defined as mutually proximal heavy atom pairs (e.g., atom $\mathrm{L}$ on the ligand is closest to atom $\mathrm{P}$ on the protein, and atom $\mathrm{P}$ is also the closest to atom L) [235]. Table 3 lists the closest contact distances between the various ligands. The residues that are parts of HX1 and HX2 are also marked. Note that KAT3B structures mentioned as PDB IDs 3biy and 4bhw bind to the same ligand (01K).

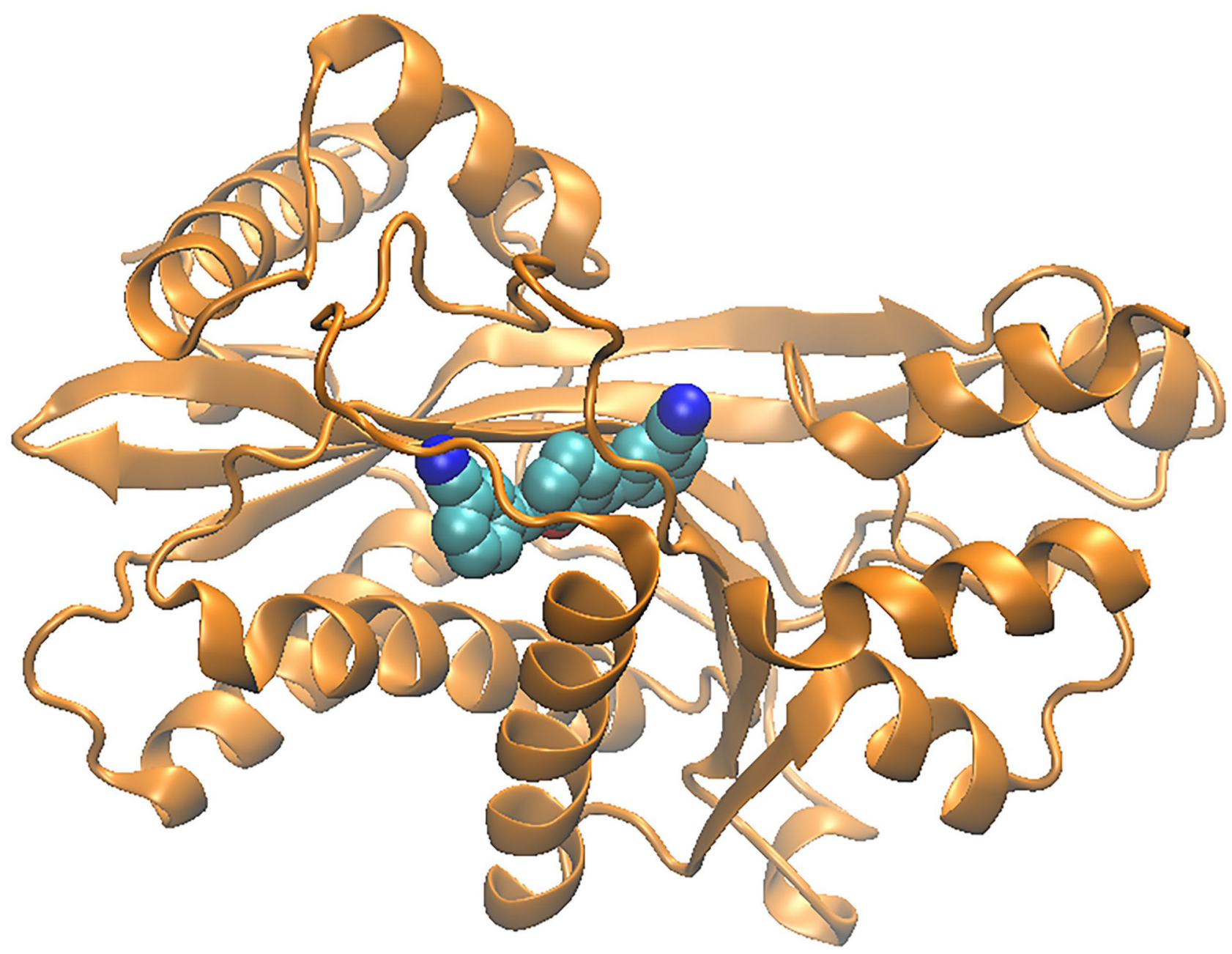

Figure 17. The ligand NiCur docked into the active site of KAT3A. The golden brown color indicates the acetyltransferase domain of KAT3A and the blue and metallic grey colors indicate the ligand, NiCur. 
Table 3. Residue-ligand distances for residues in contact with the ligand.

\begin{tabular}{|c|c|c|c|c|c|c|c|c|c|c|c|}
\hline \multicolumn{2}{|c|}{ PDB id: } & & 3 biy & 4bhw & $5 \mathrm{kj} 2$ & $6 \mathrm{pf1}$ & $6 p g u$ & $6 \mathrm{v} 8 \mathrm{k}$ & $6 v 8 n$ & $6 v 90$ & \\
\hline \multicolumn{2}{|c|}{ Ligand: } & & 01K & 01K & $6 \mathrm{TF}$ & OJ7 & OK7 & QS4 & QS1 & QSD & NiCur \\
\hline 1374 & PHE & & & & 2.99 & & & & & & \\
\hline 1379 & GLN & & & & & & & 3.68 & & & \\
\hline 1394 & TYR & & & & & & 3.52 & 3.23 & & & \\
\hline 1395 & ILE & & & & & & & & & & 2.95 \\
\hline 1396 & SER & & 3.34 & 3.17 & & & & 2.78 & & & \\
\hline 1397 & TYR & & 3.22 & 2.49 & & & & 3.23 & & & \\
\hline 1398 & LEU & & 2.91 & 2.9 & & & & & 3.21 & 3.24 & \\
\hline 1399 & ASP & & & 3.35 & 3.32 & & & & 3.25 & 3.1 & \\
\hline 1400 & SER & & 2.62 & 2.45 & 2.94 & & & & 2.69 & 2.89 & \\
\hline 1407 & LYS & $\mathrm{HX} 2$ & & 3.65 & & & & & & & \\
\hline 1410 & ARG & HX2 & 2.89 & 2.93 & & & & & & & \\
\hline 1411 & THR & HX2 & 2.68 & & & & & & & & \\
\hline 1414 & TYR & $\mathrm{HX} 2$ & 3.47 & & 3.37 & & & & 3.7 & 3.86 & \\
\hline 1434 & HIS & & & & & 3.33 & 3.18 & & & & \\
\hline 1435 & ILE & & & & & & 3.08 & & & & \\
\hline 1436 & TRP & & 2.96 & 2.78 & & & & 2.87 & & & 3.06 \\
\hline 1438 & CYS & & 3.68 & 3.7 & & & & & & & 2.7 \\
\hline 1440 & PRO & & 3.24 & 3.51 & 3.07 & & & & 3.87 & & \\
\hline 1443 & GLY & & & & & & & & 3.41 & 3.53 & \\
\hline 1444 & ASP & & & & & & & & & & \\
\hline 1446 & TYR & & 3.68 & 3.44 & & & & & & & 2.92 \\
\hline 1451 & HIS & & & & 3.24 & & & & 3.39 & 3.31 & \\
\hline 1452 & PRO & & & & & & & & & & \\
\hline 1453 & PRO & & & & & & & & & & \\
\hline 1455 & GLN & & & & 3.05 & & & & 3.21 & 3.23 & 3.07 \\
\hline 1456 & LYS & & 3.48 & & & & & & & & \\
\hline 1457 & ILE & & 2.91 & 2.69 & & & & & & & \\
\hline 1458 & PRO & & 3.17 & 3.37 & 3.09 & & & & & 3.89 & 3.34 \\
\hline 1462 & ARG & HX1 & 3.22 & 3.26 & 2.99 & & & & & & \\
\hline 1463 & LEU & HX1 & 3.93 & 4.07 & & & & & & 3.85 & 3.27 \\
\hline 1466 & TRP & HX1 & & 2.78 & 2.9 & & & & 3.19 & 3.33 & 3.8 \\
\hline 1467 & PHE & HX1 & 3.11 & 3.44 & & & & & & & 2.39 \\
\hline 1486 & ILE & & & & & 3.25 & & & & & \\
\hline 1489 & GLN & & & & & 3.21 & & & & & \\
\hline 1490 & ALA & & & & & 3.06 & & & & & \\
\hline 1495 & LEU & & & & & 3.4 & & & & & \\
\hline 1501 & LEU & & & & & 3.32 & & & & & \\
\hline 1502 & PRO & & & & & 3.25 & 3.11 & & & & \\
\hline
\end{tabular}


Table 3. Cont.

\begin{tabular}{|c|c|c|c|c|c|c|c|c|c|c|}
\hline \multicolumn{2}{|c|}{ PDB id: } & 3biy & $4 b h w$ & $5 \mathrm{kj} 2$ & $6 \mathrm{pf1}$ & $6 p g u$ & $6 \mathrm{v} 8 \mathrm{k}$ & $6 v 8 n$ & $6 v 90$ & \\
\hline \multicolumn{2}{|c|}{ Ligand: } & $01 \mathrm{~K}$ & $01 K$ & $6 \mathrm{TF}$ & OJ7 & OK7 & QS4 & QS1 & QSD & NiCur \\
\hline 1505 & GLU & & & & & & 3.53 & & & \\
\hline 1507 & ASP & & & & 2.87 & 2.8 & & & & \\
\hline 1509 & TRP & & & & 3.53 & & & & & \\
\hline 1591 & HIS & & & & & & 3.29 & & & \\
\hline 1595 & PHE & & & & 3.56 & & & & & \\
\hline 1596 & PHE & & & & 3.2 & & & & & \\
\hline 1597 & VAL & & & & 3.79 & & & & & \\
\hline
\end{tabular}

The binding patterns of ligands $01 \mathrm{~K}, \mathrm{QS4}$, and QSD were relatively similar, despite the significant differences in their structures. Note that $01 \mathrm{~K}$ was much larger than the other two. The ligands 6TF (i.e., A485), OK7, and QS4 seemed to belong to different families. Finally, the contact pattern of ligand OJ7 set it apart from the other ligands, since most of its contacts were with residues with which no other ligand was in contact, and it only shared a few contact residues with OK7 and QS4. It can be hypothesized that its action could be allosteric. Our ligand NiCur had relatively fewer contacts; most were common with the contacts of the first ligand family. If two ligands have the same binding affinity, but one of them have fewer contacts, the chances of that ligand being more specific to its target are likely to be higher.

\section{Material and Methods}

\section{Amino Acid Homology Alignment of KATs}

KAT sequences were extracted from the human KAT-containing proteins KAT1 (NP003633.2), KAT2A (NP066564.2), KAT2B (NP003875.3), KAT3A (NP004371.2), KAT3B (NP001420.2), KAT4 (EAX05294.1), KAT6A (NP006757.2), KAT6B (NP001357065.1), KAT7 (NP008998.1), KAT8 (NP115564.2), KAT9 (NP060561.3), KAT13A (NP003734.3), KAT13B (NP858045.1), and KAT13C (NP001308636.1). An EMBL sequence analysis was then used to perform a multiple sequence alignment using the Clustal Omega program tool $[142,143]$. The alignment was imported to the program Jalview [236].

\section{Discussion and Future Perspectives}

The past three decades of research to uncover the functions of KATs have gained momentum with parallel improvements in genomic and proteomic technologies. The increasing knowledge of pathways regulated by acetylation and deacetylation has facilitated a better understanding of disease pathogenesis and identification of new therapeutic targets. However, future challenges are geared toward understanding the basis for tissue specificity by KATs, epigenetic signatures on chromatin-associated protein, and a molecular basis for selectivity in forming molecular complexes to drive gene transcription.

On the chromatin landscape, acetylation is widespread across all the histone proteins, including H2A, H2B, H3, and H4, as well as $\mathrm{H} 1$ [57,151,152]. The site-specific acetylation on chromatin is a marker of nucleosomal relaxation and gene activation $[6,27,153]$. Acetylation could enhance stability, cellular localization, and transcriptional activities of transcription factors $[35,38,39]$. X-ray crystallographic studies have provided three-dimensional insights into the active sites and cofactor binding sites of KATs [28,29]. Additionally, biochemical investigations using mutagenesis have confirmed the critical residues for acetyl-CoA binding and substrate binding. The development of antibodies to acetylated lysine was instrumental in understanding the cellular interactions by immunoprecipitation and localization by fluorescence-based microscopy [111]. ChIP-based techniques elucidated the dynamics of acetylation-dependent and -independent molecular interactions on the gene promoter. 
For structural and biochemical investigations, there are often limitations with the amount of protein and the level of purification. Cell-based assays can be time-consuming and expensive. In these situations, protein modeling and virtual screening using bioinformatics tools becomes essential.

The epigenetics field has expanded from chromatin biology to gene regulation after discovering acetylation on two crucial proteins: p53 and HIV Tat [43,44]. Acetylated proteins were noted from the nucleus to mitochondria, involving at least 2000 acetylated proteins. Together, these data implicated the role of acetylation in metabolism and cellular homeostasis $[38,39]$. Studies using cellular models of p53 have identified a multitier complexity in transcriptional regulation, driven by stress-induced epigenetic modifications and molecular interactions [111]. Acetylation of p53 is readily detectable using mass spectrometry, mutagenesis, and antibody-based approaches; however, probing the molecular basis of interactions with multiple domain-containing cofactors remains challenging. Additionally, identifying the determinants by which p53 exhibits promoter selectivity in many cell types will be challenging. The CTD of p53 serves as a recruiting platform for many cofactors with equal propensities to bind the N-terminal activation domains of p53. The role of the CTD concerning the oligomerization domain is not clearly understood. The acetylation of HIV Tat by KAT3B - leading to the bromodomain-mediated recruitment of KAT2B - is central to HIV replication. Blocking the ability of HIV Tat to recruit and exploit the system of human transcription will be a target for newer generations of anti-HIV drug discovery programs [149]. Targeting epigenetic mechanisms offers the potential to overcome drug resistance to antimicrobial agents.

Most of the potential KAT inhibitors exhibit antioxidant activity, reactivity, instability, low potency, or selectivity between KAT subtypes. KATs are bisubstrate enzymes that catalyze reactions between acetyl coenzyme A and a lysine-containing peptide. A detailed characterization of the catalytic mechanism and the kinetics of small molecule inhibitors will significantly improve the selectivity of KAT modulators and provide validated starting points for further development. The kinetics that drives epigenetic modifications and the mechanistic underpinnings of molecular interactions are essential to elucidate the mechanisms of acetylation-mediated pathways. Chemical biology and gene editing-based approaches can address the questions of selectivity during gene regulation. Without perturbing gene expression levels, small molecules could target the active sites of endogenous KATs to differentiate the role of acetylation versus molecular interactions during the process of gene activation. Gene-editing technologies (such as transcription activator-like effector nucleases and CRISPR) could provide more answers about how genes are regulated compared to transient expression systems. Overall, these efforts should provide a starting point for advancing the development of therapeutic agents.

\section{Conclusions}

The ability of the amino acid lysine to undergo a multitude of epigenetic modifications is remarkable. The molecular bases of potential mutually exclusive modifications on lysine residue need to be understood in terms of tissue specificity, type of stress, and disease conditions. KAT-mediated lysine acetylation serves as a major epigenetic mark that plays a pivotal role in orchestrating many biological processes, including growth, development, and cellular responses to external and internal changes. The abnormal functions of KATs - due to mutations or deregulated stoichiometry within molecular complexesimpact human health and diseases unambiguously. The intricacies in acetylation-mediated molecular events arise from the presence of myriad targets and multiple acetylation sites on the same target. Furthermore, the mechanistic basis for selectively recruiting bromodomains versus KDACs to the acetylation site is not clear. It is still not fully clear what drives the recruitment of KAT complexes to the chromatin of the target promoter. Although we have come a long way in understanding the functions of KATs, these data also underline a need to investigate the functions of KATs using innovative approaches in order to better understand the presence of disease-specific epigenetic signatures. Finally, it is also clear 
that there must be a combination of sensitive tools to investigate the dynamics of KATs in normal and pathological situations.

Supplementary Materials: The following are available online at https:/ / www.mdpi.com/2218-273 X/11/3/455/s1, Figure S1: Multiple sequence alignment of the 16 human KATs discussed in this paper, displayed with the program Jalview. The phylogenetic tree shown in Figure $6 \mathrm{~B}$ was based on this alignment. Table S1: Biochemical details of the KATs, including their generic name, chromosomal location, number of amino acids, and cellular locations. Table S2: Human body distribution and expression of KATs in tissues and respective cancers. Table S3: The modeling of KAT3A/-3B and its ligands reveals the residue-ligand distances for residues in contact with the ligand.

Author Contributions: Conceptualization: S.M. and M.M. methodology by M.M.; investigation by C.O., S.M. and M.M.; data curationby C.O., L.I. and Z.A.; writing by S.M. and M.M., project administration S.M. and M.M.; funding acquisition, S.M. All authors have read and agreed to the published version of the manuscript.

Funding: This study was supported by grants from NIH/NCI R01CA143662, City University of New York Advanced Scientific Research Center Award and PSC CUNY; and CUNY/DASNY GRTI19 and GRTI20 to SM.

Institutional Review Board Statement: Do not involve humans and animals in this study.

Informed Consent Statement: Not applicable.

Data Availability Statement: Not applicable.

Conflicts of Interest: The authors declare no conflict of interest.

\section{References}

1. Hartl, F.U. Cellular Homeostasis and Aging. Annu. Rev. Biochem. 2016, 85, 1-4. [CrossRef]

2. Engel, M.L.; Gunnar, M.R. The development of stress reactivity and regulation during human development. Int. Rev. Neurobiol. 2020, 150, 41-76. [CrossRef]

3. Galluzzi, L.; Yamazaki, T.; Kroemer, G. Linking cellular stress responses to systemic homeostasis. Nat. Rev. Mol. Cell Biol. 2018, 19, 731-745. [CrossRef] [PubMed]

4. Baylin, S.B. Mechanisms underlying epigenetically mediated gene silencing in cancer. Semin. Cancer Biol. 2002, 12, 331-337. [CrossRef]

5. Bonasio, R.; Tu, S.; Reinberg, D. Molecular Signals of Epigenetic States. Science 2010, 330, 612-616. [CrossRef]

6. Goldberg, A.D.; Allis, C.D.; Bernstein, E. Epigenetics: A Landscape Takes Shape. Cell 2007, 128, 635-638. [CrossRef]

7. Lan, F.; Shi, Y. Epigenetic regulation: Methylation of histone and non-histone proteins. Sci. China Ser. C Life Sci. 2009, 52, 311-322. [CrossRef]

8. Lotterman, C.; Karikari, C.; Omura, N.; Feldmann, G.; Habbe, N.; Goggins, M.G.; Mendell, J.T.; Maitra, A. Epigenetic silencing of MicroRNA miR-107 regulates cyclin-dependent kinase 6 expression in pancreatic cancer. Pancreatology 2009, 9, $293-301$.

9. Jiang, Y.-H.; Bressler, J.; Beaudet, A.L. Epigenetics and Human Disease. Annu. Rev. Genom. Hum. Genet. 2004, 5, 479-510. [CrossRef]

10. Rodenhiser, D.; Mann, M. Epigenetics and human disease: Translating basic biology into clinical applications. Can. Med. Assoc. J. 2006, 174, 341-348. [CrossRef]

11. Wapenaar, H.; Dekker, F.J. Histone acetyltransferases: Challenges in targeting bi-substrate enzymes. Clin. Epigen. 2016, 8, 1-11. [CrossRef] [PubMed]

12. Belotserkovskaya, R.; Saunders, A.; Lis, J.T.; Reinberg, D. Transcription through chromatin: Understanding a complex FACT. Biochim. Biophys. Acta 2004, 1677, 87-99. [CrossRef]

13. Sarma, K.; Reinberg, D. Histone variants meet their match. Nat. Rev. Mol. Cell Biol. 2005, 6, 139-149. [CrossRef] [PubMed]

14. Portela, A.; Esteller, M. Epigenetic modifications and human disease. Nat. Biotechnol. 2010, 28, 1057-1068. [CrossRef]

15. Yap, K.L.; Li, S.; Muñoz-Cabello, A.M.; Raguz, S.; Zeng, L.; Mujtaba, S.; Gil, J.; Walsh, M.J.; Zhou, M.-M. Molecular Interplay of the Noncoding RNA ANRIL and Methylated Histone H3 Lysine 27 by Polycomb CBX7 in Transcriptional Silencing of INK4a. Mol. Cell 2010, 38, 662-674. [CrossRef]

16. Becker, P.B.; Workman, J.L. Nucleosome Remodeling and Epigenetics. Cold Spring Harb. Perspect. Biol. 2013, 5, a017905. [CrossRef]

17. Ahuja, N.; Li, Q.; Mohan, A.L.; Baylin, S.B.; Issa, J.P. Aging and DNA methylation in colorectal mucosa and cancer. Cancer Res. 1998, 58, 5489-5494.

18. Bannister, A.J.; Kouzarides, T. Reversing histone methylation. Nat. Cell Biol. 2005, 436, 1103-1106. [CrossRef] [PubMed]

19. Baylin, S.B. DNA methylation and gene silencing in cancer. Nat. Clin. Pract. Oncol. 2005, 2, S4-S11. [CrossRef] 
20. Allis, C.D.; Berger, S.L.; Cote, J.; Dent, S.; Jenuwien, T.; Kouzarides, T.; Pillus, L.; Reinberg, D.; Shi, Y.; Shiekhattar, R.; et al. New Nomenclature for Chromatin-Modifying Enzymes. Cell 2007, 131, 633-636. [CrossRef]

21. Fischle, W.; Wang, Y.; Allis, C.D. Histone and chromatin cross-talk. Curr. Opin. Cell Biol. 2003, 15, 172-183. [CrossRef]

22. Jenuwein, T.; Allis, C.D. Translating the histone code. Science 2001, 293, 1074-1080. [CrossRef] [PubMed]

23. Hoffmann, I.; Roatsch, M.; Schmitt, M.L.; Carlino, L.; Pippel, M.; Sippl, W.; Jung, M. The role of histone demethylases in cancer therapy. Mol. Oncol. 2012, 6, 683-703. [CrossRef] [PubMed]

24. Bradner, J.E.; West, N.; Grachan, M.L.; Greenberg, E.F.; Haggarty, S.J.; Warnow, T.; Mazitschek, R. Chemical phylogenetics of histone deacetylases. Nat. Chem. Biol. 2010, 6, 238-243. [CrossRef] [PubMed]

25. Hsu, J.Y.; Sun, Z.W.; Li, X.; Reuben, M.; Tatchell, K.; Bishop, D.K.; Grushcow, J.M.; Brame, C.J.; Caldwell, J.A. Mitotic phosphorylation of histone $\mathrm{H} 3$ is governed by Ipl1/aurora kinase and Glc7/PP1 phosphatase in bud-ding yeast and nematodes. Cell 2000, 102, 279-291. [CrossRef]

26. Daniel, J.A.; Torok, M.S.; Sun, Z.-W.; Schieltz, D.; Allis, C.; Yates, J.R.; Grant, P.A. Deubiquitination of Histone H2B by a Yeast Acetyltransferase Complex Regulates Transcription. J. Biol. Chem. 2004, 279, 1867-1871. [CrossRef] [PubMed]

27. Huang, J.; Zhang, L.; Qu, Y.; Zhou, Y.; Zhu, J.; Li, Y.; Zhu, T.; Zhao, F.; Tang, J.; Mu, D. Histone acetylation of oligodendrocytes protects against white matter injury induced by inflammation and hypoxia-ischemia through activation of BDNF-TrkB signaling pathway in neonatal rats. Brain Res. 2018, 1688, 33-46. [CrossRef]

28. Zaini, M.A.; Müller, C.; de Jong, T.V.; Ackermann, T.; Hartleben, G.; Kortman, G.; Gührs, K.-H.; Fusetti, F.; Krämer, O.H.; Guryev, V.; et al. A p300 and SIRT1 Regulated Acetylation Switch of C/EBPalpha Controls Mitochondrial Function. Cell Rep. 2018, 22, 497-511. [CrossRef]

29. Chen, C.D.; Welsbie, D.S.; Tran, C.; Baek, S.H.; Chen, R.; Vessella, R.; Rosenfeld, M.G.; Sawyers, C.L. Molecular determinants of resistance to antiandrogen therapy. Nat. Med. 2003, 10, 33-39. [CrossRef]

30. Chiao, P.; Zhang, X.; Zhang, X.; Lazar, M.; Seto, E.; Young, H.A.; Ye, J. Coactivators and corepressors of NF-kappaB in IkappaB alpha gene promoter. J. Biol. Chem. 2005, 280, 21091-21098.

31. Liu, Z.; Auboeuf, D.; Wong, J.; Chen, J.D.; Tsai, S.Y.; Tsai, M.-J.; O’Malley, B.W. Coactivator/corepressor ratios modulate PR-mediated transcription by the selective receptor modulator RU486. Proc. Natl. Acad. Sci. USA 2002, 99, 7940-7944. [CrossRef]

32. Andersen, C.L.; Asmar, F.; Klausen, T.; Hasselbalch, H.; Gronbaek, K. Somatic mutations of the CREBBP and EP300 genes affect response to histone deacetylase inhibition in malignant DLBCL clones. Leuk. Res. Rep. 2012, 2, 1-3. [CrossRef]

33. Jaganathan, A.; Chaurasia, P.; Xiao, G.Q.; Philizaire, M.; Lv, X.; Yao, S.; Burnstein, K.L.; Liu, D.-P.; Levine, A.C.; Mujtaba, S. Coactivator MYST1 regulates nuclear factor-kappaB and androgen receptor functions during proliferation of prostate cancer cells. Mol. Endocrinol. 2014, 28, 872-885. [CrossRef] [PubMed]

34. Debes, J.D.; Sebo, T.J.; Heemers, H.V.; Kipp, B.R.; De Anna, L.H.; Lohse, C.M.; Tindall, D.J. p300 modulates nuclear morphology in prostate cancer. Cancer Res. 2005, 65, 708-712. [PubMed]

35. Debes, J.D.; Sebo, T.J.; Lohse, C.M.; Murphy, L.M.; De Anna, L.H.; Tindall, D.J. p300 in prostate cancer proliferation and progression. Cancer Res. 2003, 63, 7638-7640. [PubMed]

36. Baylin, S.B.; Jones, P.A. Epigenetic Determinants of Cancer. Cold Spring Harb. Perspect. Biol. 2016, 8, a019505. [CrossRef]

37. Khan, S.H. Genome-Editing Technologies: Concept, Pros, and Cons of Various Genome-Editing Techniques and Bioethical Concerns for Clinical Application. Mol. Ther. Nucleic Acids 2019, 16, 326-334. [CrossRef] [PubMed]

38. Allfrey, V.G.; Faulkner, R.; Mirsky, A.E. Acetylation And Methylation Of Histones And Their Possible Role In The Regulation Of Rna Synthesis. Proc. Natl. Acad. Sci. USA 1964, 51, 786-794. [CrossRef] [PubMed]

39. Roth, S.Y.; Allis, C. Histone Acetylation and Chromatin Assembly: A Single Escort, Multiple Dances? Cell 1996, 87, 5-8. [CrossRef]

40. Marmorstein, R. Structural and chemical basis of histone acetylation. Novartis Found Symp. 2004, 259, 78-98.

41. Marmorstein, R.; Zhou, M.-M. Writers and Readers of Histone Acetylation: Structure, Mechanism, and Inhibition. Cold Spring Harb. Perspect. Biol. 2014, 6, a018762. [CrossRef]

42. Crawford, G.E.; Davis, S.; Scacheri, P.C.; Renaud, G.; Halawi, M.J.; Erdos, M.R.; Green, R.; Meltzer, P.S.; Wolfsberg, T.G.; Collins, F. DNase-chip: A high-resolution method to identify DNase I hypersensitive sites using tiled microarrays. Nat. Methods 2006, 3, 503-509. [CrossRef]

43. Sandmann, T.; Jakobsen, J.S.; Furlong, E.E.M. ChIP-on-chip protocol for genome-wide analysis of transcription factor binding in Drosophila melanogaster embryos. Nat. Protoc. 2006, 1, 2839-2855. [CrossRef]

44. Edmondson, D.; Zhang, W.; Watson, A.; Xu, W.; Bone, J.; Yu, Y.; Stillman, D.; Roth, S. In Vivo Functions of Histone Acetylation/Deacetylation in Tup1p Repression and Gcn5p Activation. Cold Spring Harb. Symp. Quant. Biol. 1998, 63, 459-468. [CrossRef]

45. Munoz-Galvan, S.; Jimeno, S.; Rothstein, R.; Aguilera, A. Histone H3K56 acetylation, Rad52, and non-DNA repair factors con-trol double-strand break repair choice with the sister chromatid. PLoS Genet. 2013, 9, e1003237. [CrossRef] [PubMed]

46. Pelletier, G.; Stefanovsky, V.Y.; Faubladier, M.; Hirschler-Laszkiewicz, I.; Savard, J.; Rothblum, L.I.; Côté, J.; Moss, T. Competitive Recruitment of CBP and Rb-HDAC Regulates UBF Acetylation and Ribosomal Transcription. Mol. Cell 2000, 6, 1059-1066. [CrossRef]

47. Sheikh, B.N.; Akhtar, A. The many lives of KATs—Detectors, integrators and modulators of the cellular environment. Nat. Rev. Genet. 2019, 20, 7-23. [CrossRef] 
48. Patel, J.H.; Du, Y.; Ard, P.G.; Phillips, C.; Carella, B.; Chen, C.-J.; Rakowski, C.; Chatterjee, C.; Lieberman, P.M.; Lane, W.S.; et al. The c-MYC Oncoprotein Is a Substrate of the Acetyltransferases hGCN5/PCAF and TIP60. Mol. Cell. Biol. 2004, 24, 10826-10834. [CrossRef]

49. Choudhary, C.; Kumar, C.; Gnad, F.; Nielsen, M.L.; Rehman, M.; Walther, T.C.; Olsen, J.V.; Mann, M. Lysine Acetylation Targets Protein Complexes and Co-Regulates Major Cellular Functions. Science 2009, 325, 834-840. [CrossRef]

50. Choudhary, C.; Weinert, B.T.; Nishida, Y.; Verdin, E.; Mann, M. The growing landscape of lysine acetylation links metabolism and cell signalling. Nat. Rev. Mol. Cell Biol. 2014, 15, 536-550. [CrossRef]

51. Narita, T.; Weinert, B.T.; Choudhary, C. Functions and mechanisms of non-histone protein acetylation. Nat. Rev. Mol. Cell Biol. 2019, 20, 156-174. [CrossRef] [PubMed]

52. Dekker, F.J.; Haisma, H.J. Histone acetyl transferases as emerging drug targets. Drug Discov. Today 2009, 14, 942-948. [CrossRef] [PubMed]

53. Dekker, F.J.; van den Bosch, T.; Martin, N.I. Small molecule inhibitors of histone acetyltransferases and deacetylases are potential drugs for inflammatory diseases. Drug Discov. Today 2014, 19, 654-660. [CrossRef] [PubMed]

54. Mujtaba, S.; He, Y.; Zeng, L.; Farooq, A.; Carlson, J.E.; Ott, M.; Verdin, E.; Zhou, M.-M. Structural Basis of Lysine-Acetylated HIV-1 Tat Recognition by PCAF Bromodomain. Mol. Cell 2002, 9, 575-586. [CrossRef]

55. Mujtaba, S.; He, Y.; Zeng, L.; Yan, S.; Plotnikova, O.; Sachchidanand; Sanchez, R.; Zeleznik-Le, N.J.; Ronai, Z.; Zhou, M.-M. Structural Mechanism of the Bromodomain of the Coactivator CBP in p53 Transcriptional Activation. Mol. Cell 2004, 13, 251-263. [CrossRef]

56. Mujtaba, S.F.; Zeng, L.; Zhou, M.-M. Structure and acetyl-lysine recognition of the bromodomain. Oncogene 2007, 26, 5521-5527. [CrossRef]

57. Zeng, L.; Yap, K.L.; Ivanov, A.V.; Wang, X.; Mujtaba, S.; Plotnikova, O.; Iii, F.J.R.; Zhou, M.-M. Structural insights into human KAP1 PHD finger-bromodomain and its role in gene silencing. Nat. Struct. Mol. Biol. 2008, 15, 626-633. [CrossRef]

58. Parthun, M.R. Histone acetyltransferase 1: More than just an enzyme? Biochim. Biophys. Acta 2012, 1819, 256-263. [CrossRef]

59. Han, N.; Shi, L.; Guo, Q.; Sun, W.; Yu, Y.; Yang, L.; Zhang, X.; Zhang, M. HAT1 induces lung cancer cell apoptosis via up regulating Fas. Oncotarget 2017, 8, 89970-89977. [CrossRef]

60. Fan, P.; Zhao, J.; Meng, Z.; Wu, H.; Wang, B.; Wu, H.; Jin, X. Overexpressed histone acetyltransferase 1 regulates cancer immunity by increasing programmed death-ligand 1 expression in pancreatic cancer. J. Exp. Clin. Cancer Res. 2019, 38, 1-12. [CrossRef]

61. Yang, G.; Yuan, Y.; Yuan, H.; Wang, J.; Yun, H.; Geng, Y.; Zhao, M.; Li, L.; Weng, Y.; Liu, Z.; et al. Histone acetyltransferase 1 is a succinyltransferase for histones and non-histones and promotes tumorigenesis. EMBO Rep. 2020, 22, e50967. [CrossRef]

62. Uhlén, M.; Fagerberg, L.; Hallström, B.M.; Lindskog, C.; Oksvold, P.; Mardinoglu, A.; Sivertsson, Å.; Kampf, C.; Sjöstedt, E.; Asplund, A.; et al. Tissue-based map of the human proteome. Science 2015, 347, 1260419. [CrossRef] [PubMed]

63. Atanassov, B.S.; Evrard, Y.A.; Multani, A.S.; Zhang, Z.; Tora, L.; Devys, D.; Chang, S.; Dent, S.Y. Gcn5 and SAGA Regulate Shelterin Protein Turnover and Telomere Maintenance. Mol. Cell 2009, 35, 352-364. [CrossRef] [PubMed]

64. Farria, A.T.; Mustachio, L.M.; Akdemir, Z.H.C.; Dent, S.Y. GCN5 HAT inhibition reduces human Burkitt lymphoma cell survival through reduction of MYC target gene expression and impeding BCR signaling pathways. Oncotarget 2019, 10, 5847-5858. [CrossRef] [PubMed]

65. Farria, A.T.; Plummer, J.B.; Salinger, A.P.; Shen, J.; Lin, K.; Lu, Y.; McBride, K.M.; Koutelou, E.; Dent, S.Y. Transcriptional Activation of MYC-Induced Genes by GCN5 Promotes B-cell Lymphomagenesis. Cancer Res. 2020, 80, 5543-5553. [CrossRef]

66. Martínez-Cerdeño, V.; Lemen, J.M.; Chan, V.; Wey, A.; Lin, W.; Dent, S.R.; Knoepfler, P.S. N-Myc and GCN5 Regulate Significantly Overlapping Transcriptional Programs in Neural Stem Cells. PLoS ONE 2012, 7, e39456. [CrossRef]

67. Mustachio, L.M.; Roszik, J.; Farria, A.T.; Guerra, K.; Dent, S.Y. Repression of GCN5 expression or activity attenuates c-MYC expression in non-small cell lung cancer. Am. J. Cancer Res. 2019, 9, 1830-1845.

68. Liu, T.; Wang, X.; Hu, W.; Fang, Z.; Jin, Y.; Fang, X.; Miao, Q.R. Epigenetically Down-Regulated Acetyltransferase PCAF Increases the Resistance of Colorectal Cancer to 5-Fluorouracil. Neoplasia 2019, 21, 557-570. [CrossRef]

69. Wang, L.; Liu, K.; Jeng, W.; Chiang, C.; Chai, C.; Chiou, S.; Huang, M.; Yokoyama, K.K.; Wang, S.; Huang, S.; et al. PCAF -mediated acetylation of ISX recruits BRD 4 to promote epithelial-mesenchymal transition. EMBO Rep. 2020, 21, e48795. [CrossRef]

70. Attar, N.; Kurdistani, S.K. Exploitation of EP300 and CREBBP Lysine Acetyltransferases by Cancer. Cold Spring Harb. Perspect. Med. 2016, 7, a026534. [CrossRef]

71. Wilson, J.E.; Huhn, A.; Gardberg, A.S.; Poy, F.; Brucelle, F.; Vivat, V.; Cantone, N.; Patel, G.; Patel, C.; Cummings, R.; et al. Early Drug-Discovery Efforts towards the Identification of EP300/CBP Histone Acetyltransferase (HAT) In-hibitors. ChemMedChem 2020, 15, 955-960.

72. Iyer, N.G.; Ozdag, H.; Caldas, C. p300/CBP and cancer. Oncogene 2004, 23, 4225-4231. [CrossRef]

73. Iyer, N.G.; Xian, J.; Chin, S.F.; Bannister, A.J.; Daigo, Y.; Aparicio, S.; Kouzarides, T.; Caldas, C. p300 is required for orderly G1/S transition in human cancer cells. Oncogene 2007, 26, 21-29. [CrossRef]

74. Rühlmann, F.; Windhof-Jaidhauser, I.M.; Menze, C.; Beißbarth, T.; Bohnenberger, H.; Ghadimi, M.; Dango, S. The prognostic capacities of CBP and p300 in locally advanced rectal cancer. World J. Surg. Oncol. 2019, 17, 1-8. [CrossRef]

75. Scolnick, D.M.; Chehab, N.H.; Stavridi, E.S.; Lien, M.C.; Caruso, L.; Moran, E.; Berger, S.L.; Halazonetis, T.D. CREB-binding protein and p300/CBP-associated factor are transcriptional coactivators of the p53 tumor suppressor protein. Cancer Res. 1997, 57, 3693-3696. 
76. Welti, J.; Sharp, A.; Brooks, N.; Yuan, W.; McNair, C.; Chand, S.N.; Pal, A.; Figueiredo, I.; Riisnaes, R.; Gurel, B.; et al. Targeting p300/CBP axis in lethal prostate cancer. Cancer Discov. 2021. [CrossRef]

77. Li, J.; Huang, C.; Xiong, T.; Zhuang, C.; Zhuang, C.; Li, Y.; Ye, J.; Gui, Y. A CRISPR Interference of CBP and p300 Selectively Induced Synthetic Lethality in Bladder Cancer Cells In Vitro. Int. J. Biol. Sci. 2019, 15, 1276-1286. [CrossRef]

78. Tavassoli, P.; Wafa, L.A.; Cheng, H.; Zoubeidi, A.; Fazli, L.; Gleave, M.; Snoek, R.; Rennie, P.S. TAF1 differentially enhances androgen receptor transcriptional activity via its N-terminal kinase and ubiq-uitin-activating and -conjugating domains. Mol. Endocrinol. 2010, 24, 696-708. [CrossRef]

79. Xu, Y.; Man, N.; Karl, D.; Martinez, C.; Liu, F.; Sun, J.; Martinez, C.J.; Martin, G.M.; Beckedorff, F.; Lai, F.; et al. TAF1 plays a critical role in AML1-ETO driven leukemogenesis. Nat. Commun. 2019, 10, 1-15. [CrossRef]

80. Ribeiro, J.R.; Lovasco, L.A.; Vanderhyden, B.C.; Freiman, R.N. Targeting TBP-Associated Factors in Ovarian Cancer. Front. Oncol. 2014, 4, 45. [CrossRef]

81. Cregan, S.; McDonagh, L.; Gao, Y.; Barr, M.P.; O’Byrne, K.J.; Finn, S.P.; Cuffe, S.; Gray, S.G. KAT5 (Tip60) is a potential therapeutic target in malignant pleural mesothelioma. Int. J. Oncol. 2016, 48, 1290-1296. [CrossRef]

82. Halkidou, K.; Gnanapragasam, V.J.; Mehta, P.B.; Logan, I.R.; E Brady, M.; Cook, S.; Leung, H.Y.; E Neal, D.; Robson, C.N. Expression of Tip60, an androgen receptor coactivator, and its role in prostate cancer development. Oncogene 2003, 22, $2466-2477$. [CrossRef] [PubMed]

83. Idrissou, M.; Rifaï, K.; Daures, M.; Penault-Llorca, F.; Bignon, Y.-J.; Bernard-Gallon, D. Exciting History of Tip60 and Its Companions in Carcinogenesis Across the Heterochromatin Landscapes. OMICS A J. Integr. Biol. 2018, 22, 626-628. [CrossRef] [PubMed]

84. Judes, G.; Dubois, L.; Rifaï, K.; Idrissou, M.; Mishellany, F.; Pajon, A.; Besse, S.; Daures, M.; Degoul, F.; Bignon, Y.-J.; et al. TIP60: An actor in acetylation of H3K4 and tumor development in breast cancer. Epigenomics 2018, 10, 1415-1430. [CrossRef] [PubMed]

85. Judes, G.; Rifaï, K.; Ngollo, M.; Daures, M.; Bignon, Y.-J.; Penault-Llorca, F.; Bernard-Gallon, D. A bivalent role of TIP60 histone acetyl transferase in human cancer. Epigenomics 2015, 7, 1351-1363. [CrossRef]

86. Sakuraba, K.; Yasuda, T.; Sakata, M.; Kitamura, Y.-H.; Shirahata, A.; Goto, T.; Mizukami, H.; Saito, M.; Ishibashi, K.; Kigawa, G.; et al. Down-regulation of Tip60 gene as a potential marker for the malignancy of colorectal cancer. Anticancer Res. 2009, 29 , 3953-3955. [PubMed]

87. Sakuraba, K.; Yokomizo, K.; Shirahata, A.; Goto, T.; Saito, M.; Ishibashi, K.; Kigawa, G.; Nemoto, H.; Hibi, K. TIP60 as a potential marker for the malignancy of gastric cancer. Anticancer Res. 2011, 31, 77-79.

88. Shiota, M.; Yokomizo, A.; Masubuchi, D.; Tada, Y.; Inokuchi, J.; Eto, M.; Uchiumi, T.; Fujimoto, N.; Naito, S. Tip60 promotes prostate cancer cell proliferation by translocation of androgen receptor into the nucleus. Prostate 2009, 70, 540-554. [CrossRef] [PubMed]

89. Deguchi, K.; Ayton, P.M.; Carapeti, M.; Kutok, J.L.; Snyder, C.S.; Williams, I.R.; Cross, N.C.; Glass, C.K.; Cleary, M.L.; Gilliland, D. MOZ-TIF2-induced acute myeloid leukemia requires the MOZ nucleosome binding motif and TIF2-mediated recruitment of CBP. Cancer Cell 2003, 3, 259-271. [CrossRef]

90. Huntly, B.J.; Shigematsu, H.; Deguchi, K.; Lee, B.H.; Mizuno, S.; Duclos, N.; Rowan, R.; Amaral, S.; Curley, D.; Williams, I.R.; et al. MOZ-TIF2, but not BCR-ABL, confers properties of leukemic stem cells to committed murine hematopoietic progenitors. Cancer Cell 2004, 6, 587-596. [CrossRef]

91. Kitabayashi, I.; Aikawa, Y.; Nguyen, L.A.; Yokoyama, A.; Ohki, M. Activation of AML1-mediated transcription by MOZ and inhibition by the MOZ-CBP fusion protein. EMBO J. 2001, 20, 7184-7196. [CrossRef] [PubMed]

92. Kitabayashi, I.; Aikawa, Y.; Yokoyama, A.; Hosoda, F.; Nagai, M.; Kakazu, N.; Abe, T.; Ohki, M. Fusion of MOZ and p300 histone acetyltransferases in acute monocytic leukemia with a $\mathrm{t}(8 ; 22)(\mathrm{p} 11 ; \mathrm{q} 13)$ chromosome translocation. Leukemia 2001, 15, 89-94. [CrossRef] [PubMed]

93. Largeot, A.; Perez-Campo, F.M.; Marinopoulou, E.; Lie-A-Ling, M.; Kouskoff, V.; Lacaud, G. Expression of the MOZ-TIF2 oncoprotein in mice represses senescence. Exp. Hematol. 2016, 44, 231-237. [CrossRef]

94. Mohammadi, K.; Safaralizadeh, R.; Hosseinpour-Feizi, M.; Dastmalchi, N.; Moaddab, Y. Investigation of the changes in the ex-pression levels of MOZ gene in colorectal cancer tissues. J. Gastrointest Oncol. 2019, 10, 68-73. [CrossRef]

95. Ullah, M.; Pelletier, N.; Xiao, L.; Zhao, S.P.; Wang, K.; Degerny, C.; Tahmasebi, S.; Cayrou, C.; Doyon, Y.; Goh, S.-L.; et al. Molecular Architecture of Quartet MOZ/MORF Histone Acetyltransferase Complexes. Mol. Cell. Biol. 2008, 28, 6828-6843. [CrossRef]

96. Yang, X.-J.; Ullah, M.F. MOZ and MORF, two large MYSTic HATs in normal and cancer stem cells. Oncogene 2007, 26, 5408-5419. [CrossRef] [PubMed]

97. Liu, C.L.; Sheu JJ, C.; Lin, H.P.; Jeng, Y.M.; Chang CY, Y.; Chen, C.M.; Cheng, J.; Mao, T.L. The overexpression of MYST4 in human solid tumors is associated with increased aggressiveness and de-creased overall survival. Int. J. Clin. Exp. Pathol. 2019, 12, 431-442.

98. Guo, L.-L.; Yu, S.-Y.; Li, M. Functional analysis of HBO1 in tumor development and inhibitor screening. Int. J. Mol. Med. 2016, 38, 300-304. [CrossRef] [PubMed]

99. Iizuka, M.; Takahashi, Y.; Mizzen, C.A.; Cook, R.G.; Fujita, M.; Allis, C.D.; Frierson, H.F.; Fukusato, T.; Smith, M.M. Histone acetyltransferase Hbo1: Catalytic activity, cellular abundance, and links to primary cancers. Gene 2009, 436, 108-114. [CrossRef]

100. MacPherson, L.; Anokye, J.; Yeung, M.M.; Lam, E.Y.N.; Chan, Y.-C.; Weng, C.-F.; Yeh, P.; Knezevic, K.; Butler, M.S.; Hoegl, A.; et al. $\mathrm{HBO} 1$ is required for the maintenance of leukaemia stem cells. Nat. Cell Biol. 2020, 577, 266-270. [CrossRef] 
101. Song, B.; Liu, X.S.; Rice, S.J.; Kuang, S.; Elzey, B.D.; Konieczny, S.F.; Ratliff, T.L.; Hazbun, T.; Chiorean, E.G. Plk1 Phosphorylation of Orc2 and Hbo1 Contributes to Gemcitabine Resistance in Pancreatic Cancer. Mol. Cancer Ther. 2013, 12, 58-68. [CrossRef]

102. Chen, Z.; Ye, X.; Tang, N.; Shen, S.; Li, Z.; Niu, X.; Lu, S.; Xu, L. The histone acetylranseferase hMOF acetylates Nrf2 and regulates anti-drug responses in human non-small cell lung cancer. Br. J. Pharmacol. 2014, 171, 3196-3211. [CrossRef] [PubMed]

103. Dou, Y.; Milne, T.A.; Tackett, A.J.; Smith, E.R.; Fukuda, A.; Wysocka, J.; Allis, C.D.; Chait, B.T.; Hess, J.L.; Roeder, R.G. Physical association and coordinate function of the H3 K4 methyltransferase MLL1 and the H4 K16 acetyltrans-ferase MOF. Cell 2005, 121, 873-885. [CrossRef] [PubMed]

104. Pfister, S.; Rea, S.; Taipale, M.; Mendrzyk, F.; Straub, B.; Ittrich, C.; Thuerigen, O.; Sinn, H.P.; Akhtar, A.; Lichter, P. The histone acetyltransferase hMOF is frequently downregulated in primary breast carcinoma and medullo-blastoma and constitutes a biomarker for clinical outcome in medulloblastoma. Int. J. Cancer 2008, 122, 1207-1213. [CrossRef] [PubMed]

105. Song, J.S.; Chun, S.M.; Lee, J.Y.; Kim, D.K.; Kim, Y.H.; Jang, S.J. The Histone Acetyltransferase hMOF is Overexoressed in Non-small Cell Lung Carcinoma. Korean J. Pathol. 2011, 45, 386-396. [CrossRef]

106. Wu, L.; Zee, B.M.; Wang, Y.; Garcia, B.A.; Dou, Y. The RING finger protein MSL2 in the MOF complex is an E3 ubiquitin ligase for H2B K34 and is involved in crosstalk with H3 K4 and K79 methylation. Mol. Cell 2011, 43, 132-144. [CrossRef] [PubMed]

107. Delaunay, S.; Rapino, F.; Tharun, L.; Zhou, Z.; Heukamp, L.; Termathe, M.; Shostak, K.; Klevernic, I.; Florin, A.; Desmecht, H.; et al. Elp3 links tRNA modification to IRES-dependent translation of LEF1 to sustain metastasis in breast cancer. J. Exp. Med. 2016, 213, 2503-2523. [CrossRef]

108. Li, M.-T.; Liang, J.-Y.; Sun, Y.-P.; Jin, J.; Xiong, Y.; Guan, K.-L.; Yuan, H.-X. ELP3 Acetyltransferase is phosphorylated and regulated by the oncogenic anaplastic lymphoma kinase (ALK). Biochem. J. 2019, 476, 2239-2254. [CrossRef]

109. Rosu, A.; El Hachem, N.; Rapino, F.; Rouault-Pierre, K.; Jorssen, J.; Somja, J.; Remery, E.; Thiry, M.; Nguyen, L.; Jacquemyn, M.; et al. Loss of tRNA-modifying enzyme Elp3 activates a p53-dependent antitumor checkpoint in hematopoiesis. J. Exp. Med. 2021, 218, e20200662. [CrossRef] [PubMed]

110. Wang, B.; Jin, C.; Zhang, X.; Sun, M.; Zhang, Y.; Zhang, G. Clinical implications of the coexpression of SRC1 and NANOG in HER-2-overexpressing breast cancers. OncoTargets Ther. 2016, 9, 5483-5488. [CrossRef]

111. Berns, E.M.; Van Staveren, I.L.; Klijn, J.G.; Foekens, J.A. Predictive value of SRC-1 for tamoxifen response of recurrent breast cancer. Breast Cancer Res. Treat. 1998, 48, 87-92. [CrossRef]

112. Browne, A.L.; Charmsaz, S.; Varešlija, D.; Fagan, A.; Cosgrove, N.; Cocchiglia, S.; Purcell, S.; Ward, E.; Bane, F.; Hudson, L.; et al. Network analysis of SRC-1 reveals a novel transcription factor hub which regulates endocrine resistant breast cancer. Oncogene 2018, 37, 2008-2021. [CrossRef]

113. Deblacam, C.; Byrne, C.; Hughes, E.; McIlroy, M.; Bane, F.; Hill AD, K.; Young, L.S. HOXC11-SRC-1 regulation of S100beta in cutaneous melanoma: New targets for the kinase inhibitor da-satinib. Br. J. Cancer 2011, 105, 118-123. [CrossRef]

114. Fleming, F.J.; Myers, E.R.; Kelly, G.M.; Crotty, T.B.; McDermott, E.W.; O’Higgins, N.J.; Hill, A.D.K.; Young, L.S. Expression of SRC-1, AIB1, and PEA3 in HER2 mediated endocrine resistant breast cancer; a predictive role for SRC-1. J. Clin. Pathol. 2004, 57, 1069-1074. [CrossRef]

115. Liu, Z.; Wong, J.; Tsai, S.Y.; Tsai, M.-J.; O'Malley, B.W. Steroid receptor coactivator-1 (SRC-1) enhances ligand-dependent and receptor-dependent cell-free transcription of chromatin. Proc. Natl. Acad. Sci. USA 1999, 96, 9485-9490. [CrossRef]

116. Liu, Z.; Wong, J.; Tsai, S.Y.; Tsai, M.-J.; O’Malley, B.W. Sequential recruitment of steroid receptor coactivator-1 (SRC-1) and p300 enhances progesterone receptor-dependent initiation and reinitiation of transcription from chromatin. Proc. Natl. Acad. Sci. USA 2001, 98, 12426-12431. [CrossRef]

117. McBryan, J.; Theissen, S.M.; Byrne, C.; Hughes, E.; Cocchiglia, S.; Sande, S.; O’Hara, J.; Tibbitts, P.; Hill, A.D.; Young, L.S. Metastatic Progression with Resistance to Aromatase Inhibitors Is Driven by the Steroid Receptor Coactivator SRC-1. Cancer Res. 2012, 72, 548-559. [CrossRef]

118. McCartan, D.; Bolger, J.C.; Fagan, A.; Byrne, C.; Hao, Y.; Qin, L.; McIlroy, M.; Xu, J.; Hill, A.D.; Gaora, P.Ó.; et al. Global Characterization of the SRC-1 Transcriptome Identifies ADAM22 as an ER-Independent Mediator of Endocrine-Resistant Breast Cancer. Cancer Res. 2012, 72, 220-229. [CrossRef]

119. McIlroy, M.; McCartan, D.; Early, S.; Ogaora, P.; Pennington, S.; Hill, A.; Young, L. Interaction of developmental transcription factor HOXC11 with steroid receptor coactivator SRC-1 mediates resistance to endocrine therapy in breast cancer [corrected]. Cancer Res. 2010, 70, 1585-1594. [CrossRef]

120. Myers, E.; Fleming, F.J.; Crotty, T.B.; Kelly, G.; McDermott, E.W.; O’Higgins, N.J.; Hill, A.D.K.; Young, L.S. Inverse relationship between ER-beta and SRC-1 predicts outcome in endocrine-resistant breast cancer. Br. J. Cancer 2004, 91, 1687-1693. [CrossRef] [PubMed]

121. Myers, E.; Hill, A.D.; Kelly, G.; McDermott, E.W.; O’Higgins, N.J.; Buggy, Y.; Young, L.S. Associations and Interactions between Ets-1 and Ets-2 and Coregulatory Proteins, SRC-1, AIB1, and NCoR in Breast Cancer. Clin. Cancer Res. 2005, 11, $2111-2122$. [CrossRef]

122. Gojis, O.; Rudraraju, B.; Alifrangis, C.; Krell, J.; Libalova, P.; Palmieri, C. The role of steroid receptor coactivator-3 (SRC-3) in human malignant disease. Eur. J. Surg. Oncol. 2010, 36, 224-229. [CrossRef] [PubMed]

123. Gojis, O.; Rudraraju, B.; Gudi, M.; Hogben, K.; Sousha, S.; Coombes, C.R.; Cleator, S.; Palmieri, C. The role of SRC-3 in human breast cancer. Nat. Rev. Clin. Oncol. 2009, 7, 83-89. [CrossRef] 
124. Lonard, D.M.; O'Malley, B.W. SRC-3 Transcription-Coupled Activation, Degradation, and the Ubiquitin Clock: Is There Enough Coactivator to Go Around in Cells? Sci. Signal. 2008, 1, pe16. [CrossRef]

125. Song, X.; Chen, H.; Zhang, C.; Yu, Y.; Chen, Z.; Liang, H.; Van Buren, G.; McElhany, A.L.; Fisher, W.E.; Lonard, D.M.; et al. SRC-3 inhibition blocks tumor growth of pancreatic ductal adenocarcinoma. Cancer Lett. 2019, 442, 310-319. [CrossRef] [PubMed]

126. Song, X.; Zhang, C.; Zhao, M.; Chen, H.; Liu, X.; Chen, J.; Lonard, D.M.; Qin, L.; Xu, J.; Wang, X.; et al. Steroid Receptor Coactivator3 (SRC-3/AIB1) as a Novel Therapeutic Target in Triple Negative Breast Cancer and Its Inhibition with a Phospho-Bufalin Prodrug. PLoS ONE 2015, 10, e0140011. [CrossRef]

127. Xu, J.; Liao, L.; Ning, G.; Yoshida-Komiya, H.; Deng, C.; O'Malley, B.W. The steroid receptor coactivator SRC-3 (p/CIP/RAC3/AIB1/ACTR/TRAM-1) is required for normal growth, puber-ty, female reproductive function, and mammary gland development. Proc. Natl. Acad. Sci. USA 2000, 97, 6379-6384. [CrossRef]

128. Morales-Santana, S.; Morell, S.; Leon, J.; Carazo-Gallego, A.; Jimenez-Lopez, J.C.; Morell, M. An Overview of the Polymorphisms of Circadian Genes Associated With Endocrine Cancer. Front. Endocrinol. 2019, 10, 104. [CrossRef]

129. Sun, X.J.; Man, N.; Tan, Y.; Nimer, S.D.; Wang, L. The Role of Histone Acetyltransferases in Normal and Malignant Hemato-poiesis Front. Oncol. 2015, 5, 108. [CrossRef]

130. Vu, L.P.; Luciani, L.; Nimer, S.D. Histone-modifying enzymes: Their role in the pathogenesis of acute leukemia and their ther-apeutic potential. Int. J. Hematol. 2013, 97, 198-209. [CrossRef]

131. UniProt. UniProt: The universal protein knowledgebase in 2021. Nucleic Acids Res. 2021, 49, D480-D489. [CrossRef]

132. Björling, E.; Uhlén, M. Antibodypedia, a Portal for Sharing Antibody and Antigen Validation Data. Mol. Cell. Proteom. 2008, 7 , 2028-2037. [CrossRef]

133. Pornputtapong, N.; Nookaew, I.; Nielsen, J. Human metabolic atlas: An online resource for human metabolism. Database 2015, 2015, bav068. [CrossRef] [PubMed]

134. Gaudet, P.; Argoud-Puy, G.; Cusin, I.; Duek, P.; Evalet, O.; Gateau, A.; Gleizes, A.; Pereira, M.; Zahn-Zabal, M.; Zwahlen, C.; et al. neXtProt: Organizing Protein Knowledge in the Context of Human Proteome Projects. J. Proteome Res. 2012, 12, $293-298$. [CrossRef] [PubMed]

135. Zahn-Zabal, M.; Lane, L. What will neXtProt help us achieve in 2020 and beyond? Expert Rev. Proteom. 2020, 17, 95-98. [CrossRef] [PubMed]

136. Smith, C.L.; Onate, S.A.; Tsai, M.J.; O'Malley, B.W. CREB binding protein acts synergistically with steroid receptor coactiva-tor-1 to enhance steroid receptor-dependent transcription. Proc. Natl. Acad. Sci. USA 1996, 93, 8884-8888. [CrossRef] [PubMed]

137. Menet, J.S.; Pescatore, S.; Rosbash, M. CLOCK:BMAL1 is a pioneer-like transcription factor. Genes Dev. 2014, 28, 8-13. [CrossRef] [PubMed]

138. Moreira, F.; Pedrazzoli, M.; Coelho, F.M.D.S.; Pradella-Hallinan, M.; Da Conceição, M.C.L.; Peregrino, A.J.P.; De Oliveira, E.C.; Tufik, S. Clock gene polymorphisms and narcolepsy in positive and negative HLA-DQB1*0602 patients. Mol. Brain Res. 2005, 140, 150-154. [CrossRef] [PubMed]

139. Luger, K.; Mäder, A.W.; Richmond, R.K.; Sargent, D.F.; Richmond, T.J. Crystal structure of the nucleosome core particle at $2.8 \AA$ resolution. Nat. Cell Biol. 1997, 389, 251-260. [CrossRef]

140. Viotti, M.; Wilson, C.; McCleland, M.; Koeppen, H.; Haley, B.; Jhunjhunwala, S.; Klijn, C.; Modrusan, Z.; Arnott, D.; Classon, M.; et al. SUV420H2 is an epigenetic regulator of epithelial/mesenchymal states in pancreatic cancer. J. Cell Biol. 2017, 217, 763-777. [CrossRef]

141. Kanz, C. The EMBL Nucleotide Sequence Database. Nucleic Acids Res. 2004, 33, D29-D33. [CrossRef]

142. Madeira, F.; Madhusoodanan, N.; Lee, J.; Tivey, A.R.N.; Lopez, R. Using EMBL-EBI Services via Web Interface and Programmatically via Web Services. Curr. Protoc. Bioinform. 2019, 66, e74. [CrossRef] [PubMed]

143. Madeira, F.; Park, Y.M.; Lee, J.; Buso, N.; Gur, T.; Madhusoodanan, N.; Basutkar, P.; Tivey, A.R.N.; Potter, S.C.; Finn, R.D.; et al. The EMBL-EBI search and sequence analysis tools APIs in 2019. Nucleic Acids Res. 2019, 47, W636-W641. [CrossRef]

144. Berman, H.M. The Protein Data Bank: A historical perspective. Acta Crystallogr. 2007, 64, 88-95. [CrossRef] [PubMed]

145. Berman, H.M.; Kleywegt, G.J.; Nakamura, H.; Markley, J.L. The Protein Data Bank at 40: Reflecting on the Past to Prepare for the Future. Structure 2012, 20, 391-396. [CrossRef] [PubMed]

146. Berman, H.M.; Westbrook, J.; Feng, Z.; Gilliland, G.; Bhat, T.N.; Weissig, H.; Shindyalov, I.N.; Bourne, P.E. The Protein Data Bank. Nucleic Acids Res. 2000, 28, 235-242. [CrossRef] [PubMed]

147. Larkin, M.A.; Blackshields, G.; Brown, N.P.; Chenna, R.; Mcgettigan, P.A.; McWilliam, H.; Valentin, F.; Wallace, I.M.; Wilm, A.; Lopez, R.; et al. Clustal W and Clustal X version 2.0. Bioinformatics 2007, 23, 2947-2948. [CrossRef]

148. Wang, Z.; Zang, C.; A Rosenfeld, J.; E Schones, D.; Barski, A.; Cuddapah, S.; Cui, K.; Roh, T.-Y.; Peng, W.; Zhang, M.Q.; et al. Combinatorial patterns of histone acetylations and methylations in the human genome. Nat. Genet. 2008, 40, 897-903. [CrossRef]

149. Conway, E.; Healy, E.; Bracken, A.P. PRC2 mediated H3K27 methylations in cellular identity and cancer. Curr. Opin. Cell Biol. 2015, 37, 42-48. [CrossRef]

150. Deevy, O.; Bracken, A.P. PRC2 functions in development and congenital disorders. Development 2019, 146. [CrossRef]

151. Shiio, Y.; Eisenman, R.N. Histone sumoylation is associated with transcriptional repression. Proc. Natl. Acad. Sci. USA 2003, 100, 13225-13230. [CrossRef] [PubMed]

152. Latham, J.A.; Dent, S.Y.R. Cross-regulation of histone modifications. Nat. Struct. Mol. Biol. 2007, 14, 1017-1024. [CrossRef] 
153. Bell, O.; Wirbelauer, C.; Hild, M.; Scharf, A.N.; Schwaiger, M.; MacAlpine, D.M.; Zilbermann, F.; van Leeuwen, F.; Bell, S.P.; Imhof, A.; et al. Localized H3K36 methylation states define histone H4K16 acetylation during transcriptional elongation in Drosophila. EMBO J. 2007, 26, 4974-4984. [CrossRef] [PubMed]

154. Liu, Y.; Tavana, O.; Gu, W. p53 modifications: Exquisite decorations of the powerful guardian. J. Mol. Cell Biol. 2019, 11, 564-577. [CrossRef] [PubMed]

155. Wang, S.-J.; Li, D.; Ou, Y.; Jiang, L.; Chen, Y.; Zhao, Y.; Gu, W. Acetylation Is Crucial for p53-Mediated Ferroptosis and Tumor Suppression. Cell Rep. 2016, 17, 366-373. [CrossRef] [PubMed]

156. Wang, S.-J.; Ou, Y.; Jiang, L.; Gu, W. Ferroptosis: A missing puzzle piece in the p53 blueprint? Mol. Cell. Oncol. 2016,3 , e1046581. [CrossRef] [PubMed]

157. Rossetto, D.; Avvakumov, N.; Cote, J. Histone phosphorylation: A chromatin modification involved in diverse nuclear events. Epigenetics 2012, 7, 1098-1108. [CrossRef]

158. Li, J.; Gorospe, M.; Barnes, J.; Liu, Y. Tumor Promoter Arsenite Stimulates Histone H3 Phosphoacetylation of Proto-oncogenes c-fos and c-jun Chromatin in Human Diploid Fibroblasts. J. Biol. Chem. 2003, 278, 13183-13191. [CrossRef]

159. Maksimoska, J.; Segura-Peña, D.; Cole, P.A.; Marmorstein, R. Structure of the p300 Histone Acetyltransferase Bound to AcetylCoenzyme A and Its Analogues. Biochemistry 2014, 53, 3415-3422. [CrossRef]

160. Poux, A.N.; Marmorstein, R. Molecular Basis for Gcn5/PCAF Histone Acetyltransferase Selectivity for Histone and Nonhistone Substrates. Biochemistry 2003, 42, 14366-14374. [CrossRef]

161. Rojas, J.R.; Trievel, R.C.; Zhou, J.; Mo, Y.; Li, X.; Berger, S.L.; Allis, C.D.; Marmorstein, R. Structure of Tetrahymena GCN5 bound to coenzyme A and a histone H3 peptide. Nat. Cell Biol. 1999, 401, 93-98. [CrossRef]

162. Daujat, S.; Bauer, U.-M.; Shah, V.; Turner, B.; Berger, S.; Kouzarides, T. Crosstalk between CARM1 Methylation and CBP Acetylation on Histone H3. Curr. Biol. 2002, 12, 2090-2097. [CrossRef]

163. Cheung, W.L.; Turner, F.B.; Krishnamoorthy, T.; Wolner, B.; Ahn, S.-H.; Foley, M.; Dorsey, J.A.; Peterson, C.L.; Berger, S.L.; Allis, C.D. Phosphorylation of Histone H4 Serine 1 during DNA Damage Requires Casein Kinase II in S. cerevisiae. Curr. Biol. 2005, 15, 656-660. [CrossRef]

164. Patel, J.; Pathak, R.R.; Mujtaba, S. The biology of lysine acetylation integrates transcriptional programming and metabolism. Nutr. Metab. 2011, 8, 12. [CrossRef]

165. Eisenberg, T.; Schroeder, S.; Andryushkova, A.; Pendl, T.; Küttner, V.; Bhukel, A.; Mariño, G.; Pietrocola, F.; Harger, A.; Zimmermann, A.; et al. Nucleocytosolic Depletion of the Energy Metabolite Acetyl-Coenzyme A Stimulates Autophagy and Prolongs Lifespan. Cell Metab. 2014, 19, 431-444. [CrossRef] [PubMed]

166. Mews, P.; Donahue, G.; Drake, A.M.; Luczak, V.; Abel, T.; Berger, S.L. Acetyl-CoA synthetase regulates histone acetylation and hippocampal memory. Nature 2017, 546, 381-386. [CrossRef]

167. Lai, B.; Lee, J.E.; Jang, Y.; Wang, L.; Peng, W.; Ge, K. MLL3/MLL4 are required for CBP/p300 binding on enhancers and super-enhancer formation in brown adipogene-sis. Nucleic Acids Res. 2017, 45, 6388-6403. [CrossRef] [PubMed]

168. Demetriadou, C.; Kirmizis, A. Histone Acetyltransferases in Cancer: Guardians or Hazards? Crit. Rev. Oncog. 2017, 22, 195-218. [CrossRef]

169. Han, M.; Jia, L.; Lv, W.; Wang, L.; Cui, W. Epigenetic Enzyme Mutations: Role in Tumorigenesis and Molecular Inhibitors. Front. Oncol. 2019, 9, 194. [CrossRef]

170. Lavau, C.; Du, C.; Thirman, M.; Zeleznik-Le, N. Chromatin-related properties of CBP fused to MLL generate a myelodysplasticlike syndrome that evolves into myeloid leukemia. EMBO J. 2000, 19, 4655-4664. [CrossRef]

171. Li, Z.; Luo, R.T.; Mi, S.; Sun, M.; Chen, P.; Bao, J.; Neilly, M.B.; Jayathilaka, N.; Johnson, D.S.; Wang, L.; et al. Consistent Deregulation of Gene Expression between Human and Murine MLL Rearrangement Leukemias. Cancer Res. 2009, 69, 1109-1116. [CrossRef]

172. Der Poel, S.Z.-V.; McCabe, N.R.; Gill, H.J.; Espinosa, R.; Patel, Y.; Harden, A.; Rubinelli, P.; Smith, S.D.; Lebeau, M.M.; Rowley, J.D. Identification of a gene, MLL, that spans the breakpoint in 11q23 translocations associated with human leukemias. Proc. Natl. Acad. Sci. USA 1991, 88, 10735-10739. [CrossRef]

173. Jakovcevski, M.; Ruan, H.; Shen, E.Y.; Dincer, A.; Javidfar, B.; Ma, Q.; Peter, C.J.; Cheung, I.; Mitchell, A.C.; Jiang, Y.; et al. Neuronal Kmt2a/Mll1 histone methyltransferase is essential for prefrontal synaptic plasticity and work-ing memory. J. Neurosci. 2015, 35, 5097-5108. [CrossRef] [PubMed]

174. Santillan, D.A.; Theisler, C.M.; Ryan, A.S.; Popovic, R.; Stuart, T.; Zhou, M.M.; Alkan, S.; Zeleznik-Le, N.J. Bromodomain and histone acetyltransferase domain specificities control mixed lineage leukemia pheno-type. Cancer Res. 2006, 66, 10032-10039. [CrossRef] [PubMed]

175. Sobulo, O.M.; Borrow, J.; Tomek, R.; Reshmi, S.; Harden, A.; Schlegelberger, B.; Housman, D.; Doggett, N.A.; Rowley, J.D.; ZeleznikLe, N.J. MLL is fused to CBP, a histone acetyltransferase, in therapy-related acute myeloid leukemia with a $\mathrm{t}(11 ; 16)(\mathrm{q} 23 ; \mathrm{p} 13.3)$. Proc. Natl. Acad. Sci. USA 1997, 94, 8732-8737. [CrossRef] [PubMed]

176. Wiesel-Motiuk, N.; Assaraf, Y.G. The key roles of the lysine acetyltransferases KAT6A and KAT6B in physiology and pathology. Drug Resist. Update 2020, 53, 100729. [CrossRef]

177. Karin, M. Nuclear factor-kappaB in cancer development and progression. Nature 2006, 441, 431-436. [CrossRef]

178. Karin, M. NF-kappaB and cancer: Mechanisms and targets. Mol. Carcinog. 2006, 45, 355-361. [CrossRef] 
179. Karin, M.; Lawrence, T.; Nizet, V. Innate Immunity Gone Awry: Linking Microbial Infections to Chronic Inflammation and Cancer. Cell 2006, 124, 823-835. [CrossRef]

180. Baud, V.; Karin, M. Is NF-kappaB a good target for cancer therapy? Hopes and pitfalls. Nat. Rev. Drug Discov. 2009, 8, 33-40. [CrossRef]

181. Durand, J.K.; Baldwin, A.S. Targeting IKK and NF-kappaB for Therapy. Adv. Protein Chem. Struct. Biol. 2017, 107, 77-115. [PubMed]

182. Brasier, A.R.; Tian, B.; Jamaluddin, M.; Kalita, M.K.; Garofalo, R.P.; Lu, M. RelA Ser276 phosphorylation-coupled Lys310 acetylation controls transcriptional elongation of inflamma-tory cytokines in respiratory syncytial virus infection. J. Virol. 2011, 85, 11752-11769. [CrossRef]

183. Karin, M.; Cao, Y.; Greten, F.R.; Li, Z.W. NF-kappaB in cancer: From innocent bystander to major culprit. Nat. Rev. Cancer. 2002, 2, 301-310. [CrossRef]

184. Lu, T.; Stark, G.R. NF-kappaB: Regulation by Methylation. Cancer Res. 2015, 75, 3692-3695. [CrossRef]

185. Stark, G.R.; Wang, Y.; Lu, T. Lysine methylation of promoter-bound transcription factors and relevance to cancer. Cell Res. 2010, 21, 375-380. [CrossRef]

186. Smale, S.T. Hierarchies of NF-kappaB target-gene regulation. Nat. Immunol. 2011, 12, 689-694. [CrossRef]

187. Liu, W.; Ma, Q.; Wong, K.; Li, W.; Ohgi, K.; Zhang, J.; Aggarwal, A.K.; Rosenfeld, M.G. Brd4 and JMJD6-Associated Anti-Pause Enhancers in Regulation of Transcriptional Pause Release. Cell 2013, 155, 1581-1595. [CrossRef]

188. Hah, N.; Benner, C.; Chong, L.-W.; Yu, R.T.; Downes, M.; Evans, R.M. Inflammation-sensitive super enhancers form domains of coordinately regulated enhancer RNAs. Proc. Natl. Acad. Sci. USA 2015, 112, E297-E302. [CrossRef]

189. Herrmann, H.; Blatt, K.; Shi, J.; Gleixner, K.V.; Cerny-Reiterer, S.; Müllauer, L.; Vakoc, C.R.; Sperr, W.R.; Horny, H.-P.; Bradner, J.E.; et al. Small-molecule inhibition of BRD4 as a new potent approach to eliminate leukemic stem- and progenitor cells in acute myeloid leukemia (AML). Oncotarget 2012, 3, 1588-1599. [CrossRef] [PubMed]

190. Xu, Y.; Vakoc, C.R. Brd4 is on the move during inflammation. Trends Cell Biol. 2014, 24, 615-616. [CrossRef]

191. Laptenko, O.; Tong, D.R.; Manfredi, J.; Prives, C. The Tail That Wags the Dog: How the Disordered C-Terminal Domain Con-trols the Transcriptional Activities of the p53 Tumor-Suppressor Protein. Trends Biochem. Sci. 2016, 41, 1022-1034. [CrossRef]

192. Senturk, E.; Manfredi, J.J. Determine the Effect of p53 on Chemosensitivity. Methods Mol. Biol. 2013, 962, 113-125. [CrossRef] [PubMed]

193. Senturk, E.; Manfredi, J.J. p53 and cell cycle effects after DNA damage. Breast Cancer 2012, 962, 49-61. [CrossRef]

194. Mujtaba, S.; Zeng, L.; Zhoug, M.-M. Modulating Molecular Functions of p53 with Small Molecules. Cell Cycle 2006, 5, 2575-2578. [CrossRef] [PubMed]

195. Gu, W.; Roeder, R.G. Activation of p53 Sequence-Specific DNA Binding by Acetylation of the p53 C-Terminal Domain. Cell 1997, 90, 595-606. [CrossRef]

196. Gu, W.; Shi, X.-L.; Roeder, R.G. Synergistic activation of transcription by CBP and p53. Nat. Cell Biol. 1997, 387, 819-823. [CrossRef] [PubMed]

197. Li, S.; Banck, M.; Mujtaba, S.; Zhou, M.-M.; Sugrue, M.M.; Walsh, M.J. p53-Induced Growth Arrest Is Regulated by the Mitochondrial SirT3 Deacetylase. PLoS ONE 2010, 5, e10486. [CrossRef]

198. Prives, C.; Manley, J.L. Why Is p53 Acetylated? Cell 2001, 107, 815-818. [CrossRef]

199. Tang, Y.; Zhao, W.; Chen, Y.; Zhao, Y.; Gu, W. Acetylation Is Indispensable for p53 Activation. Cell 2008, 133, 612-626. [CrossRef]

200. Turner-Ivey, B.; Guest, S.T.; Irish, J.C.; Kappler, C.S.; Garrett-Mayer, E.; Wilson, R.C.; Ethier, S.P. KAT6A, a Chromatin Modifier from the 8p11-p12 Amplicon is a Candidate Oncogene in Luminal Breast Cancer. Neoplasia 2014, 16, 644-655. [CrossRef]

201. Cosentino, M.S.; Oses, C.; Echegaray, C.V.; Solari, C.; Waisman, A.; Álvarez, Y.; Petrone, M.V.; Francia, M.; Schultz, M.; Sevlever G.; et al. Kat6b Modulates Oct4 and Nanog Binding to Chromatin in Embryonic Stem Cells and Is Required for Efficient Neural Differentiation. J. Mol. Biol. 2019, 431, 1148-1159. [CrossRef]

202. Sapountzi, V.; Logan, I.R.; Robson, C.N. Cellular functions of TIP60. Int. J. Biochem. Cell Biol. 2006, 38, 1496-1509. [CrossRef]

203. Gupta, A.; Guerin-Peyrou, T.G.; Sharma, G.G.; Park, C.; Agarwal, M.; Ganju, R.K.; Pandita, S.; Choi, K.; Sukumar, S.; Pandita, R.K.; et al. The mammalian ortholog of Drosophila MOF that acetylates histone H4 lysine 16 is essential for embryogene-sis and oncogenesis. Mol. Cell Biol. 2008, 28, 397-409. [CrossRef]

204. Li, X.; Corsa, C.A.S.; Pan, P.W.; Wu, L.; Ferguson, D.; Yu, X.; Min, J.; Dou, Y. MOF and H4 K16 Acetylation Play Important Roles in DNA Damage Repair by Modulating Recruitment of DNA Damage Repair Protein Mdc1. Mol. Cell Biol. 2010, 30, 5335-5347. [CrossRef] [PubMed]

205. Sharma, G.G.; So, S.; Gupta, A.; Kumar, R.; Cayrou, C.; Avvakumov, N.; Bhadra, U.; Pandita, R.K.; Porteus, M.H.; Chen, D.J.; et al. MOF and Histone H4 Acetylation at Lysine 16 Are Critical for DNA Damage Response and Double-Strand Break Repair. Mol. Cell Biol. 2010, 30, 3582-3595. [CrossRef] [PubMed]

206. Ho, Y.; Dehm, S.M. Androgen Receptor Rearrangement and Splicing Variants in Resistance to Endocrine Therapies in Prostate Cancer. Endocrinology 2017, 158, 1533-1542. [CrossRef] [PubMed]

207. Jentzmik, F.; Azoitei, A.; Zengerling, F.; Damjanoski, I.; Cronauer, M.V. Androgen receptor aberrations in the era of abiraterone and enzalutamide. World J. Urol. 2015, 34, 297-303. [CrossRef] [PubMed]

208. Martinez, E.; Kundu, T.K.; Fu, J.; Roeder, R.G. A Human SPT3-TAFII31-GCN5-L Acetylase Complex Distinct from Transcription Factor IID. J. Biol. Chem. 1998, 273, 23781-23785. [CrossRef] [PubMed] 
209. Terreni, M.; Valentini, P.; Liverani, V.; Gutierrez, M.I.; Di Primio, C.; Di Fenza, A.; Tozzini, V.; Allouch, A.; Albanese, A.; Giacca, M.; et al. GCN5-dependent acetylation of HIV-1 integrase enhances viral integration. Retrovirology 2010, 7, 18. [CrossRef]

210. Mujtaba, S.; Zhou, M.-M. Anti-viral opportunities during transcriptional activation of latent HIV in the host chromatin. Methods 2011, 53, 97-101. [CrossRef]

211. Zeng, L.; Li, J.; Müller, M.; Yan, S.; Mujtaba, S.; Pan, C.; Wang, Z.; Zhou, M.-M. Selective Small Molecules Blocking HIV-1 Tat and Coactivator PCAF Association. J. Am. Chem. Soc. 2005, 127, 2376-2377. [CrossRef]

212. Bryant, R.A. Posttraumatic stress disorder and traumatic brain injury: Can they co-exist? Clin. Psychol. Rev. 2001, 21, 931-948. [CrossRef]

213. Bryant, R.A. Disentangling Mild Traumatic Brain Injury and Stress Reactions. N. Engl. J. Med. 2008, 358, 525-527. [CrossRef]

214. Dash, P.K.; Orsi, S.A.; Zhang, M.; Grill, R.J.; Pati, S.; Zhao, J.; Moore, A.N. Valproate administered after traumatic brain injury provides neuroprotection and improves cognitive func-tion in rats. PLoS ONE 2010, 5, e11383. [CrossRef] [PubMed]

215. Zhang, B.; West, E.J.; Van, K.C.; Gurkoff, G.G.; Zhou, J.; Zhang, X.-M.; Kozikowski, A.P.; Lyeth, B.G. HDAC inhibitor increases histone $\mathrm{H} 3$ acetylation and reduces microglia inflammatory response following traumatic brain injury in rats. Brain Res. 2008, 1226, 181-191. [CrossRef]

216. Gao, W.-M.; Chadha, M.S.; Kline, A.E.; Clark, R.S.; Kochanek, P.M.; Dixon, C.E.; Jenkins, L.W. Immunohistochemical analysis of histone $\mathrm{H} 3$ acetylation and methylation-Evidence for altered epigenetic signaling following traumatic brain injury in immature rats. Brain Res. 2006, 1070, 31-34. [CrossRef] [PubMed]

217. Leiser, S.F.; Kaeberlein, M. A Role for SIRT1 in the Hypoxic Response. Mol. Cell 2010, 38, 779-780. [CrossRef] [PubMed]

218. Lim, J.-H.; Lee, Y.-M.; Chun, Y.-S.; Chen, J.; Kim, J.-E.; Park, J.-W. Sirtuin 1 Modulates Cellular Responses to Hypoxia by Deacetylating Hypoxia-Inducible Factor $1 \alpha$. Mol. Cell 2010, 38, 864-878. [CrossRef]

219. Lopez, M.S.; Kliegman, J.I.; Shokat, K.M. The Logic and Design of Analog-Sensitive Kinases and Their Small Molecule Inhibitors. Methods Enzymol. 2014, 548, 189-213. [CrossRef]

220. Weiss, W.A.; Taylor, S.S.; Shokat, K.M. Recognizing and exploiting differences between RNAi and small-molecule inhibitors. Nat. Chem. Biol. 2007, 3, 739-744. [CrossRef]

221. Gurevich, E.V.; Gurevich, V.V. Therapeutic Potential of Small Molecules and Engineered Proteins. Snake Venoms 2014, 219, 1-12. [CrossRef]

222. Gerona-Navarro, G.; Yoel-Rodríguez; Mujtaba, S.; Frasca, A.; Patel, J.; Zeng, L.; Plotnikov, A.N.; Osman, R.; Zhou, M.-M. Rational Design of Cyclic Peptide Modulators of the Transcriptional Coactivator CBP: A New Class of p53 Inhibitors. J. Am. Chem. Soc. 2011, 133, 2040-2043. [CrossRef] [PubMed]

223. Vincek, A.S.; Patel, J.; Jaganathan, A.; Green, A.; Pierre-Louis, V.; Arora, V.; Rehmann, J.; Mezei, M.; Zhou, M.-M.; Ohlmeyer, M.; et al. Inhibitor of CBP Histone Acetyltransferase Downregulates p53 Activation and Facilitates Methylation at Lysine 27 on Histone H3. Molecules 2018, 23, 1930. [CrossRef] [PubMed]

224. Tie, F.; Banerjee, R.; Conrad, P.A.; Scacheri, P.C.; Harte, P.J. Histone Demethylase UTX and Chromatin Remodeler BRM Bind Directly to CBP and Modulate Acetylation of Histone H3 Lysine 27. Mol. Cell. Biol. 2012, 32, 2323-2334. [CrossRef]

225. Bracken, A.P.; Pasini, D.; Capra, M.; Prosperini, E.; Colli, E.; Helin, K. EZH2 is downstream of the pRB-E2F pathway, essential for proliferation and amplified in cancer. EMBO J. 2003, 22, 5323-5335. [CrossRef] [PubMed]

226. Bandyopadhyay, D.; A Okan, N.; Bales, E.; Nascimento, L.; A Cole, P.; E Medrano, E. Down-regulation of p300/CBP histone acetyltransferase activates a senescence checkpoint in human melanocytes. Cancer Res. 2002, 62, 6231-6239. [PubMed]

227. Katsumoto, T.; Yoshida, N.; Kitabayashi, I. Roles of the histone acetyltransferase monocytic leukemia zinc finger protein in normal and malignant hematopoiesis. Cancer Sci. 2008, 99, 1523-1527. [CrossRef]

228. Lasko, L.M.; Jakob, C.G.; Edalji, R.P.; Qiu, W.; Montgomery, D.; DiGiammarino, E.L.; Hansen, T.M.; Risi, R.M.; Frey, R.; Manaves, V.; et al. Discovery of a selective catalytic p300/CBP inhibitor that targets lineage-specific tumours. Nat. Cell Biol. 2017, 550, 128-132. [CrossRef]

229. Michaelides, M.R.; Kluge, A.; Patane, M.; Van Drie, J.H.; Wang, C.; Hansen, T.M.; Risi, R.M.; Mantei, R.; Hertel, C.; Karukurichi, K.; et al. Discovery of Spiro Oxazolidinediones as Selective, Orally Bioavailable Inhibitors of p300/CBP Histone Acetyltransferases. ACS Med. Chem. Lett. 2018, 9, 28-33. [CrossRef]

230. Bowers, E.M.; Yan, G.; Mukherjee, C.; Orry, A.; Wang, L.; Holbert, M.A.; Crump, N.T.; Hazzalin, C.A.; Liszczak, G.; Yuan, H. Virtual ligand screening of the p300/CBP histone acetyltransferase: Identification of a selective small mole-cule inhibitor. Chem. Biol. 2010, 17, 471-482. [CrossRef]

231. Fang, F.; Li, G.; Jing, M.; Xu, L.; Li, Z.; Li, M.; Yang, C.; Liu, Y.; Qian, G.; Hu, X.; et al. C646 modulates inflammatory response and antibacterial activity of macrophage. Int. Immunopharmacol. 2019, 74, 105736. [CrossRef] [PubMed]

232. Wang, Y.-M.; Gu, M.-L.; Meng, F.-S.; Jiao, W.-R.; Zhou, X.-X.; Yao, H.-P.; Ji, F. Histone acetyltransferase p300/CBP inhibitor C646 blocks the survival and invasion pathways of gastric cancer cell lines. Int. J. Oncol. 2017, 51, 1860-1868. [CrossRef] [PubMed]

233. Liu, X.; Wang, L.; Zhao, K.; Thompson, P.R.; Hwang, Y.; Marmorstein, R.; Cole, P.A. The structural basis of protein acetylation by the p300/CBP transcriptional coactivator. Nat. Cell Biol. 2008, 451, 846-850. [CrossRef] [PubMed]

234. Gardberg, A.S.; Huhn, A.J.; Cummings, R.; Bommi-Reddy, A.; Poy, F.; Setser, J.; Vivat, V.; Brucelle, F.; Wilson, J. Make the right measurement: Discovery of an allosteric inhibition site for p300-HAT. Struct. Dyn. 2019, 6, 054702. [CrossRef] [PubMed] 
235. Mezei, M.; Zhou, M.-M. Dockres: A computer program that analyzes the output of virtual screening of small molecules. Source Code Biol. Med. 2010, 5, 2. [CrossRef]

236. Waterhouse, A.M.; Procter, J.B.; Martin, D.M.A.; Clamp, M.; Barton, G.J. Jalview Version 2-A multiple sequence alignment editor and analysis workbench. Bioinformatics 2009, 25, 1189-1191. [CrossRef] 